\title{
2. Die Zwei Seiten der Farben
}

\subsection{Die Analyse der Natur der Farben}

Dieses Buch hat es sich zum Ziel gesetzt, die verschiedenen Möglichkeiten, die ontologische Natur der Farben zu bestimmen, zu diskutieren und zu bewerten. Ganz allgemein betrachtet, gibt es zwei Alternativen für eine Analyse der Farben. Entweder werden sie als primitive Eigenschaften angesehen, deren Natur sich nicht auf die Naturen anderer Eigenschaften zurückführen läßt (auch wenn sie durchaus auf solchen supervenieren können); oder aber es ist eine Analyse mithilfe bereits bekannter oder mit bekannten Mitteln konstruierbaren Eigenschaften möglich. Wie sich bei der Diskussion des Primitivismus zeigen wird, ist die ontologische Differenz zwischen den beiden grundsätzlichen Möglichkeiten, Farben zu charakterisieren, nicht so einfach zu bestimmen oder auch aufrechtzuerhalten. Als erster Anhaltspunkt kann sie jedoch ohne weiteres dienen (es könnte beispielsweise als ein Nachteil des Primitivismus angesehen werden, daß er gerade nicht angeben kann, was Farben nun wirklich sind). Die nicht-primitivistischen Theorien werden demnach die Klasse der Farben auf eine Klasse anderer Eigenschaften zurückführen. Dabei kann es sich, je nach Position und Auffassung, um intrinsische oder dispositionale Eigenschaften von Dingen in der Außenwelt, aber auch um interne Merkmale des Gehirnes oder Geistes eines Subjektes handeln. Auch der Eliminativismus, demzufolge es, ganz grob gesagt, keine Farbtatsachen in der aktualen Welt gibt (weder außerhalb, noch innerhalb des Subjektes), wird zuerst angeben müssen, was Farben sind oder sein müßten, bevor er auf ihre faktische Nicht-Instantiiertheit schließt. Mit Ausnahme des Primitivismus unterstützen alle diese Theorien der Farben die Analysethese, die einfach die eben beschriebene Identifikation ausdrückt.

(ANA) Jede einzelne Farbe $F_{\mathrm{i}}$ ist mit einer Eigenschaft $P_{\mathrm{i}}$ identisch. Somit kann die Klasse $K_{\mathrm{F}}$ der $F_{\mathrm{i}}$ mit der Klasse $K_{\mathrm{P}}$ der $P_{\text {i }}$ gleichgesetzt werden. Das den Farben gemeinsame Merkmal $F$ ist mit

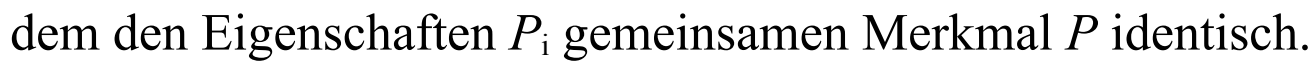


Der Begriff des gemeinsamen Merkmales wird hier sehr weit aufgefaßt (in dem Sinne, daß bestimmte Dinge etwa auch gemein haben können, von mir besessen zu werden). Die Beschaffenheit dessen, was Farben zu Farben macht, kann dementsprechend vielfältige Formen annehmen. Doch in jedem Fall ist eine Farbeigenschaft immer auch eine $P$-Eigenschaft (und umgekehrt). Im folgenden werde ich mich mit dem Buchstaben $P$ durchgängig auf die mit Farben identifizierten Eigenschaften beziehen. ${ }^{1}$ Bei den durch die These (ANA) bezeichneten Identitäten handelt es sich dabei um metaphysische Notwendigkeiten a posteriori. Daß die Notwendigkeit der Identifikationen vorerst nur aposteriorischen Status hat, weist darauf hin, daß es (wahrscheinlich) eine empirisch zu beantwortende Frage ist, welche Eigenschaften Farben genau sind; nur subjektivistische Positionen werden darüberhinaus sogar von einer apriorischen Wahrheit ausgehen. ${ }^{2}$ Es ist darauf hingewiesen worden, daß der Primitivismus versuchen wird, ohne die Analysethese auszukommen. Nun läßt es sich jedoch fragen, ob nicht generell auf die Analysethese verzichtet werden kann, indem weiterhin einfach immer von Farbeigenschaften die Rede sein wird, weil die Bezeichnungen $F$ und $P$ sich ja auf ein- und dieselben Eigenschaften beziehen. Im Grunde hat dieser Punkt seine Berechtigung, das heißt, in gewissem Sinne ist diese „Verdoppelung“ von Farb- und $P$-Eigenschaften überflüssig und läßt die ganze spätere Herleitung und Darstellung der systematischen Klassifikatio$\mathrm{n}$ recht unübersichtlich werden.

Trotzdem gibt es eine besondere Motivation für diese begriffliche Trennung. Denn als Ausgangspunkt für eine Analyse der Natur der Farben wird eine vorwissenschaftlich und introspektiv gewonnene Farbkonzeption dienen müssen, um überhaupt erst eine Theoretisierung der Farben ermögli-

$1 \quad$ Prinzipiell soll der tiefgestellte Index bei den Bezeichnungen $F_{\mathrm{i}}$ oder $P_{\mathrm{i}}$ auf individuelle Eigenschaften oder Determinanten (wie Purpur oder Bananengelb) hinweisen, während die Parameter $F$ und $P$ die entsprechende Eigenschaftsart oder Determinable (wie Farbe) benennen. Wenn der Kontext jedoch Mißverständnisse ausschließt, werde ich aus Gründen der Einfachheit auf den Index verzichten, auch wenn von konkreten Eigenschaften die Rede ist.

$2 \mathrm{Zu}$ der Möglichkeit von aposteriorischen Identitätsaussagen: vgl. Kripke (1972). Es ist zwar immer noch umstritten, ob es analytische oder apriorische Wahrheiten geben kann, aber neuerdings wird diese These wieder häufiger vertreten. Einen vielversprechenden Erklärungsvorschlag bietet etwa Boghossian (1996). 
chen zu können. Während also auf die unserem gewöhnlichen Verständnis entsprechenden Farben mit der Bezeichnung $F$ Bezug genommen wird, betrifft die theoretische Erfassung dieser naiven Farbkonzeption die mit den Farben empirisch oder begrifflich identifizierten Eigenschaften $P$. Es sollte dennoch immer in Erinnerung behalten werden, daß es das allgemeine Ziel einer jeden Theorie der Farben (mit Ausnahme vielleicht des Primitivismus) ist, a posteriori eine metaphysisch notwendige Identität zwischen den beiden Eigenschaftsarten zu ermöglichen: das heißt, eine (möglichst) vollständige Theoretisierung der introspektiv und vor aller Theorie erhaltenen Farbkonzeption. Zudem wird die Trennung in ,zwei“ Eigenschaften helfen, Merkmalszuschreibungen übersichtlicher zu gestalten und darüberhinaus den Charakter der Suche nach mit den Farben gleichzusetzenden Eigenschaften zu betonen. Dabei ist zu jeder These, in der $P$-Eigenschaften vorkommen, immer die Analysethese (ANA) hinzuzudenken.

Dahinter verbirgt sich die Idee, daß eine Theorie der Farben bestimmte Desiderata oder eine bestimmte Norm zu erfüllen hat, die von der vor-wissenschaftlich gewonnenen Farbkonzeption charakteristiert wird. Nehmen wir an, daß den Farben demgemäß das Merkmal $\Phi$ zukommen soll. Mit der These (ANA) ergibt sich damit, daß auch die Eigenschaften $P$ dieses Merkmal aufweisen sollen. Um nun die fraglichen $P$-Eigenschaften finden $\mathrm{zu}$ können, kann die Kanditatenliste auf alle $\Phi$-zeigenden Eigenschaften begrenzt werden, etwa durch die folgende These: (Farben $F \equiv$ Eigenschaften $P) \leftrightarrow$ (die Eigenschaften $P$ weisen $\Phi$ auf). ${ }^{3}$ Damit ist nicht nur die ontologische Aussage getroffen worden, daß Farben das Merkmal $\Phi$ tatsächlich zeigen, sondern auch die Forderung, daß nur die $P$-Eigenschaften für die Identifikation mit den Farben in Frage kommen, die ebenfalls $\Phi$ aufweisen. Diese Beschränkung der möglichen Kandidaten wird helfen, die Eigenschaften $P$ zu identifizieren. Im weiteren Verlauf des Buches werden alle entsprechenden Merkmalszuweisungen nach diesem Schema verlaufen, auch wenn meistens die linke Seite dieses Bikonditionals stillschweigend

$3 \quad$ Folgende Zeichenkonventionen werden in diesem Buch verwendet. Das dreifache Gleichheitszeichen „”“ bezeichnet eine Identität mit metaphysischer Notwendigkeit a posteriori, das Definitionszeichen ,,:=“ dagegen eine Identität mit metaphysischer Notwendigkeit a priori (das heißt, mit epistemischer Notwendigkeit). Das normale Gleichheitszeichen „=“ weist auf eine in der aktualen Welt kontigent wahre Prädikation hin (also nicht auf eine Identitätsrelation). 
weggelassen wird. Jedenfalls sollte die Einführung der Analysethese hiermit ausreichend motiviert sein. Damit ergibt sich das folgenden, dreistufige Schema für die Theoretisierung der Intuitiven Farbkonzeption, die schließlich zu einer Analyse der Natur der Farben führt:

Aufstellen der Desiderata. Farben sollten wesentlich die Merkmale $\Phi$ zeigen, die in der Intuitiven Farbkonzeption inbegriffen sind.

Philosophische und empirische Untersuchung. Die Eigenschaften $P$ besitzen tatsächlich die Merkmale $\Phi$.

Analyse der Farben. Die Eigenschaften $P$ sind die besten Kandidaten für die Identifizierung mit den Farben: $F \equiv P$.

Jede nicht-primitivistische Theorie der Farben muß sich im allgemeinen zwei Fragen stellen. Erstens sollte geklärt werden, was eine beliebige Eigenschaft überhaupt zu einer Farbe macht (zum Beispiel im Gegensatz zu einer Form). Dabei geht es also darum, zu bestimmen, wann eine Eigenschaft als Mitglied der Klasse $K_{\mathrm{F}}$ gilt, und wann nicht. Zweitens ist es von Bedeutung, worin genau der Unterschied zwischen den einzelnen Farbeigenschaften (wie etwa zwischen Zitronen- und Bananengelb) besteht. Es ist also erforderlich, eine Analyse davon anzufertigen, was die einzelnen Naturen der $F_{\mathrm{i}}$ ausmacht und worin diese differieren. Diese beiden Anforderungen an eine Farbtheorie spiegeln die klassische Entgegensetzung zweier Begriffe wider: den der Determinablen und den der Determinanten. Die Eigenschaft, eine Farbe zu haben, ist eine Determinable, die von einer Determinanten (oder von mehreren mit verschiedenen Spezifizierungsgraden) ausgefüllt werden muß. Zum einen sollte folglich geklärt werden, wann eine Eigenschaft als Determinante unter die Determinable Farbe fällt, was letztlich auf die Frage hinausläuft, was allen Determinanten dieser Determinablen gemeinsam ist. Zum anderen sollte die konkrete Beschaffenheit dieser einzelnen Determinanten untersucht werden, um sie auch untereinander differenzieren zu können.

Den Farbdeterminanten entsprechen dabei die Eigenschaften $F_{\text {i }}$, und der Farbdeterminablen - in etwa - das Merkmal $F$. Die Einschränkung der letzteren Behauptung ist erforderlich, weil eigentlich zwei verschiedene Eigenschaften im Spiel sind: eine Farbe zu sein und eine Farbe zu haben. Diese Zweiteilung ist typisch für Eigenschaften zweiter Ordnung, da sie 
zum einen den Eigenschaften erster Ordnung, zum anderen jedoch deren Instanzen zugeschrieben werden können. Ein roter Gegenstand hat somit, ganz allgemein gesprochen, eine Farbeigenschaft, während Rot eine Farbeigenschaft ist. Doch die erstere Redeweise kann ontologisch auf die letztere zurückgeführt werden: eine Farbe zu haben, heißt für einen Gegenstand nichts anderes, als eine eine Eigenschaft zu haben, die eine Farbe ist. Und die Determinable Farbe kann einfach durch das den Farben gemeinsame Merkmal $F$ analysiert werden: sie ist somit eine Eigenschaft zweiter Ordnung ihrer Determinanten, mithilfe derer diese in eine bestimmte Klasse zusammengefaßt werden können. Andersherum ist diese Zurückführung nicht möglich, da zum Beispiel Rot auch dann eine Farbe ist, wenn es gar nicht instantiiert sein sollte. Nun entspricht aber nicht jeder Klasse von Eigenschaften eine Determinable. Denn das Verhältnis der Determinanten zu ihrer Determinable unterliegt nun einer ganz bestimmten „Logik“, die sich in den folgenden vier Hauptpunkten zusammenfassen läßt (vgl. Armstrong (1997): 48f.).

Wenn erstens ein Gegenstand eine Determinable (in dem eben beschriebenen Sinne) instantiiert, dann impliziert dies, daß er eine (beliebige) der entsprechenden, maximal oder exakt spezifizierten Determinanten exemplifiziert. Das betreffende Objekt kann jedoch auch viele weniger genau bestimmte Determinanten instantiieren. So wird eine Fläche zum Beispiel gleichzeitig eine Farbe, Gelb, Zitronengelb und genau-diesen-Gelbton besitzen (vgl. Byrne \& Hilbert (1997c): 278). Es ensteht eine Hierarchie von Determinanten, die sich an der Genauigkeit der Spezifierung dieser Determinanten orientiert. Aber es wird trotzdem immer eine absolut bestimmbare Farbe geben müssen, die diese einfarbige Fläche zeigen wird (wie fein Farben individuiert werden können, muß dabei noch geklärt werden). ${ }^{4}$ Zweitens besteht auch das umgekehrte Implikationsverhältnis: die Instantiierung einer Determinante bedingt die Instantiierung der dazugehörigen

$4 \quad$ Im weiteren Verlauf wird sich der Ausdruck Farbe, wenn nicht anders bestimmt, immer auf diese maximal spezifizierten Farben oder Farbtöne beziehen. Daß ein Gegenstand zudem mehrere Farbeigenschaften (und wahrscheinlich sogar beliebig viele) instantiieren kann, wird ontologisch durch die These des ontological free lunch aufgefangen. Letztlich supervenieren alle entsprechenden Tatsachen auf einer fundamentalen Tatsache, die ein genuiner Bestandtteil der Realität ist und die entweder aus der Instantiierung der maximal bestimmten Farbeigenschaft oder noch einer basaleren Tatsache besteht. 
Determinable. Ein Gegenstand mit genau-diesem-Gelbton wird damit natürlich auch ganz allgemein eine Farbe aufweisen. Es ist drittens den Determinablen eigen, daß sie auf jeder Genauigkeitsstufe der Determiantenhierarchie der Spezifizierung jeweils nur mit genau einer Determinanten verbunden sein können. Eine farbige Fläche ist somit entweder rot oder gelb, entweder rubinrot oder zitronengelb, entweder von genau-diesemRotton oder von genau-diesem-Gelbton. Zusätzlich müssen die einzelnen Determinanten wiederum zusammenpassen. Es ist offensichtlich unmöglich (nimmt man die Farbbezeichnungen als rigide Designatoren), daß ein rubinroter Gegenstand genau-diesen-Gelbton zeigt. ${ }^{5}$

Viertens und letztens zeigen die einzelnen Determinanten auf jeder Genauigkeitsebene bestimmte Ähnlichkeits- und Verschiedenheitsrelationen. Insbesondere für die maximal spezifizierten Determinanten ist dies von Interesse. Chromatische Farbtöne können zum Beispiel in Kreisform angeordnet werden, und zwar ganz grob in der Reihenfolge von Gelb, Orange, Rot über Violet, Blau und Grün zurück zum Gelb. Armstrong weist noch darauf hin, daß diese „Logik“ der Determinablen und Determinanten nicht mit dem Verhältnis von Gattung und Art zu verwechseln ist (vgl. Armstrong (1997): 49). Denn während eine Art mittels der Gattung und einer von dieser unabhängigen Eigenschaft individuiert werden kann (wenn Menschen zum Beispiel in etwa als sprechende oder aufrecht gehende Säugetiere definiert werden), ist dies im Fall einer ganz bestimmten Determinante nicht möglich: es gibt keine von der Determinable unabhängige Eigenschaft, die mithilfe dieser jene individuieren könnte. Eine solche Bestimmung hätte die Form: genau-dieses-Rot ist eine Farbe, die die Eigenschaft $\Phi$ hat. Doch es gibt keine Eigenschaft - außer genau-dieses-Rot zu sein -, welche die Rolle von $\Phi$ übernehmen könnte.

Es ist zu beachten, daß dies sich auch dann nicht ändert, wenn eine vollständige Anaylse der Farben als Eigenschaften $P$ vorliegt. Denn die

5 Byrne und Hilbert entwickeln aus diesem Umstand eine Hierarchie von Determinablen und Determinanten, die für ihre Farbtheorie von besonderer Bedeutung sein wird (vgl. Byrne \& Hilbert (1997c): 276ff.). Nicht-maximal spezifizierte Determinanten können wiederum selbst als Determinablen aufgefaßt werden, die durch die genauer bestimmten Determinanten erfüllt werden können. Die Determinante Gelb kann beispielsweise als Determinable der Determinanten Zitronengelb, Bananengelb und Briefkastengelb aufgefaßt werden. 
Eigenschaften $P$ werden selbst - um wirklich als Farben gelten zu können - wieder eine Determinablen-Determinanten-Struktur aufweisen müssen. Dies stellt jedoch zum Glück für die meisten, mit Bezug auf Farben vorgebrachten Analysevorschläge kein Hindernis dar. Denn nicht nur Farben zeigen diese Determinablen-Determinanten-Struktur, sondern gerade auch die sogenannten primären Qualitäten (wie Form) oder alle durch die Physik beschreibbaren Eigenschaften (wie Masse, Länge oder auch Ladung). Ebenfalls kann solch eine Struktur auch für die in Frage kommenden Dispositionen oder intern instantiierten Eigenschaften gefunden werden. Der nächste Schritt wird nun sein, einen Ausgangspunkt für die Bestimmung der Intuitiven Farbkonzeption anzugeben, der sinnvollerweise für alle Theorien der Farbe Bestand haben sollte. Es geht also darum, einen Minimalkonsens zu finden.

\subsection{Der Minimalkonsens}

\subsubsection{Präsentation und Introspektierbarkeit}

Jede Theorie der Farben möchte eine möglichst vollständige Analyse der Natur derselben anfertigen. Einer solchen Theoretisierung muß jedoch immer eine einigermaßen genaue Individuation des fraglichen Gegenstandsbereiches vorausgehen, da es sonst nicht gewährleistet ist, daß die resultierende Debatte der konkreten Positionen untereinander wirklich über einund dieselbe, festgelegte Klasse von Eigenschaften geführt wird. Und in der Tat scheint es manchmal der Fall zu sein, daß die Anhänger verschiedener Farbtheorien aneinander vorbeireden: nämlich dann, wenn sie jeweils einen der beiden Hauptaspekte der Intuitiven Farbkonzeption dem anderen vorziehen und Farben entweder nur als repräsentierte oder nur als phänomenale Eigenschaften bestimmen. Doch könnte es nicht sein, daß eine Spezifizierung der $\mathrm{zu}$ besprechenden Klasse von Eigenschaften bereits eine Theorie über dieselben voraussetzt und somit im Grunde unmöglich wird?

„For in order to say which properties are at issue in the debate about the nature of colors, one would have to say which properties colors are - which would seem to require settling the debate before defining it. [...] Well, not quite. One can pick 
out a property by means of a contingent fact about it. And one can thereby specify the property whose nature is to be debated without preempting the debate." (Boghossian \& Velleman (1991): 68)

Farben können also über eine ihrer (kontigenten) Eigenschaften individuiert werden, ohne daß dadurch bereits eine vollständige Analyse ihrer Natur, das heißt, all ihrer wesentlichen Eigenschaften erfolgen muß. Dieses Problem der vor-theoretischen Individuation findet sich nicht nur bei einer Theorie der Farben, sondern bei allen theoretischen Untersuchungen einer bestimmten Klasse von Eigenschaften. Denn in jedem Fall ist irgendeine Abgrenzung des zu untersuchenden Gegenstandsbereiches erforderlich, bevor dieser wissenschaftlich erfaßt und beschrieben werden kann. Dabei kann es natürlich passieren, daß der Prozeß des Theoretisierens - in Maßen - zu einer Veränderung oder Verschiebung des Geltungsbereiches der betreffenden Theorie führen kann. Ob dies bei einer Theorie der Farben der Fall ist, und wenn ja, welche Konsequenzen dies mit sich bringt, soll im Verlaufe der Untersuchung deutlich werden.

Es genügt jedoch, eine einzelne Eigenschaft der Farben vor aller theoretischen Betrachtungen herauszugreifen, um eine Debatte über die ontologische Natur der Farben zu beginnen. Dieses Merkmal muß dabei von den Farben zwar faktisch, aber bloß kontigent besessen werden: wie auch Eigenschaften, die keine Farben sind, dieses Merkmal faktisch nicht aufweisen dürfen. Wenn diese Bedingungen erfüllt sind, dann ist bereits eine Spezifizierung der Klasse der Farbeigenschaften durch das fragliche Merkmal möglich. Doch auch wenn es nicht gefordert ist, kann es natürlich trotzdem der Fall sein, daß die zur Definition der Farben herangezogene Eigenschaft diesen auch notwendigerweise zukommt. $\mathrm{Ob}$ das Individuationsmerkmal ein bloß faktisches oder ein wesentliches Charakteristikum der Farben ist, wird ebenfalls erst im Verlauf der weiteren Diskussion behandelt werden.

\subsubsection{Farben als präsentierte Eigenschaften}

Farbphänomene sind alltägliche Phänomene von großer Bedeutung. Wir nutzen die gegebenen Farben von Gegenständen nicht nur dazu, um diese voneinander zu unterscheiden, sondern wir beeinflussen die Farbigkeit in 
der Welt auch gezielt, um sie als Ausdrucksmittel verwenden zu können; zudem zeigen Farben besondere Wirkungen auf unsere Psyche (vgl. Itten (1983); Albers (1975); Wittgenstein (1997)). Das läßt darauf schließen, daß ein vor-theoretisches Individuationskriterium für die Klasse der Farbeigenschaften bereits von den allermeisten Menschen mehr oder weniger bewußt angewandt wird. Deshalb wird es eng mit dem im Alltag entwickelten oder erlernten, sogenannten naiven oder gewöhnlichen Verständnisses der Natur der Farben zusammenhängen. Dieses wird somit zum Ausgangspunkt für die wissenschaftlich-philosophische Erforschung der Farben. Eine Theorie der Farben soll dann für die noch ungenau bleibende und unwissenschaftlich gewonnene, naive Farbkonezption ein solides, durch Empirie und philosophische Argumentation gestütztes Fundament bereitstellen. Der Begriff der Naivität ist hier sicherlich nicht so zu verstehen, als ob er eine vollkommene Unreflektiertheit voraussetzen würde. Vielmehr lehnt er sich stark an den Begriff eines common-sense-Verständnisses an, oder auch den Begriff der Intuition, welche oftmals bereits einen beachtlichen Theoretisierungsgrad beinhalten.

Es ist natürlich zu erwarten, daß die naive Konzeption während der Diskussion mehr oder weniger ausgeprägten Modifikationen oder Korrektionen unterzogen wird, wie dies meistens auch bei anderen Verwissenschaftlichungen einer sogenannten folk theory geschieht. Führt diese Revision der Farbkonzeption jedoch zu weit weg von der ursprünglichen Auffassung, dann kann es fraglich werden, ob in dem Fall überhaupt noch von Farben und Farbphänomenen die Rede sein sollte. Ein gewisses Kernverständnis, wie es etwa das noch zu bestimmende Individuationsmerkmal oder auch bestimmte Meinungen über Farben darstellen können, sollte auf jeden Fall erhalten bleiben. Genausogut ist es aber auch möglich, daß die im Alltag entwickelte Quasi-Theorie von den wissenschaftlich-philosophischen Überlegungen bestätigt wird und somit Bestand behält. Der hier gewählte Ansatz unterscheidet sich darin nicht von dem in anderen Bereichen der analytischen Philosophie gewählten, wonach die Begründung einer Theorie von einem uns alltäglich begegnendem Phänomen von der naiven Konzeption desselben ihren Anfang nimmt (wie etwa bei der Philosophie des Geistes, deren erklärtes Ziel es ist, eine Theorie der mentalen Zustände zu entwickeln, die von unserer folk psychology ausgeht und dieser möglichst gerecht wird). 
Nun ist es natürlich nicht so einfach, eine bestimmte Auffassung von Farben als die im Alltag vorherrschende Farbkonzeption zu etablieren. Denn was könnte hier wiederum als ein „,vor-naives“ Kriterium dienen, wenn doch die Naivität sich gerade durch Unwissenschaftlichkeit, und damit verbunden auch durch Unklarheit in der Definition oder Verwendung von Begriffen, auszeichnet? Vielleicht folgende Besonderheit: für uns stehen Farben in einer ganz spezifischen Beziehung zu unseren visuellen Wahrnehmungen. Denn allein durch diese Sinneserfahrungen scheinen wir unmittelbaren Zugang zu denjenigen Eigenschaften zu erhalten, welche wir üblicherweise als Farben bezeichnen: diese erscheinen uns in den Farb wahrnehmungen, werden uns darin präsentiert. Es soll noch ganz offen gelassen werden, um was für eine Art von Präsentation es sich dabei handelt (insbesondere, ob etwa eine Repräsentationsrelation vorliegt). Außerdem ist es unserer Meinung nach möglich, mittels Introspektion einige Erkenntnisse über die Natur der Farben zu gewinnen. Ein wesentlicher Aspekt der Farben scheint dabei zu sein, daß sie von uns als Charakteristika von Gegenständen gesehen werden: daß sie, in diesem einfachen und vor-theoretischen Sinne, wahrgenommene Eigenschaften sind. So ist es kein Wunder, daß innerhalb der analytisch geführten Diskussion über Farben diese Präsentiertheit in Wahrnehmungen als Grundannahme zur Fundierung der Debatte verwendet wird. Die beiden folgenden Passagen von Vertretern zweier entgegengesetzter Positionen - erst des Subjektivismus, dann des Objektivismus - sollen dies verdeutlichen:

\footnotetext{
„The role in which colors command attention, of course, is their role as the properties attributed to objects by a particular aspect of visual experience. They are the properties that objects appear to have when they look colored." (Boghossian \& Velleman (1991): 68)

„I start by emphasising what I take to be the most obvious fact about color, the fact that is sufficiently central to count as defining our subject. Deny it and you are no longer talking about color. [...] The prime intuition is simply that red is the property objects look to have when they look red - and if this sounds like a triviality, as surely it does, that is all to the good. It is evidence that we have found a secure starting place.“(Jackson (1996): 199f.)
}

Damit erhält man bereits diejenige Definition von Farben, welche als minimaler Bestimmungsgrund für den Gegenstandsbereich einer jeden Theorie 
der Farben gelten kann. ${ }^{6}$ Die Unterschiede zwischen den einzelnen Positionen beginnen erst mit der konkreten Auslegung oder Erweiterung dieser Definition: und zwar hinsichtlich des Umstandes, welche der uns introspektiv zugänglichen Merkmale von Farben diesen auch zukommen können oder sinnvollerweise zugesprochen werden sollten. Die Benutzung der Ausdrücke ,präsentieren“ oder „erscheinen“ sowie die Einschränkung auf anscheinende Repräsentiertheit deutet zum Beispiel an, daß Farben zumindest von einigen Objektivisten und den meisten Subjektivisten nicht als repräsentierte oder wahrgenommene Eigenschaften im eigentlichen Sinne angesehen werden. Dabei können einzelne Theorien in solchem Maße voneinander differieren, daß dieses Individuationskriterium wirklich als alleiniges, allen Farbtheorien gemeinsames Fundament betrachtet werden kann. Im Prinzip handelt es sich dabei um eine rudimentäre Variante der sogenannten Transparenzintuition, welche besagt, daß die Natur der Farben uns, wenigstens teilweise, sinnlich und introspektiv gegeben ist. Wie die einzelnen Farbtheorien diese Einsicht deuten werden, soll jedoch erst in einem eigenen, späteren Kapitel erläutert werden. Für den Augenblick reicht es aus, vor diesem Hintergrund die allgemeine Individuationsthese zu formulieren (wobei $P$ sich auf die durch die These (ANA) mit Farben notwendigerweise identischen Eigenschaften bezieht).

(IND) Aktual gilt: die Eigenschaften $P$ sind die Träger der uns faktisch in Farbwahrnehmungen präsentierten (oder erscheinenden) Merkmale. $^{7}$

6 In der Tat findet sich meines Wissens innerhalb der neueren analytischen Tradition keine Position, die dieser grundlegenden Definition widerspricht. Tolliver, der als einziger Objektivist den repräsentationalen Charakter von Farbwahrnehmungen (oder besser: Farbempfindungen) leugnet, sieht diese immer noch als informationelle Zustände über Farbtatsachen an, die vermeintlich in der Welt bestehen. Und auch die Subjektivisten (einschließlich der Eliminativisten) begründen ihre Position gerade damit, daß es die uns so präsentierten Farben in der Realität nicht geben kann.

7 Da Farbwahrnehmungen auch (allermeistens) immer Form- und Ortswahrnehmungen sind, werden uns Formen und Lokalisierungen ebenso offenbart sein. Wie Farben zu diesen Eigenschaften stehen und von ihnen unterschieden werden können, wird im Abschnitt über Referentialität und Räumlichkeit erläutert. 
Natürlich ist es kontingent, daß uns Farben faktisch sinnlich gegeben sind. Es ist durchaus denkbar, daß es Menschen geben könnte, ohne daß diese die entsprechenden Wahrnehmungen hätten (man braucht sich nur die Möglichkeit vorzustellen, daß die gesamte Erdbevölkerung erblindet). Doch auch dann würden immer noch die Eigenschaften als Farben gelten, die den Menschen, wie sie faktisch beschaffen sind, in Farbwahrnehmungen erscheinen. Der Skopus der Aktualität (oder Faktizität) erfaßt nur das Wahrgenommenwerden, nicht jedoch die Identifizierung der Eigenschaften $P$ mit den Farben. ${ }^{8}$ Nimmt man die These (ANA) hinzu, läßt sich (IND) etwa wie folgt formalisieren: (Farben $F \equiv P$ ) $\leftrightarrow$ (aktual gilt: $P$ sind die Menschen in Farbwahrnehmungen präsentierten Eigenschaften). Da die These (IND) als allgemeines Fundament für alle Theorien der Farben gelten soll, bietet es sich an, die für uns direkt ersichtlichen Umstände und Tatsachen als einen ersten Maßstab heranzuziehen. Wie nun die Beziehung zwischen den Farbeigenschaften und den entsprechenden Sinneserfahrungen genau aussieht, wird sich im Verlauf der Diskussion zeigen müssen.

Jedenfalls ist (IND) in dieser einfachen Form sicherlich als trivial anzusehen (vgl. dazu auch Jacksons Zitat). Wäre es anders, so würden wahrscheinlich auch erste Zweifel enstehen, daß es sich dabei doch nicht unbedingt um einen Minimalkonsens für eine Theorie der Farben handeln könnte. Denn damit das Prinzip (IND) überhaupt als Fundament aller möglichen Farbtheorien gelten kann, muß es als wahr angenommen werden. Erst dann kann die These tatsächlich die Menge der Farben eindeutig spezifizieren. Aber Wahrheit allein genügt noch nicht. Schließlich ist die Anwendung von (IND) nur dann sinnvoll möglich, wenn von der faktischen Existenz von Farbwahrnehmungen ausgegangen wird. Nur wenn wir - von Zeit zu Zeit - aktual Farbwahrnehmungen haben, können wir auch tatsächlich mithilfe dieser auf die dabei präsentierten Eigenschaften introspektiv Bezug nehmen. Andernfalls wäre diese Definition von Farben für eine Theorie der Farben wertlos. Doch daß Farbwahrnehmungen aktual vorkommen und von uns erlebt werden, wird dementsprechend auch von niemanden bestritten.

8 Nimmt man die These (ANA) hinzu, läßt sich (IND) etwa wie folgt formalisieren: [Farben $F \equiv P] \leftrightarrow[$ Aktual gilt: $P$ sind die Menschen in Farbwahrnehmungen präsentierten Eigenschaften]. 


\subsubsection{Introspektive Individuation von Farbwahrnehmungen}

Werden Farben darüber Farbwahrnehmungen definiert, daß sie uns ind Farbwahrnehmungen präsentiert werden, dann stellt sich natürlich automatisch die Frage, wie Farbwahrnehmungen selbst individuiert werden können. Dabei zeigt sich offenbar die Gefahr eines Zirkels, wenn die einzelnen Mitglieder der Klasse der Farbwahrnehmungen darüber bestimmt werden, daß in ihnen den Betrachtern Farbeigenschaften gegeben sind. Nun würde die Zirkularität wirklich nur dann ein Problem darstellen, wenn die These (IND) dazu gedacht wäre, die Natur der Farben zu analysieren: wie etwa bei einem subjektivistischen Dispositionalismus, der Farben über eine diesen wesentlich zukommende Relation zu den relevanten Sinneserfahrungen spezifiziert (vgl. zum Beispiel McGinn (1983): 6f.). Drückt (IND) dagegen nur eine kontingente Wahrheit aus - ist es also kein Bestandteil der Natur von Farben, uns in Farbwahrnehmungen zu erscheinen -, dann macht es nichts, daß die Farbwahrnehmungen wiederum nur mit Bezug auf Farben beschrieben werden können, da (IND) nur einen vorläufigen Charakter aufweist und durch eine noch zu bestimmende Analyse ersetzt werden sollte.

Doch es scheint in beiden Fällen eine Möglichkeit zu geben, Farbwahrnehmungen unabhängig von den Farben introspektiv zu diskriminieren. Denn mithilfe von Introspektion ist es uns möglich, mentale Zustände voneinander zu unterscheiden und in verschiedene Klassen oder Gruppen zu ordnen: sozusagen in introspektive, mentale Typen. Eine Theorie der mentalen Zustände kann natürlich zu guter Letzt zu einer ganzen anderen Typenindividuation gelangen (indem diese etwa über externe, nicht introspektiv zugängliche Faktoren spezifiziert werden). Doch trotzdem ist es uns möglich, durch Introspektion ganz unterschiedliche Arten von mentalen Zuständen zu differenzieren: wie Überzeugungen, Wünsche, Hoffnungen, Gefühle, Empfindungen, Stimmungen oder eben auch Wahrnehmungen. Und auch innerhalb der einzelnen Gruppen ist es uns möglich, Differenzen festzustellen: zwei Überzeugungen können sich beispielsweise auf verschiedene Sachverhalte beziehen; und ein Schmerzgefühl unterscheidet sich gefühlsmäßig deutlich von einem Lustgefühl.

Diese introspektive Diskriminierungsfähigkeit hat dazu geführt, daß man mentale Zustände anhand bestimmter Merkmale zu klassifizieren versucht. Die prominentesten (und vielleicht auch die einzig erforderlichen) 
sind dabei sicherlich die theoretisch definierten Eigenschaften, einen Gehalt oder ein Quale aufzuweisen. Ganz grob gesprochen hat ein mentaler Zustand einen Gehalt, wenn er Informationen über einen Sachverhalt in der Welt bereitstellt oder repräsentiert, und ein Quale, wenn sein Auftreten oder Vorhandensein immer mit einem phänomenalen Erlebnischarakter (what it is like) verbunden ist. Eine genauere, theoretische Einführung dieser beiden möglichen Charakteristika von mentalen Zuständen soll erst weiter unten erfolgen. Für den Moment ist es sinnvoller, auf ein allgemeineres Merkmal hinzuweisen, welches per definitionem allen introspektierbaren Zuständen - und somit in der Regel auch Farbwahrnehmungen - zukommt: den introspektiven Charakter von mentalen Zuständen. Dieser umfaßt die Gesamtheit der hinsichtlich eines bestimmten mentalen Zustandes introspektierbaren Information dar. Dabei handelt es sich um ein, phänomenologisch betrachtet, eine Einheit ausmachendes Konglomerat aus all den verschiedenen Merkmalen und Aspekten, welche uns gegeben sind, wenn wir auf den fraglichen Zustand introspektiv aufmerksam werden. Zwei mentale Zustandstypen können genau dann introspektiv diskriminiert werden, wenn sie über zwei unterschiedliche introspektive Charaktere verfügen. Die Feingradigkeit der mentalen Zustände ergibt sich somit aus der Feingradigkeit der introspektierbaren Differenzen; und diese schlagen sich wiederum in Unterschieden zwischen den entsprechenden introspektiven Charakteren nieder.

Dabei handelt es sich bei dem introspektiven Charakter, genau genommen, selbst noch nicht um eine Eigenschaft der introspektierten Wahrnehmung; sondern er beschreibt stattdessen einfach, wie uns der fragliche $\mathrm{Zu}$ stand gegeben ist, wie er uns in der Introspektion präsentiert wird oder erscheint. Die Wahrnehmung hat dagegen die Charakteristisk, genau diesen introspektiven Charakter zu zeigen, wenn sie introspektiert wird: und zwar, weil sie über Eigenschaften verfügt (wie etwa einen Gehalt oder ein Quale), welche diesen introspektiven Charakter exakt spezifizieren. Daß eine Wahrnehmung einen bestimmten introspektiven Charakter aufweist, ist demnach in erster Linie eine epistemische Feststellung: sie gibt an, welche Informationen wir erhalten, wenn wir auf den fraglichen Zustand introspektieren. Und der Transparenzintuition zufolge ist es sogar zu erwarten, daß diese Informationen vielmehr die präsentierte Eigenschaft, und nicht unbedingt die Wahrnehmung selbst, betreffen werden. Im Gegensatz dazu 
ist es eher eine ontologische Frage, welche Eigenschaften des mentalen Zustandes dafür verantwortlich sind, damit er auf diese Weise, und nicht anders, in der Introspektion erscheint. Der Schritt von der epistemisch gegebenen Information zur ontologischen Beschaffenheit der Wahrnehmung (und auch der präsentierten Farben) wird weiter unten, nach der Auflistung der Merkmale des introspektiven Charakters, durch die Theoretisierung desselben erfolgen.

Aber auch unter der Annahme, daß längst nicht alle Eigenschaften einer Wahrnehmung introspektiv zugänglich sind (insbesondere nicht ihre neurophysiologische Realisierung) und daß Introspektion generell keine absolute (jedoch immerhin eine sehr hohe) Zuverlässigkeit garantieren kann, ist es möglich, die introspektive Typenindividuation aufrechtzuerhalten (daneben wird es natürlich auch empirische Möglichkeiten der Individuation geben). Demgemäß lassen sich die einzelnen Farbwahrnehmungstypen sowohl untereinander als auch von anderen Zuständen (einschließlich anderer Wahrnehmungsarten) unterscheiden. Es sollte klar sein, daß die introspektive Diskriminierungsfähigkeit unser Reservoir an Farbbegriffen und -ausdrücken bei weitem übersteigen wird: selbst unter so detaillierten Bestimmungen wie „Zinnoberrotempfindung“ oder „Smaragdgrünempfindung“ werden jeweils etliche verschiedene Sinneserfahrungen fallen. Doch auch wenn ein Unterschied zwischen zwei Zustandstypen nicht begrifflich beschrieben werden kann, genügt es doch aus, wenn er introspektiv festgestellt werden kann (ähnliches gilt genauso für die Feingradigkeit der wahrgenommenen Farbeigenschaften). Die einzelnen mentalen Zustände lassen sich demgemäß aufgrund von Gleichheits- und Verschiedenheitsbeziehungen zwischen ihren introspektiven Charakteren in Klassen zusammenfassen - ganz unabhängig davon, wie die jeweils resultierenden Typen benannt werden könnten. Die Typenindividuation der Zustände erfolgt dabei über Paradigmen.

„The phrase 'looks colored' and its determinate cousins - 'looks red', 'looks blue', and so forth - have a referential as well as an attributive use. That is, one learns to associate these phrases directly with visual experiences that are introspectively recognizable as similar in kind to paradigm instances. Paradigm cases of looking red fix a reference for the phrase 'looks red', which then refers to all introspectively similar experiences. We can therefore speak of something's looking red and rely on the reader to know which kind of visual experience we mean, 
without our having to specify which property red is." (Boghossian \& Velleman (1991): 69)

Diese Bezugsfixierung wird auf der nicht-begrifflichen Ebene ähnlich funktionieren. Damit ist es also prinzipiell möglich, einzelne Farbwahrnehmungen introspektiv zu typen-individuieren, ohne auf die in ihnen präsentierte Farbe zurückgreifen zu müssen. Wie ist es aber möglich, Farbwahrnehmungen auf diesem Wege von anderen mentalen Zuständen zu unterscheiden? Dies geschieht auf genau dieselbe Weise. Dabei ist es wichtig, daß die betreffenden Subjekte natürlich nicht unbedingt wissen müssen, daß es sich um mit „Farbwahrnehmungen“ bezeichnete Zustände handelt. Auch ohne dieses linguistische Wissen sollte ein bewußtes Lebewesen wie der Mensch in der Lage sein, mittels Introspektion und Hinweise auf Paradigmata die Klasse der Wahrnehmungen und insbesondere deren Untermenge der visuellen Sinneserfahrungen bilden zu können. Auch hier kann man sich auf das gewöhnliche, intuitive Verständnis verlassen: visuelle Wahrnehmungen zeichnen sich beispielsweise dadurch aus, daß sie üblicherweise verschwinden, wenn man die Augen schließt, und umgekehrt wieder in Erscheinung treten, wenn man diese erneut öffnet. Es bleibt höchstens noch die Ungenauigkeit, Farben von anderen, visuell erfahrbaren Eigenschaften zu unterscheiden. Weiter unten wird klar werden, daß auch dies kein Problem für die introspektive Diskriminierungsfäigkeit darstellt: etwa Farben - als Flächen oder Volumen ,ausfüllende“ Eigenschaften von Formen und Lokalisierungen zu trennen (schwieriger kann es dagegen mit Phänomenen wie Glanz oder Metalligkeit werden).

\subsection{Die Intuitive Farbkonzeption}

Auf der Grundlage des introspektiven Charakters von den Wahrnehmungen, in denen Farben präsentiert werden, läßt sich nun eine naive oder common-sense-Auffassung von Farben formulieren: die Intuitive Farbkonzeption. Denn daß ein solches Farbverständnis sich überhaupt herausbilden kann, hängt unter anderem von den beiden bisher erläuterten Grundvoraussetzungen ab: der Präsentation und der Introspektierbarkeit der Farben. Dabei ist es zuerst einmal wichtig, das genaue, epistemische 
Verhältnis der an der Herausbildung dieses Farbvertändnisses beteiligten Elemente zueinander zu klären. Es geht also um die Frage, wie wir von dem Umstand, daß Farben in Farbwahrnehmungen sinnlich präsentierte Eigenschaften sind, mithilfe des introspektiven Charakters dieser Sinneserfahrungen zu der Intuitiven Farbkonzeption gelangen können. Den Ausgangspunkt stellt die These (IND) dar. Mit dem Umstand, daß Farben uns sinnlich präsentierte Eigenschaften sind, ist nun aber eng verbunden, $\mathrm{da} ß$ wir anscheinend introspektiven Zugang $\mathrm{zu}$ diesen Eigenschaften haben, die wir üblicherweise als Farben betrachten. Die Merkmale, die den introspektiven Charakter von Farbwahrnehmungen ausmachen, werden von uns - ohne daß wir groß darüber nachdenken - den präsentierten Farbeigenschaften zugesprochen.

Die Intuitive Farbkonzeption stellt nun eine „,Verbegrifflichung“ oder Beschreibung dieses introspektiven Charakters dar. „Verbegrifflichung“ meint hier eher ein naives „In-Worte-Fassen“, und nicht so sehr eine Konzeptualisierung im üblichen Sinne. Es geht nicht unbedingt darum, daß etwas sinnlich Gegebenes unter einen bestimmten Begriff gebracht wird, sondern vielmehr um eine Konzeption, die die Merkmale des introspektiven Charakter angemessen beschreibt. Denn die Entwicklung eines solchen naiven und intuitiv einsichtigen Farbverständnisses wird automatisch immer von bestimmten Hintergrundsannahmen geleitet und beeinflußt. Dabei kann es sich um generelle Meinungen über die Welt und unsere Rolle als Betrachter handeln (daß es zum Beispiel eine Realität gibt, und daß es die Realität ist, die wir wahrnehmen), aber auch um im Laufe der Zeit gewonnene Alltagserfahrungen (etwa, daß Gegenstände sich durch ihre Farbigkeit auszeichnen, oder daß Farben in besonderen Relationen zueinander stehen). Auch setzt die Herausbildung der Intuitiven Farbkonzeption voraus, daß eine einigermaßen große Anzahl von Farbwahrnehmungen gehabt und introspektiert wird, um Vergleich anstellen sowie Gemeinsamkeiten und Verschiedenheiten erkennen zu können. Und schließlich wird sich dieses Farbverständnis zum Teil auch erst innerhalb einer Gemeinschaft entwickeln können. Das erfordert, bis zu einem gewissen Grad jedenfalls, die Intersubjektivität des introspektiven Charakters von Farbwahrnehmungen. ${ }^{9}$

9 Generelle Zweifel an der Möglichkeit, Wissen auf Introspektion zu stützen oder von einer solchen Intersubjektivität im introspektiven Charakter auszugehen, finden sich in den Texten von Wittgenstein, sollen hier aber unbesprochen bleiben, 
Die resultierende Farbkonzeption ist in gewissem Sinne mehr als der introspektive Charakter, weil sie eine Beschreibung desselben ist und dementsprechend verbegrifflicht sein und einen Platz in einem Kontext von Überzeugungen einnehmen muß, wovon sie unweigerlich geprägt wird: sie ist, streng genommen, nicht neutral, sondern eben naiv, vor-theoretisch und intuitiv (wie immer man es nennen möchte). Trotzdem geht sie nicht über den introspektiven Charakter der Farbwahrnehmungen hinaus: sie beschreibt allein die Erkenntnisse über die präsentierten Farben, die wir durch introspektives Aufmerken auf unsere Sinneserfahrungen erhalten. Das heißt, die Intuitive Farbkonzeption umfaßt nur genau diejenigen Merkmale, die uns vermittels dieses Charakters zugänglich sind. Eine andere Beschreibung oder „Verbegrifflichung“ der Aspekte des introspektiven Charakters von Farbwahrnehmungen liefern dann die einzelnen Theorien der Farben. Diese Theoretisierungen können zwar zeigen, daß einige Merkmale der Intuitiven Farbkonzeption den Farben sinnvollerweise doch nicht zugesprochen werden sollten; aber eine Theorie der Farben sollte trotzdem möglichst versuchen, alle Merkmale beizubehalten.

Im folgenden Abschnitt wird eine erste und noch vorläufige Liste dieser Merkmale angefertigt, welche dann im übernächsten Abschnitt mit einer Theorie der Wahrnehmungen in Verbindung gebracht werden soll. Um möglichst zu vermeiden, daß für manche Augen das eine oder andere Charakteristikum vernachlässigt oder nicht angemessen beschrieben wird, während andere fälschlicherweise zu dem introspektiven Charakter von Farbwahrnehmungen hinzugerechnet werden, werde ich mich bei der Auflistung auf eine breite Basis an Texten von Vertretern verschiedenster Farbtheorien orientieren, zwischen denen erstaunlicherweise hinsichtlich der naiven oder in der Introspektion offensichtlichen Vorstellung über Farben im großen und ganzen Einigkeit herrscht. So sollte es sich auch bei den folgenden, die Intuitive Farbkonzeption konstituierenden Merkmalen um einen Minimalkonsens handeln. Auch wenn die einzelnen Theoretisierungen später davon immer noch erheblich abweichen können, sollte die Beibehaltung der Intuitiven Farbkonzeption - durch die Transparenzintuition gestützt, daß uns Teile der Natur der Farben in den Farbwahrnehmungen

da sie mittlerweise nicht mehr unbedingt als entscheidend angesehen werden (vgl. Chihara \& Fodor (1965)). Einige gute Bemerkungen hierzu finden sich in Shoemaker (1994b) und Budd ((1989): Kap. 1). 
bereits gegeben sind - als das Desideratum für jede Theorie der Farben gelten.

Die Präsentation von Eigenschaften in Sinneserfahrungen charakterisiert diese generell auf vielfältige Weise. Formen erscheinen uns auf eine ganz andere Weise als Farben; und Rot wird von uns deutlich anders gesehen als Grün. Erst dadurch wird es möglich, Wahrnehmungstypen voneinander zu differenzieren. In unseren Farbwahrnehmungen sind uns demgemäß eine Vielzahl von verschiedensten Merkmalen der einzelnen Farben gegeben, so daß es uns möglich ist, mit einiger Sicherheit zu erkennen, welche Eigenschaft es ist, die uns erscheint. Im folgenden sollen die Charakteristika, die wir Farben aufgrund der Information, die uns unsere Sinneserfahrungen bereitstellen, zuschreiben, einzeln aufgeführt und, wenn erforderlich, kurz erläutert werden. Natürlich handelt sich auch dabei allein um Merkmale, die die Farben in Wahrnehmungen aufzuweisen scheinen. Die folgende Liste konstituiert somit nur eine naive Konzeption der Farben. Im nächsten Abschnitt wird dann thematisiert, wie die Intuitive Farbkonzeption vor dem allgemeinen Hintergrund einer Wahrnehmungstheorie zu deuten ist. Erst danach kann entschieden werden, ob Farben die beschriebenen Merkmale auch wirklich alle besitzen.

\subsubsection{Allgemeine Merkmale wahrnehmbare Eigenschaften}

Der erste Aspekt des naiven Farbverständnisses besteht in der Einsicht, daß Farben - wie auch die meisten anderen, wahrnehmbaren Eigenschaften im allgemeinen immer im Verbund mit Gegenständen in der Außenwelt wahrgenommen werden. Das heißt, wir sehen Farben üblicherweise an einem Farbträger. ${ }^{10}$ Für uns sind Farben nichts anderes als Eigenschaften von Gegenständen; und sie kommen in der Außenwelt genauso selbstverständlich und wirklich vor wie diese. Zudem dienen Farben als eines der Hauptmerkmale, mit denen wir Objekte in unserer Umgebung

10 Selbst wenn eine farbige und sonst recht charakterlose Oberfläche unser gesamtes Gesichtsfeld einnimmt, sehen wir diese doch als Fläche. Nur manchmal scheint ein Gegenstand ganz zu fehlen; och dann betrachten wir den entsprechenden Fall als Farbillusion (zum Beispiel, wenn wir bei geschlossenen Augen Farbeindrücke erhalten: etwa durch leichtes Drücken auf die Augäpfel). 
einfach und sicher diskriminieren können (vgl. K. Campbell (1969): 157). Damit ist natürlich bereits implizit gesagt worden, daß die Farbsachverhalte von uns als Bestandteil der uns umgebenden Außenwelt gesehen werden. Die als farbig wahrgenommenen Gegenstände befinden sich allem Anschein nach ,vor unseren Augen“: sie werden nicht als Eigenschaften unseres Wahrnehmungsapparates oder unserer Wahrnehmungen selbst gesehen, sondern (fast) immer als Eigenschaften von Gegenständen in der Außenwelt. Somit sprechen wir auch von Farben als extern instantiierten Eigenschaften, wie auch Frank Jackson schreibt:

„However, although colors present themselves in visual experience in a peculiarly conspicious way, we do not use 'red' as the name of the experience itself, but rather of the property of the object putatively experienced when it looks red. For we examine objects to determine their color; we do not introspect. We look out, not in.“(Jackson (1996): 200)

Ein weiterer, wichtiger Punkt ist der Umstand, daß Farbsachverhalte (in einem gewissen Sinne) subjekt-unabhängig zu existieren scheinen. Das heißt, sie sehen aus, als ob es sie ganz unabhängig von der faktischen oder möglichen Existenz farbwahrnehmender Subjekte geben kann. Denn Instantiierungen von Farben unterscheiden sich für uns hinsichtlich ihres ontologischen Status nicht wesentlich von Formsachverhalten: beide werden von uns offensichtlich als Teil der subjekt-unabhängigen Realität angesehen; und beide scheinen intrinsische Eigenschaften der wahrgenommenen Gegenstände zu sein (vgl. Johnston (1992): 139). Farben präsentieren sich uns weder als Relationen zwischen den einzelnen Dingen in der Außenwelt (es ist für uns einsichtig, daß ein Gegenstand auch dann seine Farbe behielte, wenn er der einzige von uns wahrgenommene oder wahrnehmbare wäre), noch sehen wir sie als Relationen zu uns selbst, das heißt, zu Zuständen unseres Gehirnes oder Geistes.

Die Annahme der Subjekt-Unabhängigkeit wird auch durch die beiden folgenden Intuitionen unterstützt. Erstens ist es uns möglich, durch Einwirkungen auf die reale Beschaffenheit von Gegenständen direkten Einfluß auf deren Farbigkeit zu nehmen: zum Beispiel durch das Auf- oder Abtragen von Oberflächenschichten (wie etwa in der Malerei); oder auch durch das Mischen zweier Substanzen (wie in chemischen Versuchen). Und zwei- 
tens gehen wir davon aus, daß Gegenstände ihre aktuellen Farben behalten, auch wenn wir sie nicht gerade betrachten (weil wir die Augen geschlossen haben oder es zu dunkel ist), oder sogar überhaupt nicht mehr betrachten können (weil wir blind oder farbenblind geworden sind). Dies scheint für uns überdies dann Gültigkeit zu haben, wenn die entsprechenden Einschränkungen für alle Menschen (oder farbenwahrnehmende Subjekte) gelten würden und somit niemand mehr Farbwahrnehmungen hätte. Denn daß die wahrnehmbaren Objekte in der Außenwelt uns aktual als farbig erscheinen, genügt uns, um ihnen ihre Farben als geistunabhängige Merkmale anzuerkennen. Crispin Wright beschreibt diese zweite Intutition wie folgt:

„We do not, for instance, believe that, were we all to become colour blind, red and green things would change in colour, preferring to describe such a situation as one in which we chould lose the capacity to make a distinction which is there anyway, whether we draw it or not. Here 'appropriately receptive' [to colours der Autor] means something like: having powers of colour discrimination which human beings actually typically enjoy. [...] Where 'actually' is understood as securing [modal - der Autor] rigidity, so pre-empting the implication that a change in the typical function of our visual system - as a result of disease, perhaps would command... a change in the extension of 'Red'." (Wright (1988): 9, 16; Fn. 22, 29)

Bei den bisherigen Erläuterungen der den Farben gewöhnlicherweise zugeschriebenen Merkmale ist bereits eines stillschweigend vorausgesetzt worden: die Wahrnehmbarkeit. Diese ist natürlich auf den Umstand zurückzuführen, daß wir zum einen bestimmte Eigenschaften visuell wahrnehmen können und zum anderen diese Eigenschaften als Farben identifiziert haben: und zwar durch die Stipulation der Korrektheit von (IND). Weniger klar, aber dennoch recht wahrscheinlich ist, daß wir üblicherweise zu der Annahme tendieren, es könne keine Farbsachverhalte geben, die nicht wenigstens möglicherweise wahrgenommen werden können. In diesem Sinne sind der naiven Farbkonzeption nach vermutlich alle instantiierten Farben prinzipiell wahrnehmbar. Mit der Wahrnehmbarkeit von Eigenschaften ist jedoch ein weiteres Merkmal eng verbunden. Denn der wahrgenommene Sachverhalt wird von uns als eine wesentliche Ursache für das Auftreten der Wahrnehmung angesehen. Wir neigen dazu, den Umstand, daß wir beispielsweise die Farbe Gelb in der Außenwelt instantiiert sehen, 
normalerweise dadurch zu erklären, daß es dort wirklich auch eine Instantiierung von Gelb geben muß. Es gibt sicherlich genügend Fälle, in denen wir unseren Farbwahrnehmungen nicht vertrauen und sie als Illusionen oder Halluzinationen abtun (wie bei Nachbildern (after-images) zum Beispiel, oder bei stark monochromer Beleuchtung). ${ }^{11}$ Doch in den meisten Situationen gehen wir davon aus, daß unsere Sinneserfahrungen der Realität entsprechen: und daß sich dann die Beschaffenheit der Wahrnehmung auf die Beschaffenheit des Wahrgenommenen zurückführen läßt.

„Still, if we take the appearances at face value, we will take it that we are seeing the properties of objects in virtue of which they have the potential to produce experiences of colour.“ (J. Campbell (1993): 257)

Dabei genießen wir - wie auch bei anderen fundamentalen Eigenschaften von Gegenständen (wie Formen, Klängen, Texturen oder Düften) - zu den Farben mithilfe unserer Sinne einen direkten Zugang: und zwar geradem weil es sich um in den Sinneserfahrungen präsentierte Eigenschaften handelt (Martin (1995): 466). Diese Unmittelbarkeit ist begrifflich schwer zu fassen, doch die folgenden Bemerkungen sind wohl charakteristisch für sie: Farbsachverhalte erscheinen uns als ganz basale Bestandteile der Welt, die wir nicht über den Umweg über andere Sachverhalte erkennen müssen (dagegen ist das Wahrnehmen einer Flasche komplexer, da es, unter anderem, bestimmte Form- und Farbwahrnehmungen voraussetzt oder beinhaltet; noch mittelbarer ist die Beobachtung von magnetischen Phänomenen), weswegen höhere kognitive Funktionen (wie Konzeptualisierung oder Interpretation einschließlich des Zusammenbringens verschiedener wahrgenommener Eigenschaften) für die Farbdetektion nicht erforderlich zu sein scheinen.

Das heißt aber nichts anderes, als daß die Information, die uns Farb wahrnehmungen bereitstellen, für uns einen basalen Charakter hat und nicht mehr in kleinere Informationsmengen unterteilt werden kann. Farben zeichnen sich demnach durch Einfachheit aus (vgl. Johnston (1992): 139);

11 Vgl. Dorsch (2010) und Dorsch \& Soldati (2010) für eine ausführliche Diskussion von Halluzinationen und ihren Gemeinsamkeiten mit und Unterschieden von (veridischen) Wahrnehmungen. 
und J. Campbell (1993): 258). Denn sie lassen keine Zusammengesetztheit aus anderen Eigenschaften erkennen und scheinen auch keinerlei ,innere Struktur" aufzuweisen (dadurch läßt sich auch die anscheinende Nicht-Relationalität der Farben begründen). Insbesondere zeigen Farben keine mikro-physikalische Natur. Stattdessen erscheinen sie uns als ganz elementare Eigenschaften von Gegenständen:

„,... as... primitive unreduced [properties].“ (Maund (1981): 309)

"If we take the appearances at face value, we will not take colours to be microphysical properties of things: they do not appear as microphysical properties." (J. Campbell (1993): 257)

Dabei werden ganz unterschiedliche Gegenstände von uns als gleichfarbig wahrgenommen, doch trotz der vielfältigen Unterschiede in Material, Textur oder Konsistenz scheinen sie alle ein- und dieselbe Eigenschaft zu instantiieren. In diesem Sinne gelten Farbeigenschaften für uns als einheitlich (vgl. K. Campbells Axioms of Unity (1969): 132f.). So schließen wir aufgrund ihrer Erscheinung, daß alle roten Gegenstände ein- und dieselbe Eigenschaft besitzen: nämlich Rot. Dies gilt dementsprechend für alle Farben, die wir wahrnehmen.

\subsubsection{Spezifische Merkmale der Farben}

Die bisher erwähnten Merkmale kommen in unseren Augen wahrscheinlich den meisten - vielleicht sogar allen - unmittelbar wahrnehmbaren Eigenschaften zu (wie eben Farben, Formen, Texturen oder Klänge und Düfte), auch wenn sich Unterschiede dahingehend auftun können, inwieweit die naive Auffassung von den fraglichen Eigenschaften sich mit einer wissenschaftlichen deckt oder von dieser erklärt werden kann (wodurch sich die sogenannten primären Qualitäten von den sogenannten sekundären trennen lassen würden). Nun bilden Farben aber innerhalb der direkt wahrnehmbaren Eigenschaften eine ganz eigene Klasse. Für uns ist es kein Problem, angesichts einer bestimmten wahrgenommenen Eigenschaft $\mathrm{zu}$ entscheiden, ob es sich dabei um eine Farbe handelt oder nicht. Demnach müssen sie uns anders erscheinen als beispielsweise Form- oder Klangei- 
genschaften, so daß wir das Vorkommen der Determinable Farbe von dem der anderen Determinablen differenzieren können.

Das erste Merkmal ist natürlich der Umstand, daß wir Farben nur visuell wahrnehmen können. Unsere anderen Sinnesorgane sind sozusagen „blind“ für Farbsachverhalte. Farben haben demnach für uns einen klar visuellen Charakter: auch wenn es uns schwer fallen wird, diesen genau zu beschreiben und von einem auditiven oder taktilen Charakter abzugrenzen. Mithilfe der Visualität von Farben läßt sich auch die bedeutende Rolle erklären, die Licht für unser Farbensehen einnimmt. Denn wenn keine ausreichende Beleuchtung vorliegt, dann bemerken wir dies natürlich durch den Umstand, daß wir Farben nicht mehr oder nur sehr ungenau und durch Graustufen überdeckt sehen. Zudem herrschen manchmal Lichtbedingungen, die wir nicht als übliche anerkennen und somit den resultierenden Farbempfindungen nicht trauen, sondern sie mittels unseres Wissen über die Beleuchtung korrigieren. Wenn zum Beispiel eine weiße Wand von monochrom grünen Licht bestrahlt wird und uns grün erscheint, so erkennen wir sie trotzdem normalerweise als weiß, obwohl wir sie, genau genommen, als grün sehen.

Damit bleiben Farben eigentlich nur noch von Formeigenschaften (also Linien, Winkeln, Formen, usw.) abzugrenzen. Unsere Intuitionen scheinen uns zu sagen, daß Farben von Formen nicht zu trennen sind: eine farbige Fläche (oder Volumen) muß immer eine Form (oder eine dreidimensionale Gestalt) besitzen, wie auch eine Form niemals ohne Färbung gesehen werden kann. Diese Einsicht hat nach der naiven Auffassung wenigstens für alle ohne Hilfsmittel wahrnehmbaren, mittelgroßen Gegenstände Bestand (daß sie nicht immer ganz zutrifft, wird im späteren Abschnitt über die Referentialität und die Räumlichkeit erläutert). Dabei ist natürlich die Auffassung stillschweigend vorausgesetzt worden, daß alle Graustufen ebenfalls als Farben gelten: was einsichtig ist, wenn man die entsprechenden Farbempfindungen betrachtet, da sich darin - auf den ersten Blick - die Erscheinungen von chromatischen und achromatischen Farben nicht kategorisch unterscheiden (wie etwa Form und Farbe). Naiv besehen sind Weiß, Grau und Schwarz zuerst einmal ebenso Farbeigenschaften von Gegenständen wie Rot oder Gelb. ${ }^{12}$ Doch zurück zu dem Gegensatz von Farbe

12 Diese Einsicht geht meistens schnell verloren, wenn man den praktischen Umgang mit Farben heranzieht: etwa in der Schwarzweißphotographie, oder beim 
und Form: die Formeigenschaften scheinen unser Gesichtsfeld zu strukturieren, während die Farben aussehen, als füllten sie die „Leerräume“ innerhalb dieser Strukturen aus. Hier gilt erneut, daß der Unterschied zwischen den beiden Klassen von Eigenschaften für uns im wahrsten Sinne des Wortes offensichtlich ist, während dessen sprachliche Erfassung sich viel schwieriger gestaltet.

Trotzdem verwenden wir zwei ganz klar voneinander verschiedene Arten der Darstellung, um die betreffenden Eigenschaften zu beschreiben. Für Formeigenschaften sind Größen wie Länge, Dicke, Richtung oder auch Abstand und Lage zueinander wichtig: letztlich als geometrische Merkmale. Farbeigenschaften weisen dafür drei ganz andere Parameter auf: Farbton, Helligkeit und Sättigung. Damit lassen sich alle Farben, wie wir sie sehen, eindeutig individuieren.

„We may distinguish three dimensions of perceived color: hue, brightness, and saturation. Inevitably, we must rely on instances for their specification. Thus, the hue of a color is its redness, or greenness, or yellowness, or blueness. White and black and the grays are the colors with zero hue; they are technically known as the achromatic colors. The achromatic colors are colors in a limiting sense, just as zero is a number in a limiting sense. Those colors with nonzero hue are the chromatic colors. It is these which we demand to see when we pay for a color television set. Colors with the same hue may differ in the strength of that hue; they may have very little hue and thus be close to gray, or they may be strongly hued. We shall say that these colors differ in saturation. The spectrum is the hue gamut of maximum saturation. Finally, colors seen through apertures or perceived as self-luminous will vary along a range, with very dim colors at one end of the range and very bright or dazzling colors at the other. The colors ranged in this way vary in brightness. Objects that are not seen through apertures or perceived to be self-luminous vary in lightness." (Hardin (1988): 25f.)

Jede wahrgenommen Farbe weist also genau einen Farbton, einen Sättigungs- und einen Helligkeitsgrad auf und läßt sich so von uns vollständig

Mischen von Malfarben. Hier zeigt sich auch eine erste Ungenauigkeit der naiven Farbkonzeption: einerseits erscheinen die Grautöne wie chromatische Farben (als visuelle Nicht-Formeigenschaften von Gegenständen, die den Platz von Farben einnehmen, also unter die allgemeine Determinable fallen), andererseits aber nicht (Weiß kann mit allen Farben gemischt werden, ändert aber nicht - oder nur wenig - den Farbton; und es gibt kein transparentes Weiß). 
charakterisieren. ${ }^{13}$ Bei diesen Überlegungen handelt es sich jedoch bereits um eine erste Theoretisierung der Intuitiven Farbkonzeption. Auch wenn wir gewöhnlich von „helleren“" und „dunkleren“ oder von ,intensiveren“ und „pastellartigen“ Farben sprechen, so meinen wir mit „Farben“ doch meist nur die Farbtöne: wir ignorieren auf gewisse Weise die beiden anderen Dimensionen. Das zeigt sich auch darin, daß wir Farbtonunterschiede im Vergleich wesentlich besser diskriminieren können als etwa Helligkeitsoder gar Sättigungsdifferenzen (vor allem, wenn diese zwischen verschiedenen Farbtönen bestehen - vgl. Albers (1975): 12). Doch die Unterscheidung der drei Farben bestimmenden Parameter baut so unmittelbar auf unsere Farbwahrnehmungen auf (sie läßt sich tatsächlich nur durch Hinweis auf diese verständlich machen), daß sie wahrscheinlich ohne größere reflexive Anstrengungen von den meisten Menschen akzeptiert würde.

Ganz davon abgesehen wird sich dieses Buch weitestgehend auf Farbtöne beschränken und nur dort, wo es für die Argumentation wirklich daraufankommt, auf die beiden anderen Faktoren von Farben Bezug nehmen. Dahinter steckt die Überzeugung, daß eine Diskussion ontologischer Farbtheorien bereits auf der Ebene der Farbtöne zu weitreichenden Resultaten kommen kann. Dieser Verzicht hat zur Folge, daß die achromatischen Farben weitestgehend vernachlässigt werden, auch wenn sie in unserem alltäglichen Umgang mit farbigen Gegenständen eine wichtige Rolle spielen und ihre eigenen Besonderheiten zeigen. So können achromatische Farben keine transparenten Volumenfarben sein: es gibt keine durchsichtige Milch oder weißes Wasser. Doch während Weiß die hellste Farbe ist und es weißes Licht gibt, kann es kein graues oder schwarzes Licht geben. Und die Brauntöne nehmen ebenfalls eine Sonderrolle aus. Physikalisch betrachtet gehören sie zu den chromatischen Farben, von denen sie sich nur durch die Helligkeit unterscheiden, aber es gibt ebenfalls kein braunes Licht oder einen reinen Braunton, wie noch bei den anderen chromatischen Farben. (vgl. Wittgenstein (1997): I, §§ 17, 23, 36; III, §§ 1-3, 60, 65). Und es ließen sich noch weitere Beispiele anführen (eine exzellente

13 Es gibt noch andere, visuell wahrnehmbare Merkmale, die man zur Farbigkeit dazuzurechnen geneigt ist: wie etwa der Gegensatz von Glanz und Mattigkeit, oder der Charakter metallischer Farben. Doch dabei handelt es sich eher um material- und texturbedingte Merkmale, die höchstens das Farbensehen erschweren (etwa durch Schattenbildung). 
Besprechung der Erkenntnise von Wittgenstein liefert Westphal (1987)).

Wenn man nun Farben allein über ihren Farbton individuiert, dann unterscheiden sich die einzelnen wahrgenommenen Farbeigenschaften untereinander - und ebenso von den anderen wahrnehmbaren Eigenschaften für uns durch ihren jeweiligen, farbton-spezifischen Charakter, den sie laut unserer Farbwahrnehmungen aufzuweisen scheinen. Jede Farbe verfügt also über einen ihr eigenen und sie bestimmenden Farbtoncharakter. Allein anhand dieses Charakters können wir innerhalb unserer Wahrnehmungen Farben - ihren Farbtönen nach - voneinander unterscheiden. Um Farben introspektiv diskriminieren zu können, müssen wir mit den betreffenden Farbtönen ,vertraut sein“ oder sie „kennen“: das heißt, um eine Sinneserfahrung als Wahrnehmung einer ganz bestimmten Farbe identifizieren zu können, müssen wir in der Lage sein, den präsentierten Farbton von anderen zu differenzieren; und um zwei zeitlich nacheinander auftretende Sinneserfahrungen als Wahrnehmungen (in etwa) ein- und derselben Farbe ansehen zu können, ist es erforderlich, daß wir den entsprechenden Farbton „wiedererkennen“ oder ,erinnern“ können (wenn dies überhaupt ganz exakt möglich sein wird). Beides sollte uns aber bereits allein aufgrund unserer alltäglichen Farbwahrnehmungen möglich sein:

„What do you know about colours, not as a student of physics or physiology, but simply in your capacity as a subject of visual experience? [...] You know that red and orange are properties that things visually appear to have, and you know when things appear to have them.“ (Boghossian \& Velleman (1991): 85)

Tatsächlich können wir eine Unmenge von verschiedenen Farbtönen an Gegenständen im Vergleich zueinander unterscheiden. Ohne direkte Vergleichsobjekte - das heißt: allein auf die Erinnerung von Farbwahrnehmungen gestützt - sind solche Abwägungen weitaus schwieriger: ob das vor mir liegende und gerade von mir wahrgenommen Buch genau dieselbe Farbe hat wie das Auto, daß mich vorhin fast umgefahren hätte, kann ich aus der Erinnerung nur sehr vage beurteilen. ${ }^{14}$ Der Farbtoncharakter an sich

14 Vergleichbare Beziehungen lassen sich für Intensitäten und Sättigung nachweisen, sowie auch für die drei Dimensionen untereinander (vgl. vor allem Albers (1975) und Itten (1983)). - Es ist etwas anderes, ob wir die Unterschiede auch begrifflich oder sprachlich fassen können. Da unser Wortschatz nur sehr gering 
ist demnach ein wesentlicher Bestandteil unserer Farberscheinungen. Doch damit allein ist es noch nicht getan. Denn wir bemerken üblicherweise zwischen den verschiedenen Farbtönen ganz bestimmte Beziehungen, die erst die Farbdifferenzierungen ermöglichen.

„Thanks to its nature and the nature of the other determinate shades, canary yellow, like the other shades, has its own unique place in the network of similarity, difference and exclusion relations exhibited by the whole family of shades." (Johnston (1992): 138)

Diese Beziehungen zwischen den einzelnen chromatischen Farbtoncharakteren, mit denen wir mittels unserer Sinnesempfindungen bekannt sind, sind bereits Thema vieler frühen Untersuchungen über Farben und Farbempfinden gewesen (wie etwa von Locke und Hume: vgl. Hardin (1988): $128 ; 132)$. Und gerade Wittgenstein ist es zu verdanken, daß diese phänomenalen Beziehungen - die bereits von Denkern wie Goethe und Runge thematisiert worden sind - philosophische Relevanz erhalten haben, in dem er, wie er sagt, die „Logik“ oder die „Grammatik“ der Farbasudrücke zu beschreiben suchte:

„In den Farben: Verwandschaft, und Gegensatz. (Und das ist Logik.)“ (Wittgenstein (1997): III, § 46)

Er liefert in seinen Bemerkungen über die Farben eine der ausführlichsten und genauesten (wenn auch nicht besonders systematischen) Diskussionen dieser Beziehungen, auf die hier jedoch nur als Materialquelle für Beschreibungen der Farbmerkmale eingegangen werden soll, da sonst eine eingehendere Auseinandersetzung mit dem Ansatz Wittgensteins erforderlich wäre. ${ }^{15}$ Eine zugänglichere, da thesenartiger und kürzer formulierte Be-

ist, bleibt uns meist nichts anderes übrig, entweder auf Farbparadigmen als Vergleichsmuster zurückzugreifen (z.B. ,zitronengelb“) oder aber rein indexikalisch auf Farbtöne Bezug zu nehmen (wie in dem Satz: ,dieses Orange ist weniger rötlich als jenes"). In jedem Fall setzt der Besitz von Farbbegriffen zu einem gewissen Grad die Diskriminationsfähigkeit voraus, während diese wiederum zum Teil durch das (wenigstens in der Vergangenheit stattgefundende) Vorkommen von Farbwahrnehmungen bedingt ist (vgl. Peacocke (1992): 7f.; 27ff.).

15 In dieser Abhandlung weist er auf Besonderheiten unserer Verwendung von Farb- 
schreibung bieten dagegen Boghossian und Velleman in der oben bereits auszugsweise zitierten Passage aus ihrem zweiten Text über Farben:

„What do you know about colors, not as a student of physics or physiology, but simply in your capacity as a subject of visual experience? We think that you know, for example, that red and orange are properties; that they are different properties, though of the same kind - different determinants of the same determ-

ausdrücken hin, die aus unserer intuitiven Sicht wesentliche Eigenschaften der Farben benennen, deren Zuschreibungen somit für uns einen ausgeprägten Wahrheitscharakter besitzen: sie bestimmen in unseren Augen einen Teil der Natur der Farben. Wittgenstein ist dabei allein an einer Logik oder Grammatik der Farben, das heißt, der Farbausdrücke interessiert: worauf sich diese beziehen, ist nebensächlich (insbesondere blendet er die Ebene des Phänomenalen aus).

„Wir wollen keine Theorie der Farben finden (weder eine physiologische noch eine psychologische), sondern die Logik der Farbbegriffe. Und diese leistet, was man sich oft mit Unrecht von einer Theorie erwartet hat.“ (Wittgenstein (1997): I, § 22)

Im Grunde liefert er also eine Analyse bestimmter Aspekte unserer naiven Farbkonzeption (Westphal (1987) stellt eine ausführliche Diskussion der Überlegungen Wittgensteins dar). Zu den Einsichten, zu denen Wittgenstein während seiner Behandlung unserer Farbsprache (oder: unseres Farbsprachspieles) kommt, gehören unter anderem die folgenden, beispielhaft herausgegriffenen:

„Meinem Gefühl nach löscht Blau das Gelb aus, - aber warum sollte ich nicht ein etwas grünliches Gelb ein „bläuliches Gelb“ nennen und Grün eine Zwischenfarbe von Blau und Gelb, und ein stark bläuliches Grün ein etwas gelbliches Blau?

In einem grünlichem Gelb merke ich noch nichts Blaues. - Grün ist für mich eine besondere Station auf dem farbigen Wege von Blau nach Gelb, und Rot ist auch eine.“ (III, §§ 39f.)

„Blau und Gelb, sowie Rot und Grün, erscheinen mir als Gegensätze.“ (III, $\S \S 26)$

„Tatsache ist, [...] daß wir die Wörter „Rötlichgrün“, „Gelblichblau“ etc. nicht verwenden.“ (III, § 52)

„Wie kommt es, daß etwas Durchsichtiges grün, aber nicht weiß sein kann?“ (I, § 19) 
inable; that they are not as different from one another as they are from blue; and that they cannot simultaneously be instantiated in exactly the same place. [...]

All [these] items of knowledge are necessary propositions. Red and orange - that is, the properties that things appear to have in looking red and in looking orange - not only are distinct, similar determinants of the same determinable but are essentially so. A property that wasn't a determinate of the same determinable as red, or wasn't distinct from red, or wasn't similar to red - such a property simply wouldn't be orange. And vice versa.“ (Boghossian \& Velleman (1991): 85)

Die einzelnen Farbtoncharaktere unterscheiden sich also untereinander erst durch ihre Positionen in den zwischen ihnen bestehenden Ähnlichkeitsund Gegensatzbeziehungen. ${ }^{16}$ Es ist möglich, alle uns erscheinenden Farb-

„Was leuchtend aussieht, sieht nicht grau aus. Alles Graue sieht beleuchtet aus. “ (I, § 36)

„In einem Bild muß das Weiß die hellste Farbe sein.“ (III, § 1)

„Aber auch das reine Gelb ist heller als das reine, satte Rot, oder Blau.“ (III, $\S 4)$

Auch wenn Wittgenstein, wie oben bereits erwähnt, diese Merkmale in der Sprache lokalisiert und nicht dem introspektiven Charakter von Farbwahrnehmungen zusprechen möchte, werden sich diese von ihm (und vor ihm von Personen wie Goethe oder Runge) formulierten Einsichten in der Liste der Merkmale der Intuitiven Farbkonzeption immer wieder finden lassen.

16 Diese Beziehungen scheinen damit räumlichen - oder anderen internen - Relationen zu ähneln. Eine ganz ähnliche Stelle findet sich auch bei Armstrong, in der er Gemeinsamkeiten von Farben und Formen bespricht:

„If we consider the class of shapes and the class of the colours, then both classes exhibit the following interesting but puzzling characteristics which it would be agreeable to understand:

(a) the members of the two classes all have something in common (they are all shapes, they are all colours);

(b) but while they have something in common, they differ in that very respect (they all differ as shapes, they all differ as colours);

(c) they exhibit a resemblance-order based upon their intrinsic natures (triangularity is like circularity, redness is more like orangeness than redness is like blueness), whre closeness of resemblance has a limit in identity;

(d) they form as set-of-incompatibles (the same particular cannot be 
töne in einem Kreis anzuordnen: benachbarte Farben sind sich vergleichsweise ähnlich (wie Rot und Orange), während weiter weg- oder gegenüberliegende Farbtöne eher Gegensatzpaare - oder Komplementäre bilden (wie uns beispielsweise Rot und Grün als sehr verschieden erscheinen). ${ }^{17}$ Der Farbtonkreis stellt also nichts anderes als eine Verbildlichung der Ähnlichkeiten und Gegensätze dar. Aus unseren Sinneserfahrungen schließen wir zudem, daß jeder farbige Gegenstand, oder besser: jeder farblich homogene Teil eines farbigen Gegenstandes nur eine einzige Farbe auf einmal aufweisen kann. Es kann so keine eindeutig bestimmte Stelle einer Oberfläche geben, die sowohl Rot als auch Gelb ist, wie es auch kein Objekt geben kann, das gleichzeitig einen Meter und zwei Meter lang ist: der betreffende Teil des Gegenstandes ist entweder Rot oder Gelb, und er ist entweder einen oder zwei Meter lang. Natürlich gibt es Oberflächen, die für uns gelbe und rote Farbflecken aufweisen: aber jeder einzelne Fleck kann nur Gelb oder nur Rot sein. Zwei maximal bestimmte, verschiedene Farbtöne (wie Bananengelb oder Marineblau) erscheinen uns demgemäß niemals als exakt zur gleichen Zeit am gleichen Ort instantiiert.

Die Ähnlichkeitsbeziehungen lassen sich nun jedoch auch über die „Mischungsverhältnisse“ der einzelnen Farbtöne beschreiben. Denn es scheint vier ausgezeichnete Punkte auf dem Farbtonkreis zu geben: und zwar bei (jeweils einem ganz bestimmten Farbton von) Rot, Blau, Gelb und Grün. Betrachtet man mehrere Gegenstände, die verschiedene Rottöne aufweisen, so wird man einige vielleicht als mehr gelblich, andere als mehr bläulich beschreiben: jedoch nur einen als weder gelblich, noch bläulich oder grünlich, sondern als rein rötlich. ${ }^{18}$ Das gleiche gilt für die drei anderen besond-

simultaneously triangular and circular, or red and blue all over).“ (Armstrong (1978): 116)

17 Der Kreis ist dabei in Wirklichkeit eine eindimensionale Kreislinie. Zusammen mit Sättigung und Helligkeit ergibt sich ein dreidimensionales Gebilde, welches der grundlegenden Kreisform der Farbtonlinie wegen entweder als Kegel oder als Kugel dargestellt wird (vgl. Thompson (1995): 47; vgl. Itten (1983)).

18 Gegenstände von reinem Rot können sich natürlich trotzdem äußerlich sehr deutlich unterscheiden: nicht nur in ihren Form- und Materialeigenschaften, sondern auch hinsichtlich der Sättigungs- und Helligkeitsgrade ihres gemeinsamen Farbtones. Welche Gegenstände zudem als Instanzen reiner Farben gelten, kann von Mensch zu Mensch leicht verschieden sein (doch dazu mehr im Abschnitt über Normalbedingungen). 
eren Farbtöne. Es gibt demnach für uns vier reine chromatische Farbtöne; alle anderen sind aus diesen vier gemischt (wobei der in der Literatur gebräuchliche Ausdruck ,gemischt“ nicht allzu wörtlich genommen werden sollte, wie sich weiter unten zeigt). Orange ist beispielweise sowohl gelblich als auch rötlich, während Violett einen bläulichen und einen rötlichen Charakter in sich vereinigt. Damit ist es uns möglich, zwischen reinen und gemischten Farbtönen zu unterscheiden. Und aufgrund unserer Erfahrungen gelangen wir zu der Überzeugung, daß es nur vier reine chromatische Farben gibt, während alle anderen sich aus diesen vier ergeben (vgl. Wittgenstein (1997): III, § 134).

„Red can combine with yellow (orange) and with blue (purple); and green too can combine with yellow (green-yellow) and with blue (green-blue). Such combinations are called binary hues. The pure examples of red, green, yellow, and blue - that is, a red or green containing neither yellow or blue, and a yellow or blue containing neither red nor green - are called unitary hues or unique hues." (Thompson (1995): 46f.)

"If we reflect on what it is to be red, we readily see that it is possible for there to be a red that is unique, i.e., neither yellowish nor bluish. It is equally apparent that it is impossible for there to be an unique orange, one that is neither reddish nor yellowish.“ (Hardin (1988): 66)

Ordnet man die vier reinen Farbtöne im Abstand von jeweils neunzig Grad auf dem Farbkreis an, so gibt der Abstand eines bestimmten gemischten Farbtons von den reinen genau das den gemischten Ton konstituierende Mischverhältnis an. Eine nahe am Rot gelegener Farbton hat einen hohen Rotanteil, während mit wachsender Entfernung dieser abnimmt. Der Abstand auf dem Farbkreis ist aber auch ein Maß für die Ähnlichkeit zweier Farben. Letztere kann somit ebenso - wenn auch ungenauer - über die Mischverhältnisse beschrieben werden. Zwei Farbtöne, die beispielsweise aus viel Rot und wenig Gelb gemischt sind, sind sich untereinander ähnlicher als jeweils im Vergleich zu einem Farbton, der aus wenig Rot und viel Blau besteht: hauptsächlich, weil sie beide einen hohen Rotanteil aufweisen, aber auch, da sie aus denselben reinen Farben gemischt sind. Dabei gibt es jedoch eine interessante Einschränkung der Mischungsverhältnisse, die im obigen Zitat von Thompson bereits angeklungen ist. Denn nicht alle prinzipiell denkbaren Kombinationen von reinen Farben sind auch faktisch 
möglich.

„Certain hues mutually exclude each other and so are said to be antagonistically or opponently related: red and green are mutually exlusive (there are no reddishgreens and greenish-reds), as are yellow and blue (there are no yellowish-blues and bluish-yellows).“(Thompson (1995): 46)

Hinzukommt, daß immer nur zwei - und nicht drei oder vier - reine Farbtöne sich zu einer „Mischfarbe“ zusammensetzen. Das läßt sich auf dem Farbkreis wie folgt verdeutlichen: ein reiner Farbton beeinflußt als Mischanteil nur jeweils ein halbkreisförmiges Segment des Farbkreises. Mehr als neunzig Grad vom reinen Rot entfernt lassen sich also keine Farbtöne mehr finden, die einen Gelbanteil besitzen, da es unserer Anschauung nach keinen Farbton gibt, der sowohl rötlich als auch grünlich ist. In diesem Sinne gibt es zwei Arten von Mischungsinkompatibitlitäten, denn ein Farbton hat für uns auch nie gleichzeitig einen gelblichen und einen bläulichen Charakter. Es kann zwar sehr viele (vielleicht auch unendlich viele) gemischte Farbtöne geben, aber es kommen dabei nur ganz bestimmte Kombinationen der reinen Farben vor: insbesondere scheint jede Mischfarbe sich immer nur aus zwei reinen Farben zusammenzusetzen, niemals aber aus mehr. Mit dieser Erkenntnis kann die Auflistung der für die weitere Diskussion relevanten Merkmale, die wir gewöhnlicherweise den Farben allein aufgrund unserer alltäglichen Wahrnehmungen zusprechen, beendet werden.

Zwei abschließende Bemerkungen sind jedoch noch ratsam. Zunächst einmal ist es legitim, Zweifel an der Richtigkeit der eben gegebenen Darstellung der Intuitiven Farbkonzeption anzumelden. Im Grunde ist es wahrscheinlich unmöglich, eine naive Konzeption angemessen darzustellen: nicht nur, da eigentlich jede Beschreibung oder begriffliche Erfassung bereits Hintergrundsannahmen vorauszusetzen scheint, sondern auch, da letztlich nur Intuitionen oder Untersuchungen über die alltägliche Praxis (im Umgang mit farbigen Gegenständen wie mit Farbausdrücken) als Evidenzen herangezogen werden können, welche jedoch von Subjekt(gruppe) zu Subjekt(gruppe) differieren können. Deswegen ist hier ein anderer und einfacherer, wenn auch nicht angemessenere Weg gewählt worden, indem 
durch die Sichtung der innerhalb der traditionellen sowie der neueren analytischen Philosophie angestellten Überlegungen über Farben eine gemeinsame, vor-theoretische Basis herausgearbeitet worden ist: wie es auch die Auswahl der Zitate, welche insbesondere von Philosophen mit ganz verschiedenen ontologischen Vorstellungen in Hinsicht auf Farben stammen, verdeutlichen soll. Dieser vor-wissenschaftliche Minimalkonsens kann somit als Intuitive Farbkonzeption angesehen werden.

Trotzdem ist es vielleicht angebracht, auf ein mögliches Mißverständnis hinzuweisen. Den obigen Ausführungen zufolge gibt es vier reine Farböne, aus denen alle anderen Farbtöne des Farbkreises gemischt werden können, wobei bestimmte Kombinationen - darunter auch ein gelbliches Blau oder ein bläuliches Gelb - ausgeschlossen sind und nur jeweils Mischungen aus zwei Farben zugelassen sind. Die meisten farbwahrnehmenden Menschen werden diese Erkenntnisse jedoch alles andere als intuitiv einsichtig finden, sondern vielmehr als überraschend und ihrem Bild von den Farben widersprechend auffassen. Denn unser praktischer Umgang mit Farben - gerade im Sinne von sogenannten Mal- oder Pigmentfarben - zeigt doch gerade, daß es nur drei Grundfarben gibt (üblicherweise Rot, Gelb und Blau), aus denen sich alle andere Farben (einschließlich Grün sowie auch Braun) - additiv (zum Beispiel mithilfe von verschiedenfarbigen Lichtstrahlen) oder subtraktiv (zum Beispiel mit Pigmenten oder Lichtfiltern) - mischen lassen (vgl Albers (1975): 27). Insbesondere gibt es dann auch ein bläuliches Gelb: und zwar Grün.

Der vermeintliche Widerspruch zwischen den beiden Auffassungen kann nun dadurch aufgelöst werden, indem man eine Ambiguität im Begriff der Mischung (und damit verbunden im Begriff der reinen Grundfarbe) aufdeckt - welche auch eng mit der Zweideutigkeit des Ausdruckes „Farben“ zusammenhängt (vgl. Wittgenstein (1997): I, 8). Auf der einen Seite sprechen wir von gemischten Farbtönen im Gegensatz zu reinen Farbtönen, wobei damit eigentlich gemeint ist, daß es vier fundamentale das heißt, sich im Grunde auf keine Weise ähnelnde - Farbtoncharaktere gibt, die meistens jedoch in Paaren ,zusammenauftreten“ und dadurch eine kreisförmig darstellbare Struktur von Ähnlichkeiten bilden. Es ist dabei noch ganz ungeklärt, was dieses „Zusammenauftreten“ oder „Zusammengesetztsein“ genau heißen soll, aber es ist sicherlich keine „Mischung“ im herkömmlichen (wie im chemischen) Sinne, derzufolge zwei materielle 
Substanzen zusammengeworfen und eine einzige, neue ergeben. Vielmehr handelt es sich um eine „Gemischtheit“ im Erscheinungsbild. Dies zeigt sich vor allem darin, daß die vier fundamentalen Farbtoncharaktere keinerlei Ähnlichkeit untereinander aufweisen und sich eine Art von Kontinuum zwischen ihnen nur durch die Zwischenfarben ergeben, die jeweils zwei Grundtönen ähnlich sind, aus denen sie ,zusammengesetzt“ sind. Die englischen Bezeichnungen für reine und gemischte Farben sind deswegen eigentlich zutreffender: erstere heißen unique, da sie nicht durch andere Farben ,analysiert“ werden können; und letztere werden als binary charakterisiert, da sie sich immer auf zwei reine Farben zurückführen lassen.

Auf der anderen Seite gibt es praktische und wörtlich zu verstehende Mischung von Pigmentfarben oder Lichtstrahlen. Es geht also in diesem zweiten Fall um eine methodische, physikalische Beeinflußung von Gegenständen hinsichtlich derer Farben, während im ersten es sich um Ähnlichkeiten und Gegensätze zwischen Farberscheinungen handelt. Die Erkenntnisquelle ist jeweils sehr verschieden: praktisches Handeln und Empirie einerseits, Aufmerksamkeit und Introspektion andererseits. Und ein Mischprozeß liegt tatsächlich nur in der Praxis vor: ihm Kopf werden keineswegs Farbtöne auf irgendeine Weise miteinander „vermischt“. Zudem können beide Phänomene auch vollkommen unabhängig voneinander auftreten: ein Betrachter, der nie selbst die Farbigkeit von Gegenständen in der Welt beeinflußt oder verändert hat, wird trotzdem, wenn er normalsichtig ist, über die eben ausführlich beschriebene Farbphänomenalität verfügen; und ein Blinder kann Pigmentfarben wissentlich zu angestrebten Resultaten mischen, ohne diese sehen zu können. Damit verbunden ist auch der zweite Punkt, auf den hier noch hingewiesen werden soll. Denn es ist ebenso klar, daß die gegebene Darstellung der Intuitiven Farbkonzeption - auch wenn sie als Minimalkonsens gelten soll - keinen Anspruch auf Vollständigkeit erheben kann. Es gibt noch genügend andere Merkmale, vor allem in Verbindung mit dem Sättigungs- und dem Helligkeitsgrad von Farben, die hier unberücksichtigt bleiben, da sie für die weitere Diskussion nicht unbedingt von Bedeutung sind. 


\subsection{Theoretische Grundlagen}

Bevor die einzelnen Merkmale der Intuitiven Farbkonzeption in eine Ordnung gebracht und, so gut es geht, theoretisch erfaßt werden sollen, ist ein kurzer Blick auf allgemein anerkannte Punkte einer Theorie der Wahrnehmungen erforderlich. Eines der charakteristischen und herausragenden Merkmale von Sinneserfahrungen ist es, daß sie typischerweise sowohl über einen Gehalt als auch über ein Quale verfügen; ein anderes ist ihre besondere Rolle als eine Art Schnittstelle zwischen den mittels der Sinne aus der wahrgenommenen Außenwelt empfangenen Reizen und dem Bewußtsein des wahrnehmenden Subjektes. Durch ihre Mentalität unterscheiden sie sich von den nicht-bewußten und nicht-introspektierbaren, komputationellen Gehirnzuständen, die zum Beispiel die basalen Verarbeitungsprozeße im visuellen System realisieren. Durch den qualitativen Charakter differieren sie von Überzeugungen und Meinungen, während ihre Repräsentationalität sie von Stimmungen oder auch bestimmten Empfindungen trennt (wenn diese überhaupt nicht-repräsentational sein können). Es lohnt sich, einen genaueren Blick auf diese beiden letzteren Charakteristika von Wahrnehmungen zu werfen, da beide eng mit dem introspektiven Charakter von Farbwahrnehmungen verbunden sind. Da es sich bei Gehalt und Quale um theoretische Begriffe handelt, heißt das nichts anderes, als die betreffenden Theorien zu skizzieren.

\subsubsection{Gehalt}

Es ist allgemein akzeptiert, daß Wahrnehmungen (im Gegensatz vielleicht zu bestimmten Empfindungen) einen intentionalen Gehalt haben: sie repräsentieren den von uns wahrgenommenen Sachverhalt; ihr Gehalt gibt an, was wahrgenommen wird. ${ }^{19}$ Dabei handelt es sich ja gerade um das Kernstück des Direkten Realismus (oftmals auch Intentionalismus genannt). Wenn wir eine Blau-und-Quadratisch-Wahrnehmung haben, dann nehmen

19 Innerhalb der Farbendiskussion sind Averill (1982) und Tolliver (1994) die einzigen, die einen nicht-repräsentationalen, rein informationalen Gehalt ohne Fehlermöglichkeit annehmen. Die resultierende Position des Informationalismus wird im Zusammenhang mit dem Starken Physikalismus abgehandelt. 
wir eben nicht ein wie auch immer beschaffenes, Bläulichkeit und Quadratförmigkeit exemplifizierendes Sinnesdatum wahr, sondern sehen die Eigenschaften Blau und Quadratrisch als in der Außenwelt instantiiert. Wahrnehmungen informieren uns somit über Tatsachen in der Welt, wobei die Repräsentationalität wesentlich die Möglichkeit eines Fehlers mit einschließt. In dem genannten Beispiel ist es also ohne weiteres möglich, daß in Wirklichkeit sich kein blauer und quadratischer Gegenstand vor den Augen des Betrachters befindet. Ob einen Wahrnehmung veridisch ist, hängt also davon $\mathrm{ab}$, ob der wahrgenommene Sachverhalt auch tatsächlich in der Welt besteht (vgl. Martin (1994): 464). Zwei Fragen sind nun zu klären: wie erstens die Repräsentationsrelation beschaffen ist und es dazu kommt, daß eine Wahrnehmung einen bestimmten Gehalt hat; und wie zweitens dieser Gehalt beschaffen ist.

Hinsichtlich von Wahrnehmungen haben sich mittlerweile rein externalistische Gehaltstheorien durchgesetzt (vgl. Tye (1995): 105; und Tye (1992)). Das heißt nichts anderes, als daß der Umstand, welchen Gehalt eine Wahrnehmung hat oder was sie repräsentiert, allein durch (gegenwärtige oder auch historische) Faktoren in der Umwelt des wahrnehmenden Subjektes bestimmt wird. Die verschiedenen externalistischen Gehaltstheorien deuten diese Faktoren unterschiedlich. Die Vertreter eine teleologischen Semantik gehen zum Beispiel davon aus, daß eine gegebene Wahrnehmung genau dann eine bestimmte Eigenschaft repräsentiert, wenn der entsprechende Wahrnehmungstypus während der evolutionären Entwicklung die Funktion erhalten hat, die betreffende Eigenschaft zu detektieren; und daß diese Funktion (die natürlich nicht unter allen Umständen erfüllt werden kann und somit Raum für Fehlrepräsentation läßt) dem Zustand des fraglichen Subjektes auch zukommt, setzt voraus, daß irgendwann in der Vergangenheit der betreffenden Spezies diese Funktion dadurch erworben worden ist, daß es für die natürliche Selektion günstig gewesen ist, die entsprechenden Detektionen aufzuweisen (was wiederum erfordert, daß die detektierten Sachverhalte innerhalb dieser Adaptionsphase auch wirklich Bestand gehabt haben). ${ }^{20}$

20 Dieser Ansatz wird in unterschiedlichen Ausformungen von Dretske ((1986); (1995a)) und Millikan ((1984); (1994)) vertreten. Andere externalistische Semantiken stellen die Theorie der kausalen Kovarianz (vgl. Tye (1995): 100ff.) und Fodors Theorie der asymetrischen Dependenz dar (vgl. dazu Stich \& Warfield 
Doch die konkrete Form einer solchen Gehaltstheorie ist hier von geringerem Interesse. Stattdessen genügt es, auf eine Grunderkenntnis hinzuweisen, die sich in allen externalistischen Theorien über den Wahrnehmungsgehalt wiederfindet. Daß die Information, die wir in sinnlichen $\mathrm{Zu}$ ständen erhalten, mit der Welt übereinstimmt, kann alleine noch nicht garantieren, daß es sich um eine Wahrnehmung des betreffenden Objektes handelt. Denn es kann Fälle sogenannter veridischer Halluzinationen geben, die zwar mit der Realität voll und ganz übereinstimmen, deren Auftreten aber nicht auf einem Prozeß beruht, welchen wir als Sehen bezeichnen würden. David Lewis hat solche Fälle einer ausführlichen Diskussion unterzogen. Ein Beispiel von ihm kann in etwa wie folgt beschrieben werden (vgl. Lewis (1980): 277f.). In das Gehirn einer blinden Person werden Elektroden implantiert, die genau dann eine visuelle Erfahrung von einer ganz bestimmten Landschaft hervorrufen, wenn ein mit den Elektroden verbundener Beleuchtungsmesser feststellt, daß die Intensität des die Person umgebenden Lichtes einen bestimmten Schwellenwert überstiegen hat. Herrscht nun helles Tageslicht vor und befindet sich zufälligerweise genau die fragliche Landschaft vor den Augen der Person, dann entspricht der in ihr hervorgerufene sinnlichen Eindruck genau der Realität (und auch der Sinneserfahrung, die eine normalsichtige Person von dieser Position aus hätte). Doch trotz dieser Übereinstimmung scheint es nicht möglich zu sein, hier von einer Wahrnehmung zu sprechen.

Der Grund hierfür liegt interessanterweise nicht in dem Umstand, auf welche Weise das Auftreten des mentalen Zustandes kausal bewirkt worden ist. Dafür entwickelt Lewis den Fall des prosthetischen Sehens (Lewis (1980): 279f.). Danach verfügt die blinde Person über eine Kamera vor ihren Augen, die vermittels eines implantierten Computers und den Elektroden das Gehirn derart anregt, daß die resultierenden sinnlichen Erfahrungen der Umgebung - oder auch den Wahrnehmungszuständen eines Normalsichtigen - entsprechen. In diesem Fall ist man dazu geneigt, die Rede von einem Sehprozeß zu akzeptieren, auch wenn die Kausalkette, die von den Tatsachen in der Umgebung zu den Sinneserfahrungen führt, von der bei normalsichtigen Menschen vorherrschenden stark abweicht. Es ist also nicht so wichtig, über welchen Weg die Information dem Bewußtsein geliefert wird. Vielmehr spielt der Gedanke des Zufalls eine entscheidende 
Rolle, um Fälle von Wahrnehmen von anderen differenzieren zu können. Denn während das prosthetische Auge in denselben Umgebungen funktionieren wird wie ein menschliches, so stimmt die vom Lichtmesser verursachte Erfahrung nur dann mit der Umwelt überein, wenn das Subjekt sich zufälligerweise vor der ganz konkreten Landschaft befindet. ${ }^{21}$ Die Differenz liegt woanders:

\begin{abstract}
„What distinguishes our cases of veridical hallucination from genuine seeing natural or prosthetic, lasting or momentary - is that there is no proper counterfactual dependence of visual experience on the scene before the eyes. If the scene had been different, it would not have caused correspondingly different visual experience to match that different scene. Any match that occurs is a lucky accident. It depends on the scene being just right. In genuine seeing, the fact of match is independent of the scene. Just as the actual scene causes matching visual experience, so likewise would alternative scenes. Different scenes would have produced different visual experience, and thus the subject is in a position to discriminate between the alternatives.

This is my proposal: if the scene before the eyes causes matching visual experience as part of a suitable pattern of counterfactual dependence, then the subject sees; if the scene before the eyes causes matching visual experience without a suitable pattern of counterfactual dependence, then the subject does not see." (Lewis (1980): 281)
\end{abstract}

Die Idee, die sich dahinter verbirgt, läßt sich einfach wie folgt ausdrücken: damit eine Eigenschaft von einem bestimmten Zustandstypus als wahrgenommen gelten kann, muß zwischen den beiden Entitäten eine nomologische Korrelation bestehen. Das heißt idealerweise: unter allen Umständen, in denen die Naturgesetzmäßigkeiten konstant bleiben, führt diese Eigenschaft - und nur diese - zu dem entsprechenden Typus von Sinneserfahrungen. Doch dieser Idealfall ist nicht erreichbar, da einerseits die Unbestimmtheit der Wahrnehmung dafür verantwortlich ist, daß das visuelle System immer nur einen der Realität angenäherten Eindruck vermitteln kann, und da andererseits Repräsentation immer auch die Möglichkeit

21 Auch die Häufigkeit des Auftretens der entsprechenden Zustände kann keine Unterscheidung begründen. Es ist mit Bezug auf ein Subjekt sowohl denkbar, daß ständig veridische Halluzinationen vorliegen, als auch, daß normales Sehen nur selten oder sogar nur in einem einzigen Augenblick erfolgt (vgl. Lewis (1980): 280f.). 
von Fehlrepräsentation miteinschließt. Unter bestimmten Umständen sollte es jedoch möglich sein, veridische Wahrnehmungen zu haben. Wenn man nun diese Bedingungen als Normalbedingungen bezeichnen, läßt sich Repräsentation als nomologische Korrelation unter Normalbedingungen auffassen (die Beschaffenheit der Normalbedingungen wird weiter unten in einem eigenen Kapitel behandelt). Dabei läßt es sich rein stipulativ definieren, daß eine Wahrnehmung genau dann vom Wahrnehmungstypus $W_{\Phi}$ ist, wenn sie die Eigenschaft $\Phi$ repräsentiert.

$\left(\mathrm{NK}_{\mathrm{NB}}\right)$ Eine Wahrnehmung ist genau dann vom Wahrnehmungstypus $W_{\Phi}$ (das heißt: repräsentiert die externe Eigenschaft $\Phi$ ), wenn das Auftreten eines Zustandes vom Typus $W_{\Phi}$ und eine Instantiierung der Eigenschaft $\Phi$ unter Normalbedingungen nomologisch korreliert sind (oder kurz gesagt: wenn $W_{\Phi}$ und $\Phi$ unter Normalbedingungen nomologisch korreliert sind).

In diesem Fall hat die Wahrnehmung einen $\Phi$-Gehalt. Liegen keine Normalbedingungen vor, verändert sich natürlich nicht der Gehalt der Wahrnehmung, sondern es wird einfach die nomologische Korrelation aufgebrochen, da in der Realität keine dem Gehalt entsprechende $\Phi$-Tatsache zu finden sein wird. In diesem Sinne gibt es eine Norm, die bestimmt, was ein mentaler Zustand repräsentiert, und die diese Gehaltsbestimmung auch auf die Bedingungen ausdehnt, die der Norm nicht mehr entsprechen. Die einzelnen Gehaltstheorien differieren nun darin, wie sie diese Normativität weiter konkretisieren. Es ist üblich, die Sprechweise zu verwenden, daß der Gehalt mit der repräsentierten Eigenschaft identisch sei; doch da es sich bei dem Gehalt um eine Eigenschaft des repräsentierenden Zustandes handeln muß, kann dies genau genommen nicht zutreffen. Der Gehalt ist vielmehr die Eigenschaft, eine bestimmte Eigenschaft $\Phi$ zu repräsentieren: er ist damit eine repräsentationale Eigenschaft. Er kann unter Umständen und abhängig von der konkret gewählten Gehaltstheorie - auf die in $\left(\mathrm{NB}_{\mathrm{K}}\right)$ beschriebene, relationale Eigenschaft reduziert werden, die zwischen dem Wahrnehmungstypus $\mathrm{W}_{\Phi}$ und der repräsentierten Eigenschaft $\Phi$ besteht. Trotz dieser wichtigen Differenz werde ich mich im weiteren Verlauf dem allgemeinen, philosophischen Sprachgebrauch folgend - mit dem 
Ausdruck „Gehalt" nicht nur auf die repräsentationale Eigenschaft des Zustandes, sondern auch auf die repräsentierte Eigenschaft $\Phi$ beziehen (in den meisten Fällen wird der Unterschied auch nicht relevant sein; sonst wird der Kontext klären helfen).

Zwar ist schon durch das physikalistische Weltbild vorgegeben, daß jede veridische Repräsentation durch eine zugrundeliegende singuläre Kausalrelation realisiert wird, da Kausation der einzige Vermittler zwischen der Außenwelt und den Sinnesorganen sein kann. Doch dies heißt noch nicht, wie Lewis Beispiele gezeigt haben, daß es sich bei der Korrelation zwischen der Eigenschaft und dem Zustandstypus unbedingt um eine kausal-nomologische handeln muß: eine kontrafaktische Abhängigkeit genügt vollkommen. Insbesondere wird es sich herausstellen, daß bestimmte Farbobjektivisten, die Farben mit von Farbwahrnehmungen repräsentierten Dispositionen gleichsetzen, dazu gezwungen sind, Farben als epiphänomenal anzunehmen. Eine Instantiierung der Eigenschaft $\Phi$ muß also nicht einmal die Wahrnehmung vom Typus $W_{\Phi}$ kausal verursachen, damit letztere als eine korrekte Repräsentation von ersterer gelten kann.

Der Gehalt von Wahrnehmungen zeigt jedoch noch weitere Wesensmerkmale (vgl. Martin (1994): 468ff.). Zuerst einmal zeichnet er sich durch Nicht-Begrifflichkeit aus, wodurch er sich von den begrifflichen Überzeugungsgehalten unterscheiden läßt (eine Unterscheidung, die durch Fälle wie die Müller-Lyer-Illusion motiviert wird). Üblichen Redeweisen zufolge handelt es sich bei einem nicht-begrifflichen Gehalt um einen „,analogen“" oder „,bildhaften“, was den Umstand der Reichhaltigkeit zu erfassen sucht: daß solche Gehalte wesentlich informationsdichter und feingradiger sind als etwa die von Meinungen (so verfügen wir im Vergleich zur Anzahl wahrnehmbarer Farben nur über einen Bruchteil an Begriffen oder Ausdrücken). Dazu tritt zum einen die Verfügbarkeit für das kognitive System, das heißt, die Möglichkeit, Wahrnehmungen konzeptualisieren und dadurch direkt für das begriffliche Gedanken zugänglich machen zu können (vgl. Evans (1982): 227); und zum anderen die Allgemeinheit. Ein allgemeiner Gehalt ist ein solcher, der nur auf die mit den betreffenden Wahrnehmungen verbundenen Eigenschaften, nicht aber auf deren individuelle Referenten Bezug nimmt. Denn für das Bestehen der nomologischen Korrelation ist es gleichgültig, von welchem Objekt die betreffende Eigenschaft instantiiert ist (wenn sie instantiiert ist). Denn es handelt sich allein 
um eine Relation zwischen den Eigenschaften und Wahrnehmungstypen.

$\mathrm{Zu}$ den jeweiligen Referenten der einzelnen Wahrnehmungen gelangt man mittels der Referenzbedingungen. Denen zufolge ist ein bestimmter Gegenstand genau dann der Referent einer solchen Wahrnehmung, wenn erstens der Gegenstand mindestens eine der Eigenschaften aus dem allgemeinen Gehalt des Wahrnehmungszustandes instantiiert, und wenn zweitens eine (andere) Eigenschaft des Objektes das Autreten der Sinneserfahrung kausal verursacht hat. Daß andere Eigenschaften als die repräsentierten als kausal wirksame zugelassen sind, entspricht der obigen Bemerkung, daß die nomologische Korrelation nicht kausaler Natur sein muß. Instantiiert der Gegenstand alle durch den allgemeinen Gehalt repräsentierten Eigenschaften, dann ist die Wahrnehmung veridisch; sonst handelt es sich um eine (partielle) Illusion. Werden die Referenzbedingungen dagegen von keinem Gegenstand erfüllt, gibt es dementsprechend auch keinen Referenten: und es liegt eine Halluzination vor. Im Falle der Existenz eines Referenten kann auch ein ,individueller Gehalt" formuliert werden, indem zu dem allgemeinen Gehalt das betreffende Objekt einfach hinzugenommen wird. Dem wahrnehmenden Subjekt ist der Gegenstand jedoch allein vermittels der repräsentierten Eigenschaften gegeben (weswegen es ihm auch unmöglich ist, veridische von nicht-veridischen Wahrnehmungen introspektiv zu unterscheiden). Im weiteren Verlauf wird der Ausdruck „Gehalt“ sich somit immer auf den allgemeinen Gehalt beziehen.

Die Reichhaltigkeit des Gehaltes und die Referenzbedingungen legen nahe, daß Wahrnehmungen nicht nur eine einzelne Eigenschaft, sondern immer mehrere repräsentieren. So ist es auch nicht verwunderlich, daß Farben zusammen mit Formen gesehen werden, und daß beide immer als innerhalb des egonzentrisch bestimmten Raumes lokalisiert repräsentiert werden. Im Normalfall nehmen wir sogar etliche Farben und Formen gleichzeitig wahr. Der allgemeine Gehalt einer sehr einfachen Wahrnehmung von einer beispielsweise homogen blaugefärbten, quadratischen und an einer Wand vor dem Betrachter befindlichen Fläche besteht, grob gesagt, aus drei verschiedenen Eigenschaften: der Farbe Blau, der Form Quadratisch und der (zum Beispiel) indexikalischen Ortsbestimmung Dort-vormir. Weiter unten wird der Zusammenhang zwischen diesen drei Eigenschaftsarten genauer disktutiert werden. Dort wird auch versucht werden, die These plausibel zu machen, daß Farbwahrnehmungen ohne den Form- 
oder Örtlichkeitsaspekt nicht repräsentational sein könnten, da dann kein Referent - als Objekt im Raum verstanden - vorliegen könnte. Solche nicht-repräsentationalen Farbempfindungen sind zwar denkbar, weil die Farbigkeit von den Form- und Ortseigenschaften relativ unabhängig zu sein scheint, aber faktisch wird es sich wahrscheinlich nicht geben können.

Bevor die Diskussion zum nächsten Thema übergeht, sollte noch kurz auf eine andere Form von Gehalt hingewiesen werden: den informationalen Gehalt. Die damit verbundene Relation ist die Detektion oder Information. Wie der Name bereits andeutet, handelt es sich dabei um Begriffe aus der Informationstheorie, die von Dretske und anderen in die Philosophie des Geistes eingeführt worden sind (vgl. Dretske (1986); (1995)). Bei der Detektion handelt es sich einfach um eine Repräsentation ohne Normalbedingungen. Zwischen dem Zustandstypus und der detektierten Eigenschaft muß einfach eine nomologische Korrelation bestehen. Das heißt aber nichts anderes, als daß, wenn ein detektierender Zustand vorliegt, dieser veridisch sein muß: Fehldetektion ist ausgeschlossen. Dretskes bekanntes Beispiel ist die Tankanzeige eines Autos. Entweder zeigt sie den Benzinstand in einem Tank an: wenn eine Gesetzmäßigkeit zwischen Anzeige und Benzinstand besteht. Oder sie detektiert gar nichts: wenn keine solche Gesetzmäßigkeit besteht, weil zum Beispiel die Tankanzeige kaputt oder nicht mit einem Tank verbunden ist (natürlich könnte sie trotzdem noch unter den entsprechenden Umständen etwas anderes anzeigen). Der informationale Gehalt ist ebenso ein allgemeiner Gehalt, das heißt, er nimmt nur auf die detektierte Eigenschaft Bezug; und die informationale Relation muß ebenfalls nicht unbedingt kausal-nomologisch begründet sein. Damit läßt sich, ganz analog, die Detektionsrelation für informationale Zustände wie folgt definieren:

(NK) Ein informationaler Zustand ist genau dann vom Typus $D_{\Phi}$ (das heißt: detektiert die externe Eigenschaft $\Phi)$, wenn das Auftreten eines Zustandes vom Typus $D_{\Phi}$ und eine Instantiierung der Eigenschaft $\Phi$ nomologisch korreliert sind (oder kurz gesagt: wenn $D_{\Phi}$ und $\Phi$ nomologisch korreliert sind). 


\subsubsection{Referentialität und Räumlichkeit}

Der allgemeine Gehalt von Farbwahrnehmungen beinhaltet nun nicht nur die betreffende Farbeigenschaften, sondern auch Form- und Ortseigenschaften. Die letzteren beiden können, ganz grob, unter dem Aspekt der Räumlichkeit zusammengefaßt werden. Die Form eines Gegenstandes oder, besser gesagt, die Form von dessen Oberfläche kann dabei als durch einzelne Punkte im egozentrisch gegebenen Raum zusammengesetzt vorgestellt werden. Daß der objektive Raum dem jeweiligen Betrachter egozentriert zu sein scheint, heißt nichts anderes, als daß dieser jenem sein ,eigenes Koordinatensystem“ auferlegt, dessen „Ursprung“ die Augen darstellen und deren „Achsen“ durch Bestimmungen wie „,von mir aus gesehen rechts oben vorne" beschrieben werden können: es handelt sich somit um eine subjektrelative Weise, den objektiven Raum zu repräsentieren. Der Betrachter wird die Form einer quadratischen Tischplatte anhand der Position ihrer vier Ecken innerhalb seines egozentrischen Raumes erkennen. Auf seinem Gesichtsfeld wird vielleicht nur ein flaches, trapezförmiges Gebilde zu ,sehen“ sein; doch mithilfe der durch die Existenz der beiden optischen Nerven ermöglichte Tiefenwahrnehmung wird es ihm möglich sein, zwei Ecken als etwas näher und die zwei anderen als etwas weiter weg wahrzunehmen, und alle in vier in einem solchen Abstandsverhältnisses, daß er sie nicht als trapezförmig, sondern als quadratisch angeordnet sieht.

„To have visual experiences of four points of light arranged in a square amounts to no more than being in a complex informational state which embodies information about the egocentric location of those lights." (Evans (1985b): 392)

Insbesondere spielen die folgenden beiden Faktoren bei solch einer mit Tiefenwahrnehmung verbundenen Repräsentation von Formen eine wesentliche Rolle: zum einen die Perspektive, das heißt, die Orientierung oder Positionierung des Betrachters im objektiven Raum in Hinsicht auf den wahrgenommenen Gegenstand, und zum anderen die Distanz zu dem betrachteten Objekt, oder auch dessen Ausdehnung oder Größe. Erst aufgrund der Tiefenwahrnehmung ist es dem wahrnehmenden Subjekt möglich, Distanzen zu erkennen und seine eigene Position mit Bezug auf den 
Gegenstand sinnlich zu spezifizieren: dieser erscheint ihm innnerhalb des egozentrischen Raumes. Und in jedem Fall beruht die Wahrnehmung von Formen auf Wahrnehmungen von räumlichen Eigenschaften, so daß wird uns in der weiteren Argumentation auf letztere beschränken können.

Im folgenden soll nun die Hypothese plausibel gemacht werden, daß eine Repräsentation von Farben allein noch keine Referentialität ermöglicht: diese ist erst durch das Hinzukommen der Wahrnehmung von räumlichen Eigenschaften gewährleistet. Zwei Argumente oder Überlegungen sollen zur Unterstützung dieser These angeführt werden. Der erste Punkt konzentriert sich auf die Referenzbedingungen für Wahrnehmungen. Die Bestimmung der Repräsentationsrelation als nomologische Korrelation unter Normalbedingungen garantiert die Möglichkeit von Fehlrepräsentationen. Doch es werden im Falle von Wahrnehmungen üblicherweise zwei Formen von sinnlichen Fehlrepräsentationen auseinandergehalten: Illusionen und Halluzinationen. Der Unterschied kann dabei mit mithilfe des möglicherweise existierenden Referenten einer Sinneserfahrung erläutert werden: bei einer Farbillusion liegt zwar noch ein Referent vor, doch dieser instantiiert nicht die repräsentierte Farbeigenschaft, sondern eine andere; bei einer Farbhalluzination fehlt hingegen der Referent ganz, so daß die Wahrnehmung zu keiner Farbtatsache in der Welt in irgendeinem besonderen Bezug steht. Die Bestimmung dessen, ob eine gegebene Sinneserfahrung einen Referenten hat und, wenn ja, um welchen Gegenstand es sich dabei handelt, leisten die eben bereits erwähnten Referenzbedingungen.

Das erste Argument besteht nun aus der These, daß eine Unterscheidung zwischen Illusionen und Halluzinationen nur dann getroffen werden kann, wenn die in Frage stehenden Wahrnehmungen mindestens zwei (Arten von) Eigenschaften repräsentieren, mittels derer ein möglicher Referent unabhängig identifiziert werden kann. Betrachten wir ein einfaches Beispiel. Eine Sinneserfahrung repräsentiert die Eigenschaft $F$. Ein bestimmter Gegenstand ist nun genau dann der Referent der betreffenden Sinneserfahrung, wenn er zum einen für das Auftreten der Sinneserfahrung kausal verantwortlich ist und zum anderen mindestens eine Eigenschaft aus dem allgemeinen Gehalt der Wahrnehmung instantiiert. Die letztere Bedingung ist erforderlich, damit nicht jedes beliebige Element aus der singulären Kausalkette, die zu der Sinneserfahrung geführt hat, als Referent in Frage kommt. Nun besteht der allgemeine Gehalt in dem beschriebenen Fall bloß 
aus einer Eigenschaft. Um die Referenzbedingungen also vollständig erfüllen zu können, muß der Gegenstand die Eigenschaft $F$ auch tatsächlich instantiieren. Damit hat die Wahrnehmung aber entweder einen Referenten und ist zugleich veridisch, oder sie hat keinen Referenten und ist - eine Halluzination.

Illusionen hinsichtlich von $F$ können dagegen nur dann vorliegen, wenn noch eine zweite Eigenschaft $G$ von der Sinneserfahrung repräsentiert wird: dann kann ein Gegenstand, der $F$ nicht besitzt, die Referenzbedingungen trotzdem noch dadurch erfüllen, daß er die ebenfalls repräsentierte Eigenschaft $G$ instantiiert (und zudem eine Kausalursache für die Sinneserfahrung darstellt). Illusionen sind damit immer partiell veridische Wahrnehmungen. Damit folglich neben Farbhalluzinationen auch Farbillusionen vorliegen können, müssen Farbwahrnehmungen außer den Farben noch weitere Eigenschaften repräsentieren: wie zum Beispiel die räumlichen Form- oder Ortseigenschaften. Über diese kann der Referent auch dann bestimmt werden, wenn die Farbe nicht korrekt wahrgenommen wird. Das erste Argument für die Hypothese ist damit etabliert.

Der zweite Punkt betrifft nun den engen Zusammenhang von räumlicher Repräsentation auf der einen Seite und Referentialität auf der anderen. Dieser Überlegung unterliegt die zweiteilige Idee, daß zum einen die Lokalisierung im egozentrischen Raum eine wichtige Rolle bei einer Objektkonstituierung aus der Sicht des Subjektes spielt, und daß zum anderen Referentialität immer eine solche Konstituierung bedingt. Letzteres sollte eigentlich klar sein. Eine Wahrnehmung kann keinen Referenten haben, wenn sie nicht bestimmte Informationen über ein Einzelding enthält, die es erlauben, daß dieses aus seiner Umgebung herausgegriffen und individuiert werden kann. Wie wir gesehen haben, sind dafür mindestens zwei Eigenschaften vonnöten. Doch in den allermeisten Fällen werden es wesentlich mehr sein, so daß die fraglichen Objekte von dem betreffenden Subjekt sehr genau diskriminiert und erfaßt werden können. In jedem Fall kann es erst dadurch, daß genügend Information vorliegt, dazu kommen, daß bestimmte, repräsentierte Eigenschaften als Eigenschaften ein- und desselben Gegenstandes gesehen werden, so daß es sinnvoll wird, davon zu sprechen, daß der fragliche Betrachter sich mit seinen Sinneserfahrungen auf ein Objekt beziehen kann.

Kommen wir nun zu der Idee, daß hinsichtlich unserer Wahrnehmungen 
eine Lokalisierung im egozentrischen Raum für jede Objektkonstituierung von großer Bedeutung ist. Dieser Gedanke soll hier nur anhand einer phänomenologischen Betrachtung über zwei Beispiele von Farbsinneseindrücken einsichtig gemacht werden. Auf der einen Seite erscheinen uns oft genug Nachbilder: wenn wir zum Beispiel erst auf eine helle, farbige Lampe schauen und einen neutralen, weißen Hintergrund betrachet. Dabei erscheint uns ein Farbfleck vor den Augen, der in seiner Farbigkeit der Farbe der Lampe komplementär entgegengesetzt ist. Doch davon abgesehen übernimmt das Nachbild einige der Eigenschaften, die wir vorher als Eigenschaft der (Glühbirne der) Lampe gesehen haben: vor allem die (wenn auch etwas vage) Form und die Distanz zum Auge. In diesem Sinne wird nicht nur eine Farbe, sondern auch räumliche Eigenschaften repräsentiert (vgl. Tye (1995): 108f.). Und theoretisch könnte auch ein Referent vorliegen; doch Nachbilder sind (voraussichtlich) als Halluzinationen anzusehen. Schließen wir dagegen unsere Augen und pressen auf die Augäpfel, werden wir zwar ebenfalls einer Art von Farbeindrücken gewahr, doch diese scheinen nun keinerlei räumliche Informationen zu enthalten: weswegen wir ihnen auch die Referentialität absprechen werden (ob sie noch repräsentieren können, kann ebenfalls angezweifelt werden).

Dieser zweite Fall ist zwar nicht so klar zu fassen wie noch die Nachbilder; doch jemand, der für die durch das Augenpressen hervorgerufenen Sinneseindrücke ebenfalls einen räumliche Eigenschaften beinhaltenden Gehalt zuerkennen möchte, wird aller Wahrscheinlichkeit damit auch die Möglichkeit der Bezugnahme auf Einzeldinge verbinden. In jedem Fall scheint Referentialität sehr eng mit repräsentierter Räumlichkeit zusammenzuhängen. Dies entspricht auch der Überlegung, daß eine Wahrnehmung, um sich auf ein Objekt richten zu können, welches als wahrnehmbares Objekt nur der raum-zeitlichen Welt angehören kann, dieses zumindest im egozentrischen Raum des betrachtenden Subjektes lokalisieren muß. Dahinter verbirgt sich die (vielleicht auch Kantische) Intuition, daß Wahrnehmungen ohne räumliche (und zeitliche?) Repräsentationalität nicht möglich sind. Doch bei dieser Intuition wird es hier auch belassen werden müssen. Es ist auf alle Fälle klar geworden, daß Referentialität - und damit auch „vollständige“ Repräsentationalität, die sowohl Illusionen als auch Halluzinationen erlauben soll - erst dann möglich ist, wenn mehr als eine Eigenschaft von den betreffenden Sinneserfahrungen repräsentiert wird. 
Und hinsichtlich von Wahrnehmungen sind die besten (und vielleicht auch erforderlichen) Kandidaten für die zweite Art von Merkmalen die räumlichen Eigenschaften. ${ }^{22}$

Interessanterweise ist es indessen möglich, Formeigenschaften ohne Farbeigenschaften ,vollständig“ zu repräsentieren, da (wahrscheinlich) diese automatisch räumlich lokalisiert sind (auch dies spricht für den engen Zusammenhang von Referentialität und Räumlichkeit). Und zwar ist dieser Fall dann gegeben, wenn die Formwahrnehmung, das heißt: die Wahrnehmung der Begrenzungen der Form nicht auch gleichzeitig eine Wahrnehmung des diese Begrenzungen ausfüllenden Raumes ist. Denn Farbe ist gerade eine Eigenschaft, die in diesen Zwischenbereichen gesehen wird (ganz gleich, ob es sich dabei um Flächen- oder Volumenfarben handelt). Zum einen lassen sich solche, von der Farbigkeit befreiten Formwahrnehmungen in anderen Sinnesmodalitäten finden, weil diese offensichtlich keine Farbwahrnehmungen liefern können. Es ist so ohne weiteres vorstellbar, daß ein Blinder von einer Tafel nur vier hervorstehende Punkte fühlt, aber nicht die dazwischenliegende und zurückgesetzte Fläche: er wird die Form eines Quadrates erkennen können, ohne zum Beispiel die Textur desselben angeben zu können (vgl. Martin (1993): 216). Ein anderes Beispiel bieten zwei zu einem Hexagramm angeordnete Dreiecke dar, von denen jeweils nur die Eckbereiche sichtbar sind, während der größte Teil ihrer Seitenlinien fehlen. Doch unser Gehirn ist ohne weiteres in der Lage, die Dreiecke als solche zu sehen, indem es die fehlende Information einfach kognitiv ergänzt (natürlich findet keine sinnliche Ergänzung statt: wie etwa bei den Phänomene, die sich auf den Blinden Fleck zurückführen lassen). Und in beiden Fällen bleibt die Referentialität erhalten, da unter anderem auch die Räumlichkeit bestehen bleibt.

Genauso einsichtig ist auch der Umstand, daß Form und Farbe bis zu einem gewissen Grade unabhängig voneinander sind. Ein Quadrat einer bestimmten Größe kann von uns als rot, als blau oder auch in einer ganz an-

22 Die Unterscheidung von „,vollständig“ repräsentierenden und referierenden Zuständen einerseits und „bloß“ repräsentierenden Zuständen andererseits deckt sich in etwa mit der zwischen Wahrnehmungen (perceptions) und Sinnesempfindungen (sensations). Ob letztere wirklich noch repräsentieren oder bloß detektieren, und ob sie zudem auch tatsächlich existieren, sind zwei Fragen, die hier nicht disktutiert werden sollen. 
deren Farbe gesehen werden; und es gibt sowohl rote Dreiecke, als auch rote Quadrate und Kreise, die wir wahrnehmen können. Die einzelnen Wahrnehmungszustände unterscheiden sich jeweils durch ihren introspektiven Charakter. Und mit der Methode der Variation können auch die beiden grundsätzlichen Eigenschaftsarten Form und Farbe voneinander begrifflich getrennt werden. Doch damit ist erst einmal genug über die Repräsentationalität und Referentialität von Wahrnehmungen gesagt; nun ist die Phänomenalität der Sinneserfahrungen an der Reihe.

\subsubsection{Qualia}

Die Bestimmung der Natur von qualitativen Charakteren (oder kurz: Qualia), die bestimmte mentale Zustände aufzuweisen scheinen und andere nicht, stellt immer noch eine der größten Herausforderungen für die Philosophie des Geistes dar, die eine möglichst einheitliche und mit dem materialistischen Weltbild verträgliche Beschreibung von Bewußtsein und Mentalität zum Ziel hat. Dies zeigt sich insbesondere in der oftmals vertretenen Auffassung, daß Qualia oder das mit ihnen eng verbundene phänomenale Bewußtsein im Grunde nicht definierbar sind, sondern nur durch Umschreibungen oder Hinweise auf sie Bezug genommen werden kann (vgl. Block (1994a) und (1994b)). ${ }^{23}$ Ein solcher, mittlerweise klassischer Bestimmungsversuch ist durch die Redewendung what it is like gegeben: der phänomenale Charakter eines mentalen Zustand besteht demnach darin, wie es ist (oder wie es sich anfühlt), sich in dem entsprechenden Zustand zu befinden. Eine Rotwahrnehmung zu haben, fühlt sich demnach phänomenal ganz anders an, als eine Blauwahrnehmung oder auch eine taktile Erfahrung von einer rauhen Oberfläche zu erleben. Üblicherweise werden Qualia für alle sinnlichen Zustände angenommen: also Wahrnehmungen, Empfindungen oder auch Stimmungen und Gefühle. Es ist umstrittener, ob

23 Dennett formuliert zum Beispiel eine sehr starke und unplausible Definition von Qualia, nur um dann deren Nichtexistenz nachzuweisen (1991). Doch die meisten Vertreter der Existenz von Qualia schreiben diesen verhältnismäßig unkontroverse Eigenschaften zu, so daß ihre Existenz kaum mehr geleugnet werden kann (Block (1994b). Um eine solche Minimalbestimmung handelt es sich beid den folgenden Ausführungen ebenfalls. 
auch Wünsche, Hoffnungen oder gar Überzeugungen einen qualitativen Charakter aufweisen (eine Fragestellung, die für dieses Buch jedoch irrelevant ist).

Eine Minimalkonzeption von Qualia schreibt diesen drei wesentliche Merkmale zu: (i) sie sind Eigenschaften von (bestimmten) mentalen $\mathrm{Zu}-$ ständen; (ii) sie sind mittels Introspektion auf die betreffenden Zustände zugänglich; (iii) und sie sind für den phänomenalen Charakter dieser $\mathrm{Zu}-$ stände verantworlich (vgl. Block (1994b): 514). Manchmal werden auch die fraglichen Zustände selbst als „Qualia“ bezeichnet; doch diese Redeweise soll hier ausdrücklich vermieden werden. Das mentale Zustände für uns einen phänomenalen Charakter aufweisen, heißt nichts anderes, als daß sie uns phänomenal bewußt sind. Somit läßt sich phänomenales Zustandsbewußtsein auf Qualia zurückführen. Aufgrund der introspektiven Zugänglichkeit ist es uns möglich, Zustände mit verschiedenen Qualia zu unterscheiden, indem wir unsere Aufmerksamkeit auf sie lenken und dabei die phänomenalen Differenzen bemerken. Der enge Zusammenhang zwischen der Natur der Qualia und dem phänomenalen Bewußtsein, daß wir von ihren Instanzen haben (oder daß ihre Instanzen aufweisen), zeigt sich auch in einer möglichen Ambiguität hinsichtlich des Ausdruckes phänomenaler (oder qualitativer) Charakter: so kann der phänomenale Charakter als mit dem Quale identisch aufgefaßt werden; einem anderen Verständnis nach (welches in (iii) zum Ausdruck kommt) besteht er dagegen aus dem Erlebnischarakter (dem what it is like), der die phänomenale Bewußtheit des Quale begleitet oder sich darin zeigt.

Im ersten Fall handelt es sich klar um eine Eigenschaft des mentalen Zustandes (eben das Quale), im zweiten, wie es scheint, um eine Eigenschaft zweiter Ordnung dieses Quale. Aber es ist nicht immer so ganz einfach, diese beiden Aspekte auseinanderzuhalten. Im weiteren Verlauf der Diskussion soll jedoch trotzdem versucht werden, vorrangig die erste Redeweise zu verwenden, nach der der phänomenale Charakter mit dem Quale gleichgesetzt wird. Wie genau die Introspektivität der Qualia zustande kommt, und wie das phänomenale Erleben oder Bewußtsein derselben zu erklären ist, hängt in jedem Fall unausweichlich davon ab, welche Theorie über die Natur der Qualia gewählt wird. Welche ontologische Beschaffenheit diese Charakteristika genau aufweisen, braucht uns hier nicht weiter zu interessieren. Aber es lohnt sich, kurz auf die beiden Hauptfragen der ge- 
genwärtig stattfindenden Qualiadebatte einzugehen: ob die Qualia intrinsische, eng-funktionale oder weit-funktionale Eigenschaften der Zustände sind; und in welchem Verhältnis sie zu dem ebenfalls introspektiv zugänglichen Gehalt stehen.

Daß Qualia intrinsische Eigenschaften von Zuständen sein können, wird nicht mehr so oft wie früher vertreten, da zum einen die Introspektierbarkeit von intrinsischen Eigenschaften von mentalen Zuständen (vgl. Shoemaker (1994a); (1994c)), und zum anderen die Existenz phänomenaler Zustände ohne Gehalt angezweifelt wird. Block ist vermutlich einer der wenigen, der explizit für die Gegenthese argumentiert (vgl. Block (1995) und die Diskussionen im selben Band), doch auch er schließt die Möglichkeit der Relationalität von Qualia nicht aus (vgl. Block (1994b): 514). In jedem Fall ist die Frage nach der Eigenschaftsart eng mit der nach der Beziehung zum Gehalt verbunden. Hinsichtlich der letzteren Fragestellung gibt es zwei grundlegende Positionen: entweder ist das Quale einer Wahrnehmung mit deren repräsentationalem Gehalt gleichzusetzen, wird von diesem ganz ausgeschöpft; oder aber Gehalt und Quale sind voneinander zu trennen, da der qualitative Charakter nicht auf repräsentationale Eigenschaften reduziert werden kann. Block beschreibt die (immer noch laufende) Diskussion zwischen Phänomenalisten und Repräsentationalisten wie folgt (wobei der Ausdruck ,phänomenaler Charakter“" sich auf Qualia bezieht):

„The greatest chasm in the philosophy of mind - maybe even all of philosophy divides two perspectives on consciousness. The two perspectives differ on whether there is anything in the phenomenal character of conscious experience that goes beyond the intentional, the cognitive and the functional. [...] The debates about qualia have recently focused on the notion of representation, with issues about functionalism always in the background. [...] The recent focus of disagreement is on whether the phenomenal character of experience is exhausted by... representational contents. Is say no. [...] I think that it is often the phenomenal character itself that has the representational content. What I deny is that representational content is all there is to phenomenal character. I insist that phenomenal character outruns representational content. We can call this view 'phenomenism'. [...] The opposite view, which we can call 'representationism', holds that the phenomenal character of an experience does not go beyond its representational content. (Terminological note: everyone believes that experience has phenomenal character - the disagreement is about whether that phenomenal character is exhausted by its representational content.)" (Block (1995): 19f.) 
Auf der einen Seite der Debatte befinden sich also die Repräsentationalisten, die das Quale allein durch den Gehalt bestimmt sehen wollen. Üblicherweise wird es als identisch mit einer besonderen Form von Gehalt - als repräsentationale Eigenschaft verstanden - angesehen (vgl. Tye (1995): 137ff.). ${ }^{24}$ Der phänomenale Charakter läßt sich damit rein externalistisch oder weit-funktional erklären. Wahrnehmungen lassen sich somit über eine einzige, aber recht komplexe ihrer Eigenschaften bestimmen: denn Quale und Gehalt fallen ineins. Auf der anderen Seite steht der Phänomenalismus, der behauptet, das der phänomenale Charakter nicht durch den Gehalt vollständig bestimmt ist. Das dann bestehende Verhältnis zwischen den beiden Merkmalen von Wahrnehmungen ist meistens jedoch nicht ganz klar formuliert. Es läßt sich aber festhalten, daß die Qualia dann zumindest teilweise internalistisch spezifiziert werden müssen. Ein vielversprechender Vorschlag scheint es zu sein, den phänomenalen Charakter als eine engfunktionale Art von „Gegebenheitweise“ oder „Sinn“ anzusehen (vgl. zu dieser Idee Shomaker (1990): 102ff.). Doch es können auch andere Analysen bevorzugt werden; auf einige Beispiele werden wir später noch zu sprechen kommen (so auf Shoemakers (1994b) phenomenal properties und Peacockes (1983) sensational properties). Der Hauptteil der Debatte bezieht sich nun auf Gegenbeispiele gegen die repräsentationalistische Identifikation von Gehalt und Quale. ${ }^{25}$ Dieses Buch wird sich später nur auf einige Probleme konzentrieren, die für den Repräsentationalisten im Zusammenhang mit einer objektivistischen Theorie der Farben entstehen. Bis dahin soll keine der beiden Positionen bevorzugt werden.

24 Dretske ((1995a); (1995b)) identifiziert das Quale ebenfalls mit dem Gehalt: doch diesmal als repräsentierte Eigenschaft gedeutet. Somit sind nach ihm Qualia von Gegenständen in der Außenwelt instantiiert.

25 Klassische Beispiele, wie die Qualia-Inversion oder -Abwesenheit, aber auch Jacksons Wissensargument oder das Problem der Explanatorischen Lücke, werden zum Beispiel von Tye ((1992); (1995): Kap. 6f.) vielversprechend zurückgewiesen. Auch einige, andere Argumente gegen den Repräsentationalismus scheinen nicht ohne weiteres durchzugehen. 


\subsection{Die zwei Aspekte der Intuitiven Farbkonzeption}

Die Intuitive Farbkonzeption, wie sie oben bestimmt worden ist, nimmt zwar auf vollständige Farbwahrnehmungen Bezug, sieht aber im großen und ganzen von den mitrepräsentierten Form- und Ortseigenschaften ab, da es hier allein um die Formulierung einer ontologischen Theorie der Farben geht. In diesem Abschnitt soll nun versucht werden, eine Aufteilung der Merkmale des introspektiven Charakters von Farbwahrnehmungen - oder eben der Intuitiven Farbkonzeption - auf zwei große Aspekte zu motivieren. Diese Aspekte werden dabei - in Anlehnung an die Differenzierung von Gehalt und Quale - auf der einen Seite mit der Repräsentationalität von Wahrnehmungen und auf der anderen Seite mit deren Phänomenalität in einem engen Zusammenhang stehen. Dadurch soll plausibel gemacht werden, daß die Einführung der theoretischen Begriffe des Gehaltes und des Quale ihre Motivierung in den beiden Aspekten des introspektiven Charakters findet. Daß Farbwahrnehmungen repräsentieren und gleichzeitig phänomenal bewußt sind (ganz unabhängig davon, wie diese beiden Aspekte zueinander stehen), wird dann als die angemessenste Interpretation der introspektierbaren Merkmale gelten können.

Die aufgelisteten Merkmale können natürlich auf verschiedene Weisen gruppiert werden. Doch es bietet sich an, sie danach zu differenzieren, ob sie als Charakteristika eher der repräsentierten Eigenschaft des wahrgenommenen Gegenstandes oder der phänomenalen Eigenschaft der Wahrnehmung zuzurechnen sind. Damit ergeben sich zwei Aspekte des introspektiven Charakters. Der repräsentationale Aspekt des introspektiven Charakters betrifft dabei den Gehalt: die ihn ausmachenden Merkmale werden von der repräsentierten Eigenschaft instantiiert. Der phänomenale Aspekt besteht dagegen aus Merkmalen, die als Eigenschaften des Quale interpretiert werden. ${ }^{26}$ Es sollte betont werden, daß der Gehalt (im Sinne der repräsentierten Eigenschaften) nicht mit dem repräsentationalen Aspekt identisch ist, sondern diesen exemplifiziert. Genau dasselbe gilt für das Quale und den phänomenalen Aspekt: letzterer wird von ersterem instantiiert. Mit anderen Worten, es bestehen die folgenden, ontologischen Bezie-

26 Zusätzlich zum phänomenalen Farbaspekt gibt es auch noch einen phänomenalen Formaspekt, der hier jedoch vernachlässigt werden soll. 
hungen: (i) die Wahrnehmungen instantiieren sowohl einen Gehalt als auch ein Quale; (ii) das Quale wiederum instantiiert die Merkmale, die den phänomenalen Aspekt ausmachen; (iii) der Gehalt (hier als repräsentationale Eigenschaft verstanden) ist eine Relation zwischen dem Wahrnehmungstyp und der entsprechenden, repräsentierten Eigenschaft; (iv) die repräsentierte Eigenschaft instantiiert die Merkmale, die den repräsentationalen Aspekt ausmachen; (v) der phänomenale und der repräsentationale Aspekt (oder die diese konstituierenden Merkmale) bilden zusammen den introspektiven Charakter.

Da nun die Intuitive Farbkonzeption eine Beschreibung des introspektiven Charakters ist, weist sie natürlich ebenso zwei Aspekte auf, die sich auf die jeweiligen Aspekte dieses Charakters beziehen. Deswegen werde ich der Einfachheit halber die beiden Aspekte der Intuitiven Farbkonzeption ebenfalls als repräsentationaler und phänomenaler Aspekt bezeichnen: denn sie betreffen jeweils genau die Merkmale ihrer Gegenstücke vom introspektiven Charakter. Es sei noch darauf hingewiesen, daß ein Repräsentationalismus hinsichtlich der Qualia dazu führt, daß sowohl das Quale und der Gehalt als auch der phänomenale und der repräsentationale Aspekt jeweils ineinsfallen. Die Merkmale des introspektiven Charakters werden in diesem Fall alle von der repräsentierten Eigenschaft instantiiert. Für den Phänomenalisten hingegen werden die jeweiligen Eigenschaften und Aspekte verschieden bleiben. In den folgenden Abschnitten sollen nun zuerst die einzelnen Merkmale den beiden Aspekten des introspektiven Charakters - oder der Intuitiven Farbkonzeption - zugeteilt werden. Im Anschluß daran soll beschrieben werden, wie uns Gehaltsunterschiede von Wahrnehmungen introspektiv zugänglich sein können. Es wird sich heraustellen, daß hierfür beide Aspekte des introspektiven Charakters gleichermaßen benötigt werden. Denn der repräsentationale Aspekt - zusammen mit der wahrgenommenen Räumlichkeit - kann eigentlich nur dahingehend gedeutet werden, daß etwas repräsentiert wird; erst die Phänomenalität wird dann in gewissem Sinne klären können, was genau repräsentiert wird.

\subsubsection{Der repräsentationale Aspekt}

Die Grundannahme, die der repräsentationale Aspekt motivieren soll, ist, 
daß Farben repräsentierte Eigenschaften sind. Der allgemeine Gehalt wird dementsprechend eine Farbeigenschaft beinhalten. Daß diese Annahme nicht so trivial ist, wie sie auf den ersten Blick scheint, wird sich später herausstellen, wenn subjektivistische Theorien Gegenstand der Diskussion werden. Doch zuerst einmal ist es wichtig, diejenigen Merkmale des introspektiven Charakter zu individuieren, die auf eine Repräsentationalität hinsichtlich der Farben schließen lassen. Vorab sollen jedoch einige fundamentale Charakteristika genannt werden, die diesen Gedanken plausibel machen. Auf die introspektiv zugängliche Abhängigkeit der Farbigkeit von räumlichen Eigenschaften - wie Formen oder Ortsangaben - ist bereits hingewiesen worden. Es sollte also eine Repräsentation von Eigenschaften in der Außenwelt vorliegen. Ebenso scheinen Farbwahrnehmungen den grundlegenden Eindruck zu vermitteln, daß an Gegenständen in der Außenwelt lokalisiert zu sein scheinen. Und der visuelle Charakter, der sich beispielsweise darin zeigt, daß üblicherweise genügend Licht vorhanden sein muß, damit Farben gesehen werden können, weist ebenso auf die Repräsentiertheit der Farben hin. Doch diese Charakteristika sind noch zu allgemein, um allein Farben als repräsentierte Eigenschaften zu etablieren. Aber ein erster Schritt in diese Richtung ist getan worden. Es sollte nun möglich sein, die folgenden fünf Merkmale der Intuitiven Farbkonzeption als Kernstück des repräsentationalen Aspektes anzunehmen. Sie alle sind Merkmale, die den von Farbwahrnehmungen repräsentierten Eigenschaften zugewiesen werden sollten. Damit sie dann auch Farbeigenschaften zugesprochen werden können, ist es unausweichlich, daß diese als von Farb wahrnehmungen repräsentierte Eigenschaften gedeutet werden.

Externalität: Farben sind ,vor den Augen“ in der Außenwelt instantiiert. Die in Wahrnehmungen präsentierten Farbsachverhalte werden von uns als ein Bestandteil der Außenwelt gesehen. Farben sind für uns somit Eigenschaften externer Gegenstände. Externalität kann somit dadurch beschrieben werden, daß die fraglichen Sachverhalte „,vor den Augen“ lokalisiert zu sein scheinen. Das heißt, sie müssen von unserem Gesichtsfeld erfaßt werden können, so daß keine internen Zustände des Gehirn (einschließlich des visuellen Systemes) oder des Geistes in Frage kommen. Zudem garantiert die Externalität auch, daß Farbtatsachen im egozentrisch oder objektiv bestimmten Raum lokalisiert werden können. 
Objektivität: Farbtatsachen bestehen ontologisch geistunabhängig. Dieses Merkmal der Geistunabhängigkeit, wenn es denn den Farben wirklich zukommt, garantiert, daß die den Direkten Realismus begründende Objektivitätsthese (OT) aufrechterhalten werden kann. Zugleich wird der Forderung nach einer rigiden Bestimmung der Farbausdrücke nachgegeben: wenn unter den faktischen Umständen (bezogen auf die farbwahrnehmenden Subjekten, die vorherrschenden Lichtbedingungen sowie die bestehenden Naturgesetzmäßigkeiten) einem Gegenstand aufgrund seiner Eigenschaften eine bestimmte Farbe zugeschrieben wird, dann behält er diese Farbe auch dann, wenn die Umstände sich verändern sollten. Vor dem Hintergrund eines globalen Physikalismus als Ergänzung zum ontologischen Realismus läßt sich auch schließen, daß objektive Farben physikalisch beschreibbare Eigenschaften sein müssen.

Intrinsität und Rigidizität: Farbtatsachen supervenieren allein auf den intrinsischen Beschaffenheiten der Farbträger. Farben weisen - wie auch Formen oder andere primäre Qualitäten - einen intrinsischen, nicht-relationalen Charakter auf. Dahinter verbirgt sich natürlich die Objektivitätsintuition. Denn wenn Farben unabhängig von Subjekten durch externe Gegenstände instantiiert werden, sollten die Beschaffenheit der betreffende Objekte selbst für die Instantiierung verantwortlich sein. Die Überlegungen zur Rigidizitätsintuition zeigen, daß sogar nur intrinsische Faktoren der Gegenstände, und keine anderen Tatsachen, für die Farbigkeit in der Welt verantwortlich sein sollten. Ein Farbobjektivismus fordert geradezu, daß Zuschreibungen von Farben durch Tatsachen über die fraglichen Gegenstände wahrgemacht werden. Demgemäß können Farben nur dann das Merkmal der Intrinsität zeigen, wenn sie entweder intrinsische Eigenschaften der als farbig gesehenen Dinge in der Außenwelt sind oder auf anderen intrinsischen Eigenschaften supervenieren. Damit sind auch als Dispositionen verstandene Farben zugelassen (befreit man diese von ihrer ontologischen Abhängigkeit von Naturgesetzmäßigkeiten). Es sollte noch darauf hingewiesen werden, daß durch die Aufgabe der Externalität oder auch der damit verbundenen Repräsentierbarkeit - die Intrinsität automatisch uninteressant wird. Denn Farben sind uns ganz deutlich in unseren Sinneserfahrungen nicht als interne Eigenschaften (als Qualia vielleicht, 
oder als Eigenschaften des visuellen Gesichtsfeldes) gegeben: es macht also auch gar keinen Sinn, von der introspektierbaren Intrinsität solcher interner Eigenschaften zu sprechen.

Erklärungskraft: Farbtatsachen können das Auftreten von entsprechenden Farbwahrnehmungen erklären. Damit Instantiierungen von Farbeigenschaften bestimmten Farbwahrnehmungen erklären können, müssen ganz grob zwei Bedingungen erfüllt sein: zum einen darf die Instanz der Farben nicht die Wahrnehmung selbst sein (ein mentaler Zustand kann nicht selbst sein eigenes Vorkommen erklären); und zum anderen muß irgendeine Gesetzmäßigkeit vorliegen, die die Farbtatsache mit der Wahrnehmung verbindet. Zwei offensichtliche Kandidaten sind eine mögliche Kausalgesetzmäßigkeit oder die Repräsentationsrelation, die ja nichts anderes als eine nomologische Korrelation unter Normalbedingungen ist. Daß es auch nicht-kausale Erklärungen geben kann, scheint relativ unproblematisch zu sein, insbesondere, wenn man, wie Armstrong, von einem ontological free lunch ausgeht und nicht-kausale - oder nicht-physikalische - Gesetzmäßigkeiten auf kausalen supervenieren läßt (vgl. Armstrong (1997): 231ff.). Broackes diskutiert ein einfaches Beispiel für eine nicht-kausale Erklärung, welches ursprünglich von Putnam stammt. Dieses Beispiel findet sich auch bei John Campbell, der ebenfalls für die hier vertretene These argumentiert (vgl. J. Campbell (1993): 262ff.).

\begin{abstract}
„But we should not need reminding that good explanation is not always explanation in the terms of basic physics. As Putnam said, we can explain why a square peg will not fit into a round hole, by saying the board and the peg ar rigid, and the round hole is smalle than the peg. An 'explanation' in quantum mechanics, or whatever other basic terms, would miss the relevant features. For 'the same [higher-level] explanation will go in any world (whatever the microstructure) in which those higher level structural features [rigidity and size] are present. In that sense this explanation is autonomous'. "(Broackes (1992): 423)
\end{abstract}

In diesem Sinne muß nur eine bestimmte, nomologische Korrelation zwischen Farben und Farbwahrnehmungen vorliegen, damit erstere mit Hinsicht auf letztere eine Erklärungskraft aufweisen. Liegt also eine Repräsentations- oder Detektionsrelation zwischen Farben und Farbwahrnehmungstypen vor, dann können Farbtatsachen auch das Auftreten von solchen Sin- 
neserfahrungen erklären. ${ }^{27}$

Wahrnehmbarkeit oder Repräsentierbarkeit: Farben werden von Farb wahrnehmungen repräsentiert. Mit der Akzeptanz einer direkt-realistischen und externalistischen Gehaltstheorie ist es bereits impliziert, daß die repräsentierten Eigenschaften (wenn überhaupt) sowohl extern als auch objektiv instantiiert sein müssen. Die Objektivität hat - zusammen mit dem Umstand, daß die Farben auch wirklich als Eigenschaften der repräsentierten Gegenstände gesehen werden - zugleich die Intrinsität zur Folge. Da Farben laut unserer Intuitiven Farbkonzeption alle drei Merkmale zeigen, liegt es nahe, sie als repräsentierte Eigenschaften anzusehen. Zwei weitere Punkte unterstützen diesen Schluß. Zum einen erklärt er ganz einfach den Umstand, daß Farben uns in Farbwahrnehmungen präsentiert werden, so daß es uns scheint, als ob wir sie wahrnehmen würden. Und zum anderen garantiert er auf einfache Weise die Erklärungskraft der Farben, da ja im Falle der Repräsentiertheit unter Normalbedingungen eine nomologische Korrelation zwischen Farben und Farbempfindungen vorliegt. Außerdem erlauben, mit Bezug auf repräsentierte Farbeigenschaften, die eben genannten fünf Merkmale, daß Farbwahrnehmungen sowohl veridisch als auch illusorisch oder halluzinatorisch sein können.

\subsubsection{Der phänomenale Aspekt}

In diesem Abschnitt geht es um das Verständnis von Farben als phänomenale Eigenschaften. Auch für diese Annahme können genügend Merkmale der Intuitiven Farbkonzeption als Fundament gefunden werden. ${ }^{28}$ Dabei

27 Broackes zeigt zudem, daß es daneben noch weitere Farbgesetzmäßigkeiten gibt. Erstens basieren Simultan- und Sukzessivkontrast immer auf der Tatsache, daß zwischen den Kontrastpartnern (der beinflußenden und der beeinflußten Farbe) immer Komplementarität vorherrscht. Zweitens kann additive Farbmischung von farbigem Licht allein anhand der drei Parameter Farbton, Helligkeit und Sättigung erklärt werden. Und schließlich gibt es gesetzmäßige Veränderungen der Farbtöne, wenn die Sättigung zu- oder abnimmt (vgl. Broackes (1992): 427ff.).

28 Es läßt sich fragen ob die Unterscheidung in einen repräsentationalen und einen phänomenalen Aspekt der Intuitiven Farbkonzeption bereits erschöpft, oder ob doch einige Merkmale ohne Zuordnung bleiben. Die Hypothese dieses Buches 
werden nur die explizit auf Farbtöne bezugnehmende Charakteristika in Betracht gezogen, weil die Diskussionen innerhalb dieses Buches sich weitestgehend auf diesen Parameter beschränken und die beiden anderen „Dimensionen“ von Farben wissentlich vernachlässigen. Dabei wird gleich das erste angeführte Merkmal die Rede von einem phänomenalen Aspekt genügend motivieren können. Denn der Grundgedanke wird es sein, den Farbtoncharakter - also daß, wie uns eine bestimmte Farbe (in Abstraktion von Helligkeit und Sättigung) in Sinneserfahrungen erscheint und introspektiv gegeben ist - mit dem entsprechenden phänomenalen Erlebnischarakter der Farbwahrnehmung gleichzusetzen. Der Farbton wird demgemäß mit dem Farbquale identifiziert, und der Farbtoncharakter (einschließlich der anderen, phänomenalen Merkmale) mit dem Charakter, wie wir das Farbquale phänomenal-bewußt erleben. Es ist jedoch schwierig, die ontologische Natur eines Quale von seinem Erlebnischarakter zu trennen. Die Idee dieses nicht-auftrennbaren Zusammenhanges (einer Varianate des esse est percipi) ist auf die Aktualimusintuition - daß immer, wenn eine Rotwahrnehmung vorliegt, es auch immer etwas Rötliches gibt - zurückzuführen und findet sich auch schon, auf die Sensa bezogen, in der Sinnesdatentheorie. In jedem Fall ist das Quale eine theoretisch postulierte Eigenschaft von Wahrnehmungen, welche die Merkmale des phänomenalen Aspektes des zu der Wahrnehmung gehörenden introspektiven Charakters instantiiert (Farbähnlichkeiten sind somit zum Beispiel in Wirklichkeit Ähnlichkeiten unter Farbqualia).

wird es sein, daß die hier vorgeschlagene Theoretisierung ausreicht, um alle Merkmale zu erfassen. Da jedoch gerade die Auflistung der in der Intuitiven Farbkonzeption vereinigten Charakteristika keinen Anspruch auf Vollständigkeit gestellt hat, kann es nicht ausgeschlossen werden, daß bestimmte Merkmale nicht dem einen oder dem anderen Aspekt zugeordnet werden können. Dies ist allerdings nicht sehr wahrscheinlich; es würde zudem die einfache Analyse von Wahrnehmungen allein über deren Gehalt und deren Quale in Frage stellen. Davon abgesehen wird es sicherlich Fälle geben, in denen die Einschätzung nicht unbedingt zu einem eindeutigen Ergebnis kommen mag (zum Beispiel hinsichtlich der weiter unten erwähnten Einheitlichkeit oder Einfachheit). Das zeigt auch die enge Verbindung beider Aspekte, die sie schon einfach dadurch genießen, daß die Transparenzintuition sie beide auf Farbeigenschaften bezieht. Bei den meisten Fällen wird jedoch einigermaßen Klarheit herrschen, auf welche Seite sie zu rechnen sind. 
Die Redewendung esse est percipi trifft im Grunde nur metaphorisch oder mittels Analogie zu. Zum einen ist uns wahrscheinlich nicht die gesamte Natur der Qualia gegeben (eine zu erwartende physikalische Realisierung ist zum Beispiel alles andere als offensichtlich), und zum anderen handelt es sich bei der bloßen oder introspektierenden Aufmerksamkeit auf Qualia nicht um einen der externen Wahrnehmung vergleichbaren Akt (vgl. Shoemaker (1994a); (1994c)). Außerdem ist Introspektion fallibel. Mit Bezug auf Qualia scheint dies aber eher zu bedeuten, daß wir nicht absolut sicher sein können, uns wirklich in einem Zustand mit dem entsprechend erlebten Quale zu befinden. Sich über die introspektierten Merkmale zu irren, scheint dagegen wenig Sinn zu machen. Erlebt jemand introspektiv ein reines, ungemischtes Farbquale $Q$, dann kann er sich vielleicht darüber irren, eine reine Farbe wahrzunehmen, aber er kann sich nicht darüber irren, daß die Introspektion auf die Farbwahrnehmung zu einem Erlebnis eines solchen reinen Quales geführt hat - und nicht zu dem Erlebnis eines gemischten (dieser Fehler wäre erst möglich, wenn eine Introspektion noch höherer Ordnung auf die erste gerichtet wäre). Denn die Reinheit ist ein wesentlicher Bestandteil des Erlebnischarakters des fraglichen Quale: wäre sie nicht erlebt, wäre eben nicht dieses Quale, sondern ein anderes erlebt. Vergleichbares läßt sich aller Wahrscheinlichkeit nach für die anderen phänomenalen Merkmale sagen. Sie sind alle zusammen für das betreffende Quale $Q$ konstitutiv. Liegt also ein Erlebnischarakter vor, der eines dieser Merkmale nicht zeigt, dann kann es sich nicht um ein entsprechendes $Q$ Erlebnis handeln (wohl aber um ein inkorrektes Introspektieren oder Erleben eines $Q$-Quale). ${ }^{29}$

Eine naturalistische Theorie der Qualie - wie etwa der Repräsentationalismus - kann vielleicht darauf hoffen, daß die Natur derselben unabhängig davon bestimmt werden kann, wie sie uns introspektiv gegeben sind. Bis

29 Auch wenn aufmerkendes oder introspektierendes Erleben nicht nach dem Wahrnehmungsmodell erklärt werden sollte (vgl. Shoemaker (1994a)), gibt es doch die folgende Analogie. Eine nicht-veridische Rotwahrnehmung bezieht sich zwar nicht auf eine Rot-Tatsache in der Welt, aber sie instantiiert trotzdem faktisch immer einen Rot-Gehalt und ein Rot-Quale. Genau dasselbe gilt für das Quale und seine Reinheit. Die Introspektion auf eine Farbwahrnehmung kann dieser zwar fälschlicherweise ein $Q$-Quale zusprechen, aber trotzdem wird das in der Introspektion involvierte $Q$-Erleben immer die für das $Q$-Quale wesentlichen Merkmale offenbaren (wie etwa Reinheit). 
dahin ist es unausweichlich, Qualia über unser phänomenales oder introspektives Bewußtsein von ihnen zu bestimmen. Jedenfalls wird der Farbtoncharakter mit dem theoretisch postulierten phänomenalen Charakter von Wahrnehmungen gleichgesetzt. Wie genau diese Einsicht mit der ebenfalls in der Intuitiven Farbkonzeption verborgenen Idee der Farben als repräsentierte Eigenschaften zusammenpaßt, soll uns für den Moment nicht weiter beschäftigen. Die anderen phänomenalen Merkmale werden sich jedenfalls auf diese Identifikation zurückführen lassen, indem sie als Beschreibungen davon angesehen werden können, wie Farbqualia von uns erlebt werden. Eine Theorie der Qualia wird dann entscheiden, in welchem Verhältnis der phänomenale Aspekt des introspektiven Charakters einer Farbwahrnehmung zum repräsentationalen sowie zu ihrem Gehalt steht.

Farbtoncharakter: jede einfache Farbwahrnehmung weist genau ein farbspezifisches Quale auf. Hierbei handelt es sich um die Farbqualia, wie sie oben bereits bestimmt worden sind. Da einzelne Wahrnehmungen pro wahrgenommener Farbe nur jeweils ein einziges Farbquale aufweisen, und da trotzdem jede Farbwahrnehmung über ein solches Quale verfügt, erfüllen letztere auch die Bedingungen für eine Determinablen-DeterminantenStruktur.

Einfachheit, Einheitlichkeit und Homogenität. Drei Merkmale kennzeichnen dabei die Phänomenalität der Farbquale ganz allgemein (wobei es nicht eindeutig geklärt ist, ob Einfachheit und Einheitlichkeit wirklich dem phänomenalen Aspekt zugerechet werden sollten, da sie eigentlich sowohl die repräsentierte Eigenschaft als auch das Quale zu betreffen scheinen). Erstens erscheinen sie uns einfach zu sein, daß heißt, nicht aus anderen Elementen oder Charakteristika zusammengesetzt: eine den Farbtatsachen möglicherweise zugrundeliegende Realisierungsebene ist uns in der Introspektion nicht offenbar. Zweitens zeichnen sie sich für uns durch einen einheitlichen Charakter aus. Ganz unabhängig davon, mit welchen Gegenständen sie verbunden werden, behalten die einzelnen Farbtöne in ihrer Erscheinung ihren Erscheinungscharakter bei: Unterschiede in der physikalischen Realisierung von Farbtatsachen spiegeln sich nicht im qualitativen Charakter wider. Zwei Objekte können denselben Rotton instantiieren, auch wenn ihre sonstige Oberflächenbeschaffenheit, ihre Textur oder Mate- 
rialität im Vergleich zu ganz unterschiedlichen Farbwahrnehmungen führt. Schließlich gibt es drittens chromatische und achromatische Farbqualia, die zwar in einigen Aspekten deutlich voneinander differieren, jedoch innerhalb den uns gegebenen Erscheinungen von der Wirklichkeit eine vergleichbare Rolle einnehmen: diese Eigenschaften scheinen uns damit eine einzige, homogen Gruppe zu sein.

Phänomenale Beziehungen: Farbqualia sind durch eine Struktur von Ähnlichkeiten und Verschiedenheiten spezifiziert. Die Relationen supervenieren dabei auf dem intrinsischen Charakter der einzelnen Qualia (welche eine Theorie der Qualia möglichst erklären sollte): es handelt sich also um interne Relationen. Ein Rotquale ist für uns einem Orangequale ganz einfach deshalb ähnlicher als einem Blauquale, weil die drei betreffenden Qualia genauso sind, wie sie sind: und uns dementsprechend in der Introspektion unterschiedlich gegeben sind. Aufgrund der phänomenalen Beziehungen bilden die Qualia ein kreisförmiges Gebilde (und zusammen mit Helligkeit und Sättigung einen Kegel oder eine Kugel). Die Distanz zweier Qualia auf dem Kreis gibt den Grad ihrer (Un-)Ähnlichkeit an. Es sei noch einmal darauf hingewiesen, daß nicht-reine, binäre Farbqualia sich immer nur aus zwei reinen Qualia ergeben, somit nur diesen ähnlich sind und zwischen ihnen positioniert werden. Die reinen Farbqualia selbst stehen dabei als die vier Fixpunkte an den vier Seiten des Kreises fest: es macht im Grunde keinen Sinn, zwischen ihnen nach Ähnlichkeiten zu suchen. Im weiteren Verlauf des Buches werden die Bezeichnungen „phänomenale Merkmale“ oder ,phänomenale Beziehungen“" auch die im nächsten Absatz beschriebenen Eigenschaften zweiter Ordnung der Qualia miteinschließen.

Eigenschaften zweiter Ordnung: es gibt vier reine (unike) Farbquale, aus denen - unter Berücksichtigung zweier Inkompatibilitäten - alle anderen Farbqualia binär ,gemischt" sind. Die Redeweise von einer Mischung ist dabei nur metaphorisch zu verstehen; tatsächlich handelt es sich um das Bestehen bestimmter Ähnlichkeitsbeziehungen zwischen dem ,gemischten" Quale und den entsprechenden zwei reinen Qualia. Vier Farbqualia zeigen Unikheit oder „Ungemischtheit“ (Rot, Grün, Blau und Gelb). Alle anderen sind jeweils zwei von diesen reinen Qualia ähnlich, wobei Kombinationen aus dem Rot- und dem Grünquale einerseits und aus dem Gelb- 
und dem Blauquale andererseits nicht vorkommen. Wie sich zeigen wird, kann dieser Befund durch die Gegenfarbtheorie erklären (vgl. das Kapitel über die Wissenschaft der Farben).

\subsubsection{Introspektivität des Gehaltes}

Der repräsentationale Aspekt der Intuitiven Farbkonzeption bestimmt Farben als repräsentierte und der phänomenale Aspekt als qualitative oder phänomenale Eigenschaften. Gehen wir vorerst von der Gültigkeit beider Bestimmungen aus. Die repräsentieren Farben und die Farbqualia sind bereits erfolgreich mit dem introspektiven Charakter von Farbwahrnehmungen in Relation gesetzt worden: als Instanzen von dessen Merkmalen. Die introspektiv zugänglichen Merkmale, die dem Quale zukommen, genügen dafür, daß wir mittels Introspektion Wahrnehmungen mit unterschiedlichen, phänomenalen Charakteren differenzieren können. Doch wie sieht es mit dem Gehalt aus: wie kann introspektiv festgestellt werden, welche Farbeigenschaft genau repräsentiert wird?

Es ist bereits behauptet worden, daß die repräsentationalen Merkmale nur ganz allgemein darauf hinweisen, daß Farben repräsentierte Eigenschaften sind. Daß auf Repräsentationalität geschlossen werden kann, läßt sich - vor dem Hintergrund der obigen Überlegungen - dadurch begründen, daß diese Merkmale sowohl einen Hinweis auf die Externalität der Farben als auch einen auf den engen Zusammenhang mit Formeigenschaften miteinschließen. Betrachtet man den repräsentationalen Aspekt, so kann man zudem leicht nachvollziehen, daß dieser im Grunde bei allen Farbwahrnehmungen derselbe ist. Jede Introspektion auf solche Sinneserfahrungen zeigt für Farben die typischen Merkmale Repräsentiertheit, Externalität, Intrinsität, Objektivität und Erklärungskraft. Wäre es nicht so, könnte es sich gar nicht um repräsentierende Farbwahrnehmungen handeln. Natürlich unterscheiden sich die meisten Wahrnehmungen dadurch, daß sie die Farben an unterschiedlichen Gegenständen oder an verschiedenen Orten im Raum lokalisieren. Doch diese Gehaltsdifferenzen können nicht entscheidend dafür sein, daß wir Wahrnehmungen introspektiv auseinanderhalten können, allein weil sie verschiedene Farbeigenschaften repräsentieren. In diesem Sinne sagt uns der repräsentationale Aspekt - 
in Verbindung mit der wahrgenommenen Räumlichkeit - nur, daß eine Farbeigenschaft repräsentiert wird.

Wie genau stellen wir dann aber mittels Introspektion fest, ob eine Wahrnehmung Rot - und nicht etwa Blau - repräsentiert? Es ist klar, daß beide Wahrnehmungstypen über unterschiedliche introspektive Charaktere verfügen werden. Doch es läßt sich noch mehr sagen. Betrachtet man zwei Sinneserfahrungen, die sich nur hinsichtlich der repräsentierten Eigenschaft, aber nicht hinsichtlich der räumlichen Lokalisierung derselben oder auch Formaspekten unterscheiden, dann wird dieser Unterschied im Gehalt, wie gesagt, nicht dem repräsentationalen Aspekt des introspektiven Charakters anzusehen sein. Unter der Voraussetzung, daß der introspektive Charakter von Farbwahrnehmungen durch die beiden eingeführten Aspekte erschöpft wird, muß eine Gehaltsdifferenz also auf einen Unterschied im phänomenalen Aspekt zurückzuführen sein. Eine Rot- und eine Blauwahrnehmungen müssen wenigstens faktisch in ihren Farbqualia differerieren. Der phänomenale Aspekt wird demgemäß benötigt, um introspektiv bestimmen zu können, was genau repräsentiert wird: also welche Farbeigenschaft.

Das hat zur Konsequenz, daß erst beide Aspekte zusammen die Introspektion des Gehaltes ermöglichen. Ein Unterschied im Gehalt der Wahrnehmung muß - wenigstens aktual - am phänomenalen Aspekt des introspektiven Charakters ausgemacht werden können. Die Individuation von Farbwahrnehmungen aufgrund der von ihnen repräsentierten Eigenschaft erfolgt anhand des Farbquale. Eine Rotwahrnehmung unterscheidet sich introspektiv von einer Blauwahrnehmung allein dadurch, daß erstere ein Rotquale und letztere ein Blauquale aufweist (wie immer auch deren Natur beschaffen ist). Der introspektive Charakter muß es ermöglichen, daß zumindest Gehaltsunterschiede, das heißt, Unterschiede in der repräsentieren Eigenschaft festgestellt werden können. Auf den repräsentationale Aspekt kommt es dabei nicht an, da dieser für alle Farbwahrnehmungen derselbe ist. Dagegen weisen verschiedene Eigenschaften repräsentierende Wahrnehmungen für ein Subjekt immer auch unterschiedliche phänomenale Aspekte auf. Differenzen im introspektiven Charakter spiegeln also immer Differenzen im Gehalt wider: andernfalls wären Gehaltsunterschiede zwischen Wahrnehmungen unterschiedlichen Typus introspektiv gar nicht feststellbar. Im Gegensatz zu der Inklusionsrelation zwischen phänomenalen 
Aspekt einer Wahrnehmung und deren Quale muß der repräsentationale Aspekt ganz deutlich vom Gehalt getrennt werden: denn auch wenn der repräsentationale Aspekt die Annahme eines allgemeinen Gehaltes motivieren kann, können erst beide Aspekte zusammen diesen genau spezifizieren.

Damit kann auch ein vermeintliches Introspektionsproblem gelöst werden, welches durch die Aufgabe des Indirekten Realismus zu entstehen scheint. Auf der einen Seite gibt es nur einen einheitlichen introspektiven Charakter. Wenn wir auf eine Rot-Wahrnehmung introspektieren, dann ist uns sozusagen nur eine „Rötlichkeit“ gegeben. Trotzdem gehen die gängigen Wahrnehmungstheorien davon aus, daß zwei Eigenschaften introspektiert werden können: der Gehalt, das heißt, die repräsentierte Eigenschaft Rot; und der qualitative Charakter, also das Rotquale. Es sollte also geklärt werden, wie diese vermeintliche „Rötlichkeit“ einerseits und die beiden Eigenschaften Rot (des repräsentierten Gegenstandes) und Rot-Quale (der Wahrnehmung) andererseits zueinander in Beziehung gesetzt werden können. Die Lösung der Sinnesdatentheorie ist sehr einfach. Die entsprechend präsentierten Sensa instantiieren jeweils eine „Rötlichkeits“-Eigenschaft, die in sich zugleich die Farbe und das Farbquale vereinigt. Sowohl Rot als auch das Rot-Quale sind somit als „Rötlichkeit“ introspektiv zugänglich. Doch mit der Aufgabe des Indirekten Realismus geht die Möglichkeit dieser einfachen Erklärung ebenfalls verloren. Aber der Direkte Realist kann alternative Wege der Erklärung finden.

Der erste Schritt ist der, daß der introspektive Charakter in mehr besteht als der bloßen „Rötlichkeit“: denn es gibt zusätzlich noch einen repräsentationalen Aspekt. Das Quale, welches der phänomenalen „Rötlichkeit“ entspricht, wird somit zu einem Bestandteil des introspektiven Charakters, schöpft diesen aber nicht aus. Der Gehalt ist indessen vorerst gar nicht (unbedingt) unmittelbar introspektiv zugänglich. Er kann aber ohne weiteres aus dem vollständigen introspektiven Charakter erschlossen werden. In diesem Sinne handelt es sich eigentlich nur um eine halbe Lösung des Introspektionsproblemes, da im Grunde einfach nur die direkte Introspektierbarkeit des Gehaltes aufgeben und durch eine indirekte, das heißt, durch Inferenzen von der introspektiv gegebenen Information gewonnene Introspektierbarkeit ersetzt wird. Was alleine bleibt, ist die faktische, unmittelbare Introspektierbarkeit von Gehaltsunterschieden, die anhand der phänomenalen Differenzen festgestellt werden kann (dazu mehr im nächsten Ab- 
schnitt). Will man diese Konsequenz vermeiden, so muß zusätzlich eine enge Beziehung zwischen Farben und Farbqualia postuliert werden, wie es etwa die Repräsentationisten oder auch die Subjektivisten tun. Ob der Gehalt auf diese Weise ebenfalls als direkt introspektiv zugänglich angesehen werden kann, müssen die entsprechenden Diskussionen erst noch nachweisen.

In jedem Fall zeigt sich in den eben angestellten Überlegungen einerseits der klare Unterschied zwischen den uns intern gegebenen Aspekten des introspektiven Charakters und den beiden theoretisch postulierten Eigenschaften Gehalt und Quale einer Wahrnehmung, andererseits aber auch der Umstand, daß letztere deswegen sinnvollerweise eingeführt werden sollten, um die Merkmale des introspektiven Charakters von Farbwahrnehmungen - und damit auch der Intuitiven Farbkonzeption - theoretisch erfassen und erklären zu können: wobei das Quale aufgrund seiner unmittelbaren Introspektierbarkeit wahrscheinlich noch einen direkteren Bezug zum introspektiven Charakter aufweisen wird als der vielleicht nur indirekt introspketierbare Gehalt.

\subsection{Die Individuierung der Farben}

\subsubsection{Die Aktualitätsthese und die Notwendigkeitsthese}

Eine weitere Konsequenz ist, daß Farbwahrnehmungen sowohl über ihren Gehalt als auch über ihr Quale typen-individuiert werden können. Beide Individuationsmethoden weisen dabei, wie es scheint, dieselbe Feingradigkeit auf (nur eine bestimmte Form des Objektivismus - der Starke Physikalismus - wird für den Gehalt eine feingradigere Diskriminierung postulieren). Doch es gibt möglicherweise einen Unterschied im epistemischen $\mathrm{Zu}$ griff. Der qualitative Charakter von Zuständen kann uns nur mittels des phänomenalen oder introspektivem Bewußtseins gegeben sein. Dagegen erlaubt die empirische Anwendung der externalistischen Gehaltstheorie, Farbwahrnehmungen aufgrund der jeweils repräsentierten Eigenschaften zu differenzieren. Doch diese Asymmetrie besteht wahrscheinlich nicht wirklich. Zum einen kann es gut möglich sein, daß auch Qualia durch eine empirische Theorie beschrieben und erklärt werden können. Zum anderen 
hängt die konkrete Anwendung einer Gehaltstheorie immer noch eng mit der Introspektion zusammen, wie etwa die Praxis in der Colorimetrie zeigt. Denn auch diese beruft sich bei ihren Experimenten letzten Endes immer auf introspektive (aber nicht infallible) Evidenzen, um zu entscheiden, ob zu einem bestimmten Zeitpunkt eine Farbwahrnehmung vorliegt, und wenn ja, welche. Üblicherweise wird auch dort die These akzeptiert, daß faktisch jedem Gehaltsunterschied auch eine phänomenale Differenz entspricht, und umgekehrt. Als Fundament aller - oder zumindest der allermeisten Farbtheorien kann somit die folgende Aktualitätsthese gelten (die nicht mit der Aktualismusthese zu verwechseln ist): ${ }^{30}$

(ACT) Aktual gilt: die Wahrnehmung $W$ eines menschlichen Subjektes $S$ repräsentiert die Farbe $F \leftrightarrow W$ hat ein $F$-spezifisches Farbquale. Das heißt: faktisch gehen $F$-Quale und $F$-Gehalt nicht auseinander.

Ein $F$-Gehalt ist, wie bereits erwähnt, als ein die Eigenschaft $F$ enthaltender Gehalt definiert. Die Definition eines $F$-Quale ist dagegen etwas umständlicher. Die Bestimmung, daß ein F-Quale genau das Farbquale ist, welches eine $P$-repräsentierende Farbwahrnehmung aktual aufweist, kann

30 Die Aktualitätsthese ist stärker als die Kontingenzthese von Byrne und Hilbert (vgl. deren Einleitung in (1997a): xiv), da letztere auch die Möglichkeit miteinschließt, daß selbst in der aktualen Welt und für Menschen diese Korrelation nicht besteht. Das heißt jedoch nicht, daß die beiden Philosophen die Aktualitätsthese für ablehnenswürdig halten: zum einen vertreten sie die viel stärkere Notwendigkeitsthese (vgl. unten), zum anderen nehmen auch sie eine (ACT) sehr ähnliche These als allgemeines Fundament an:

„We can all agree that, at least typically, a red-feeling experience is red-representing, and conversely. (And similarly for the other colors.)“ (Einleitung zu Byrne \& Hilbert (1997a): xiv)

Die Einschränkung auf „typische“ Fälle ist dabei allein durch die beiden Möglichkeiten motiviert, daß entweder jemand die Repräsentationalität von Farbwahrnehmungen leugnen könnte (wie etwa die Informationalisten Tolliver (1994) und Averill (1982)), oder daß die Bedingungen, wie sie faktisch sind, sich ändern könnten. Es handelt sich dementsprechend auch hier um die Aktualitätsthese. 
leicht zirkulär klingen. Tatsächlich handelt es sich hier um dasselbe Problem wie bei der introspektiven Individuation von Farbwahrnehmungen, die ja ebenfalls über Farbquale verlief. Auch die Lösung ist dieselbe: ein $F$ Quale kann mit Hilfe von Vergleichen von anderen Farbqualia introspektiv unterschieden werden, wobei ein bestimmtes $F$-Quale als Paradigma oder Vergleichsmaßstab gelten wird (ohne daß das Subjekt unbedingt wissen muß, daß es sich um ein $F$-Quale - und nicht ein $G$-Quale - handelt). Diese Individuation hat dabei einen rigiden Charakter. Das heißt, ein in der aktualen Welt als ein $F$-Quale individuiertes Quale bleibt auch in anderen Welten immer ein $F$-Quale. Da der qualitative Charakter von Wahrnehmungen darüber bestimmt ist, wie er uns phänomenal bewußt wird, also von uns erlebt wird, werden alle Qualia, die - ganz gleich in welcher Welt - genauso erlebt werden, wie das $F$-Quale aktual von uns erlebt wird, auch als solche gelten.

Dabei entsteht natürlich ein zweifaches Problem mit der Intersubjektivität von qualitativem Erleben. Zum einen ist es fraglich, ob wirklich alle Menschen bestimmte Qualia auf dieselbe Weise erleben (gerade Wittgenstein hat dies angezweifelt, oder diesen Zweifel doch zumindest in Erwägung gezogen und plausibel gemacht). Aufgrund der anatomischen und funktionalen Ähnlichkeit der menschlichen Gehirne sowie der offensichtlich in den meisten Fällen vorhandenen Übereinstimmungen im Verhalten kann dies Problem jedoch hier vernachlässigt werden. Es macht zum Beispiel nichts aus, daß Menschen mit den reinen Farbtöne verschiedene qualitative Erlebnisse verbinden, solange jeder nur genau vier reine Farbtöne kennt und diese auch (in etwa) als an denselben Objekten in der Außenwelt lokalisiert sind. Nun gibt es zwar unter den Menschen mehr oder wenige geringe Abweichungen in der konkreten Farberkennung (wie in dem Kapitel über Normalbedingungen ausführlicher dargestellt werden soll), aber die Struktur der Phänomenalität sowie die Diskriminierungen hinsichtlich der Farbigkeit in der Welt stimmen in den meisten Fällen ausreichend überein, so daß es gleich ist, ob alle Menschen die mit den einzelnen Gehalten verbundenen Qualia auch auf dieselbe Weise erleben. Für die Aufrechterhaltung der Aktualitätsthese genügt es jedenfalls, nur die Korrelation von $F$-Gehalt und $F$-Quale jeweils für alle farbwahrnehmenden Subjekte einzeln zu betrachten.

Es ist jedoch durchaus plausibel, davon auszugehen, daß ein Blauquale 
für die meisten Menschen denselben Erlebnischarakter aufweist, da es andernfalls schwer sein wird, dies mit einem physikalistischen Weltbild in Verbindung zu bringen und neurophysiologische Differenzen für diesen Unterschied im Erleben festzumachen. Dies zeigt sich auch darin, warum die gegen die Repräsentationalisten vorgebrachten Inversionsbeispiele sich meistens allein auf das Erleben des qualitativen Charakter selbst beschränken und nur selten auch die phänomenalen Beziehungen mit in Betracht ziehen: wobei die Beachtung der mit den Farben verbundenen, phänomenalen Beziehungen wahrscheinlich eine viel stärkere Basis bietet, um gegen den Repräsentationalismus zu argumentieren (wie es die Kritik am Objektivismus $_{\mathrm{NEC}}$ zeigen wird). Das zweite Problem der Intersubjektivität bezieht sich auf Lebewesen, die mit den Menschen, wie sie faktisch beschaffen sind, nicht übereinstimmen, und trotzdem als farbensehende Subjekte gelten sollten. Zum einen gehören die hypothetischen Fälle der Qualia-Inversion und -Abwesenheit dazu, zum anderen die meisten, höherentwickelten Tiere. In beiden Fällen entscheidet letztlich ein bestimmter Grad an Übereinstimmung mit dem neurophysiologischen Aufbau unseres visuellen Systemes sowie mit unserem farbrelevanten Verhalten darüber, ob wir dazu geneigt sind, auch sie als Lebewesen mit der Fähigkeit, Farben wahrnehmen zu können, einzustufen oder nicht. Die Aktualitätsthese bezieht sich jedoch ausdrücklich nur auf Menschen, wie sie aktual beschaffen sind.

Dabei ist wohl unumstritten, daß eine Verschiedenheit im Quale immer ein Anzeichen für eine Verschiedenheit im Gehalt ist. Bestimmte Farbtheorien - allesamt Varianten des Starken Physikalismus - versuchen jedoch, Gehalte feingradiger zu bestimmen als Qualia. Damit geben sie automatisch die These (ACT) und folglich auch die Introspektierbarkeit aller möglichen Gehaltsdifferenzen auf. Nur relativ grobe Unterschiede zwischen den repräsentierten, physikalischen Eigenschaften können noch detektiert werden. Diese Intuition wird zwar dem Unbestimmtheitscharakter von Wahrnehmungen gerecht, aber es ergibt sich zudem die Schwierigkeit, daß Qualia nicht mehr dazu verwandt werden können, Farbwahrnehmungstypen $\mathrm{zu}$ individuieren, weil diese allein mithilfe der repräsentierten Eigenschaften feingradig genug differenziert werden können. Auch wenn es noch möglich sein wird, Farben empirisch in der Welt zu diskriminieren, kann, wie es scheint, keine Verbindung mehr zu den Wahrnehmungen derselben Eigenschaften gezogen werden, da diese ein viel gröberes Raster 
auf die Welt legen. Introspektion kann nicht mehr zu Typenindividuierung der introspektierten Wahrnehmungszustände herangezogen werden. Dieses Resultat hebt nicht unbedingt die Plausibilität des der Starken Physikalismus, so daß die Ablehnung der Aktualitätsthese von dieser oder von auch anderen Theorien der Farben mit allen Mitteln vermieden werden sollte.

Wenn Gehaltsunterschiede nur mittels phänomenaler Differenzen introspektiv erkannt werden können, dann kann der allgemeine Gehalt - wie oben bestimmt - nur dann als durch Introspektion zugänglich gelten, wenn er in einer engen Beziehung mit dem entsprechenden Quale steht. Andernfalls dient das Quale nur als kontingenter Vermittler, um auf den Gehalt zu schließen. Geht man beispielsweise von der Möglichkeit von Qualia-Inversion aus, dann kann ein- und dasselbe Quale in zwei verschiedenen Welten sich auf unterschiedliche Gehalte beziehen, und ein- und derselbe Gehalt kann in verschiedenen Welten mit zwei unterschiedlichen Qualia verbunden sein. Zwar bleiben dann der repräsentationale und der phänomenale Aspekt (einschließlich des Quale) weiterhin introspektierbar, nicht aber der Gehalt selbst. Um dieser Konsequenz - die hauptsächlich natürlich eine Folge des Externalismus darstellt - in gewissem Sinne zu entgehen, versuchen die Repräsentationalisten, eine solche enge Beziehung - und zwar aller Voraussicht nach eine Identität - zwischen Gehalt und Quale zu postulieren, indem sie das Quale entweder mit der repräsentierten Eigenschaft des wahrgenommenen Gegenstandes oder mit der repräsentationalen Eigenschaft der Wahrnehmung selbst gleichsetzen. In beiden Fällen impliziert dies eine Ablehnung von Qualia-Inversion und ähnlichen Fällen, da die in der faktischen Welt miteinander verbundenen Paare aus Gehalt und Quale auch in jeder anderen möglichen Welt immer zusammen auftreten müssen. Die Konsequenz ist die sogenannte Notwendigkeitsthese, wie sie beispielsweise von Byrne und Hilbert vertreten wird, aber auch den Repräsentationalismus wesentlich mitbestimmt:

„(Necessity) For all possible subjects $\mathrm{S}_{1}, \mathrm{~S}_{2}$ and all possible worlds $\mathrm{w}_{1}$ und $\mathrm{w}_{2}$, if $\mathrm{S}_{1}$ is having a visual experience in $\mathrm{w}_{1}$ and $\mathrm{S}_{2}$ is having a visual experience in $\mathrm{w}_{2}$, then these experiences are the same in color content iff they are the same in color phenomenology.“ (Byrne \& Hilbert (1997c): 267)

Die beiden schweigen sich zwar darüber aus, welche Lebewesen als „mög- 
liche Subjekte“ in Frage kommen, doch da sie sich explizit gegen Inversionsbeispiele zur Wehr setzen, sind auf alle Fälle die entsprechenden, leicht veränderten menschlichen Subjekte zugelassen. Anders sieht es vielleicht mit Tieren aus, da deren visuelle Sinnesorgane entweder eine von unserer verschiedene Sensitivität aufweisen (zum Beispiel wegen eines leicht unterschiedlichen wahrnehmbaren Spektrums) oder einen ganz anderen Aufbau zeigen (wenn es sich beispielsweise nicht um Trichromaten mit zwei Augen handelt). Ihre Miteinbeziehung erübrigt sich möglicherweise, da ihre Farbwahrnehmungen gar nicht exakt dieselben Eigenschaften repräsentieren können (wohl aber welche von einem sehr ähnlichen Typus) und deswegen auch unter der Annahme von der Notwendigkeitsthese eine phänomenale Differenz zu erwarten ist. Interessanter ist dagegen die Überlegung, ob Tiere nicht auch über (teilweise) dieselbe Phänomenalität verfügen können: ob uns sehr ähnliche Primaten nicht auch ein reines Rot erleben können, wie wir es tun; und daß, obwohl sie dabei gleichzeitig (etwas) andere Reflektanzeigenschaften repräsentieren. Ist dies möglich, könnte die Notwendigkeitsthese vielleicht doch als widerlegt gelten. Diese Punkte sollen jedoch erst später - im Zusammenhang mit dem auf dieser Annahme basierten Farbobjektivismus - wieder aufgegriffen und, wenn möglich, entschieden werden. Vorerst soll die Notwendigkeitsthese einfach formuliert werden:

(NEC) Notwendig gilt: die Wahrnehmung $W$ eines Subjektes $S$ repräsentiert die Farbe $F \leftrightarrow W$ hat ein $F$-spezifisches Farbquale. Das heißt: notwendigerweise gehen $F$-Quale und $F$-Gehalt nicht auseinander.

Zwischen (ACT) und (NEC) gibt es also zwei fundamentale Unterschiede: zum einen in der metaphysischen Modalität; und zum anderen im Subjektskopus. Aufgrund der mit dieser erheblichen Verstärkung verbundenen Schwierigkeiten neigen viele Farbphilosophen dazu, die Notwendigkeitsthese nicht aufrechtzuerhalten, sondern sich mit der wesentlich schwächeren Aktualitätsthese zu begnügen. Doch ganz von den Problemen abgesehen bietet eine Akzeptanz der Notwendigkeitsthese auf alle Fälle den Vorteil, daß die Gültigkeit der These (ACT) - also der Umstand, daß Gehalts- 
unterschiede immer faktisch mit phänomenalen Differenzen verbunden sind - so eine einfache Erklärung erhält, indem Gehalt und Quale im Grunde auf ein- und dieselbe, zudem wahrscheinlich naturalisierbaren Charakteristik von Wahrnehmungen zurückgeführt werden sollen: und zwar auf ihre Repräsentationalität. Gerade darin liegt die Attraktivität des Repräsentationalismus. Daneben bringt die Notwendigkeitsthese, wie wir später sehen werden, für einen Objektivisten eventuell auch den Vorzug mit sich, die beiden Aspekte der Intuitiven Farbkonzeption zufriedenstellend miteinander vereinen zu können; und das Introspektionsproblem erfährt schließlich ebenfalls eine überzeugende Lösung.

\subsubsection{Wahrheitsanspruch und Transparenz}

Die Transparenzintuition motiviert die Akzeptanz der Intuitiven Farbkonzeption. Unserem gewöhnlichen Verständnis nach gehören die uns in der Introspektion auf Farbwahrnehmungen zugänglichen Merkmale auch wirklich zur Natur der Farben dazu. Es widerspricht unseren Intuitionen und Meinungen über Farben, einen der beiden Aspekte auch nur teilweise aufzugeben. Die Transparenz formuliert - vor dem allgemeinen Hintergrund eines externalistisch verstandenen Direkten Realismus - demnach einen Wahrheitsanspruch für die folgende, zweiteilige These: Farben sind wesentlich sowohl repräsentierte als auch phänomenale Eigenschaften.

Geht man zusätzlich von der Existenz von Farbtatsachen aus, dann kann man mit Bezug auf Farbwahrnehmungen und deren introspektivem Charakter verschiedene Begriffe der Veridizität einführen. Zwei sind bereits genannt worden. Eine Farbwahrnehmung zeigt repräsentationale Veridizität, wenn ihr Gehalt mit den wahrgenommenen Tatsachen in der Welt übereinstimmt (und es sich, pace Lewis, wirklich um Fälle von Wahrnehmungsakten handelt). Diese Form der Veridizität ist bereits durch die allgemeine Akzeptanz des ontologischen sowie des Direkten Realismus motiviert. Systematische Veridizität liegt dann vor, wenn alle Merkmale des repräsentationalen Aspektes auf die präsentierten Farbeigenschaften zutreffen. Als dritte kann die phänomenale Veridizität eingeführt werden: sie besteht, wenn alle Merkmale des phänomenalen Aspektes auf Farben zutreffen. Die drei Formen der Veridizität können dabei unabhängig voneinander 
gelten. Ein wichtiger Unterschied ist dabei, daß die repräsentationale Veridizität jeweils von Fall zu Fall entschieden werden muß, während die anderen beiden generell auf alle Farbwahrnehmungen zutreffen, oder auf keine. Jedenfalls betrifft der Wahrheitsanspruch der Transparenzintuition alle drei Formen der Veridizität gleichermaßen.

Unsere Sinneserfahrungen werden nun prinzipiell als repräsentational (oder informational) betrachtet (wenn sie keine Farben repräsentieren, dann richten sie sich zumindest auf andere, physikalische Eigenschaften in der Außenwelt). Diese erste Art der Veridizität ist an sich für die Unterscheidung und Bewertung von Theorien der Farben von geringem Interesse. Denn es kann nicht um die Frage gehen, ob Farbwahrnehmungen überhaupt repräsentationale Veridizität zeigen können, da dies ja bereits eine notwendige Bedingung für ihre Repräsentationalität ist. Vielmehr gewinnt die Frage an Bedeutung, ob Farbwahrnehmungen Farben repräsentieren (einschließlich der Möglichkeit veridischen und von nicht-veridischen Repräsentationen). Der eigentliche Disput wird daher darüber gehen, ob systematische und phänomenale Veridizität gleichzeitig bestehen können, und wenn nicht, welche aufzugeben ist. Müssen einige Merkmale der Intuitiven Farbkonzeption aufgegeben werden, dann wird das Resultat eine error theory sein: das heißt, eine Theorie der Farben, die einen Teil unseres naiven oder gewöhnlichen Verständnisses von Farben für fehlerhaft erklären muß, da es nicht den Tatsachen entsprechen kann. ${ }^{31}$

Einige Merkmale können wahrscheinlich ohne größere Schwierigkeiten aufgegeben werden. Auf andere dagegen kann wahrscheinlich nicht so leicht verzichtet werden, weil sie intutiv sehr einsichtig erscheinen: es ist dann besser, sie möglichst zu erhalten; und eine Theorie, die dies nicht schafft, wird sich den anderen gegenüber im Nachteil befinden. In den folgenden Abschnitten sollen die beiden entsprechenden Thesen vorgestellt werden, die Farben jeweils als repräsentierte oder als phänomenale Eigen-

31 Traditionell beziehen sich error theories allein auf eine subjektivistische oder anti-realistische Position: etwa hinsichtlich des moralischen Diskurses, aber auch mit Bezug auf sekundäre Qualitäten oder auf Bedeutungen (vgl. Boghossian (1989): 523; Wright (1993): 63ff.; Devitt (1996)). Meine Verwendung des Begriffes schließt jedoch in gewissem Sinne auch objektivistische Positionen mit ein, die bestimmte Aspekte von Farben, die wir ihnen üblicherweise als wesentliche Merkmale zuschreiben, leugnen müssen (vgl. dazu vor allem das Schlußkapitel). 
schaften charakterisieren, auf die im nächsten Kapitel dann eine systematische Klassifikation der zur Diskussion stehenden Farbtheorien aufgebaut werden kann.

\subsubsection{Farben als repräsentierte Farben}

Die repräsentationale Seite der Intuitiven Farbkonzeption beinhaltet insgesamt fünf Hauptmerkmalen (andere, wie die Visualität, können hier vernachlässigt werden). Das Herzstück bildet sicherlich die Annahme, daß wir mithilfe unserer Sinneserfahrungen Farben repräsentieren und auch diskriminieren können. Farben sind repräsentierte Eigenschaften. Ohne dieses Prinzip macht es gar keinen Sinn, von einem repräsentationalen Aspekt zu sprechen. Damit läßt sich die folgende, konkretisierte Variante der These (IND) formulieren, mithilfe der Farben individuiert werden können:

$\left(\mathrm{IND}_{\mathrm{R}}\right) \quad$ Aktual gilt: die von den Farbwahrnehmungen menschlicher Subjekte $S$ repräsentierten oder repräsentierbaren Eigenschaften sind immer $P$-Eigenschaften.

Eine Position, die Farben als repräsentierte Eigenschaften ansehen möchte, kommt um diese Minimalannahme nicht vorbei. Setzt man nun die Begriffe der Repräsentation und der Farbwahrnehmung voraus, kann die These $\left(\mathrm{IND}_{\mathrm{R}}\right)$ jedoch nur als ein vorläufiges Individuationskriterium für Farbeigenschaften gelten, da sie noch nicht in der Lage ist, die Klasse der Farben eindeutig festzulegen. Zwar definiert sie alle von unseren Farbwahrnehmungen repräsentierten Eigenschaften als Farben, aber sie sagt nichts darüber aus, ob es davon abgesehen noch weitere Farbeigenschaften geben kann. Denn zum einen könnte es noch andere farbwahrnehmende Lebewesen geben, die bestimmte Farbeigenschaften repräsentieren können, welche für uns nicht wahrnehmbar sind. Dann müßte $\left(\mathrm{IND}_{\mathrm{R}}\right)$ durch entsprechende Ergänzungen modifziert oder erweitert werden. Und zum anderen könnte es auch Farben geben, die - wenigstens faktisch - nicht mit bloßem Auge diskriminiert werden: weder von Menschen, noch von anderen Lebewesen. Dies wäre zum Beispiel der Fall, wenn $\left(\mathrm{IND}_{\mathrm{R}}\right)$ durch ein angemesseneres, gemeinsames Merkmal der Farben ersetzt werden würde, welches gar kei- 
nen Bezug mehr auf den Umstand einer aktualen Repräsentation durch Subjekte nimmt.

Trotzdem bliebe die Gültigkeit von $\left(\mathrm{IND}_{\mathrm{R}}\right)$ in beiden Fällen bestehen, da sie nur eine Aussage über die minimale Größe der Klasse der Farbeigenschaften trifft. Und für jede mögliche Ausdehnung dieser Klasse über die Menge der von uns wahrnehmbaren Farben hinaus gelten die von $\left(\operatorname{IND}_{\mathrm{R}}\right)$ individuiierten Eigenschaften als Vergleichsmaßstab. Wenn beispielsweise bestimmte Tiere vermittels ihres visuellen Sinnesorganes ganz andere Eigenschaften detektieren als Menschen, so ist es fragwürdig, ob dieser Spezies die Fähigkeit des Farbensehens zugesprochen werden sollte; detektieren sie dagegen Charakteristika in der Welt, die den von uns repräsentierten prinzipiell sehr ähnlich sind, dann liegt es nahe, auch bei den Tieren von Farbwahrnehmungen zu sprechen. Vergleichbares gilt für faktisch nichtwahrnehmbare Eigenschaften, die möglicherweise als Farben gelten sollen. Doch bis zur Klärung dieser Fragen beschränken wir uns auf das unumgängliche Fundament $\left(\mathrm{IND}_{\mathrm{R}}\right)$ : leugnet man, daß alle unsere Farbwahrnehmungen Farben repräsentieren, entspricht man nicht mehr der Grundauffassung des repräsentationalen Aspektes der Farbkonzeption, wie wir ihn aus der Introspektion auf unsere Farbwahrnehmungen gewonnen haben.

Der repräsentationale Aspekt dieses introspektiven Charakters weist jedoch, neben der Repräsentierbarkeit (oder auch Repräsentiertheit), noch vier weitere Merkmale auf: (i) Farben sind in der Außenwelt instantiiert; (ii) sie sind intrinsische Eigenschaften der betreffenden externen Gegenstände, oder supervenieren auf solchen; (iii) sie üben eine bestimmte kausale oder explanatorische Rolle hinsichtlich der auf sie gerichteten Wahrnehmungen aus; (iv) und sie sind objektiv instantiiert. Eine Farbe zu repräsentieren, heißt demgemäß nichts anderes, als eine objektive und extern instantiierte Eigenschaft mit einem intrinsischen Charakter und einer bestimmten Erklärungskraft zu repräsentieren. Eine Farbtheorie, die der repräsentationalen Seite der Intuitiven Farbkonzeption voll und ganz gerecht werden möchte, sollte demnach auch diese vier Charakteristika den Farbeigenschaften begründet zuschreiben können. Dabei ist es zu erwarten, daß, wenn die mit den Farben identifizierten Eigenschaften $P$ sie in der aktualen Welt objektiv, extern und intrinsisch sind, dies dies auch für alle anderen Welten gilt, in denen sie instantiiert vorkommen: es wird sich also um We- 
sensmerkmale der betreffenden Eigenschaften handeln. ${ }^{32}$ Vor diesem Hintergrund läßt sich die folgende These angeben, welche eine Analyse der Farben als repräsentierte Eigenschaften formuliert und somit auch $\left(\operatorname{IND}_{\mathrm{R}}\right)$ miteinschließt: ${ }^{33}$

(REP) (i) Aktual gilt: die von den Farbwahrnehmungen menschlicher Subjekte $S$ repräsentierten oder repräsentierbaren Eigenschaften sind immer $P$-Eigenschaften; zudem können sie das Auftreten von Farbwahrnehmungen erklären.

(ii) Notwendig gilt: die Eigenschaften $P$ weisen zusätzlich die ihnen wesentlichen Merkmale Objektivität, Externalität und Intrinsität auf.

Es ist natürlich klar, daß in einem gewissen Rahmen eine Revision oder Korrektur der Intuitiven Farbkonzeption möglich sein wird, weil manche Merkmale des introspektiven Charakter nur schwer und ungenau zu fassen sind. Aber es sollte genauso deutlich geworden sein, daß die in der These (REP) genannten Merkmale dem repräsentationalen Aspekt prinzipiell

32 Dies gilt natürlich nur dann, wenn man zusätzlich den ontologischen Realismus und den Physikalismus voraussetzt, wie es in diesem Buch der Fall ist. Man kann die metaphysische Notwendigkeit also entweder immer auf die entsprechenden Welten beschränken oder aber alle Welten zulassen und die fraglichen Thesen über Farben immer in Konjunktion mit diesen beiden Hintergrundsannahmen betrachten. Der Einfachheit halber werden diese zwei fundamentalen Thesen jedoch in den meisten Fällen weggelassen, ohne jedoch dadurch ihre Gültigkeitsanspruch zu verlieren. Sollte man trotzdem immer noch an der Behauptung zweifeln, daß aktual objektive, externe und intrinsische Eigenschaften dies auch notwendig sind, dann kann die folgende These (REP) einfach als die beste - und , wie es scheint, einzige plausible - Erklärung für die in Frage stehende, aktuale Tatsache interpretiert werden.

33 Es ist zu beachten, daß eine faktische Wahrheit immer auch notwendigerweise aktual wahr ist. Somit ließe sich (i) auch wie folgt beginnen: notwendig gilt, daß aktual gilt, daß ... (und so weiter). Doch nur die Bedingung (ii) garantiert, daß die These (REP) als eine (Teil-)Analyse der Farbeigenschaften $P$ angesehen werden kann, da sie den Farben Wesensmerkmale zuschreibt. Die Repräsentierbarkeit und die damit direkt verbundene Erklärungskraft gilt - ohne Zusatzannahmen nur für Menschen, wie sie aktual beschaffen sind. 
nicht abzusprechen sind. Daraus ergibt sich aber, daß Farbwahrnehmungen nur dann hinsichtlich ihres repräsentationalen Aspektes systematisch veridisch sein können, wenn die unter Normalbedingungen repräsentierten Eigenschaften wirklich alle diese fünf Merkmale zeigen. Kommt eine Theorie hingegen $\mathrm{zu}$ dem Schluß, daß den betreffenden Eigenschaften immer ein bestimmtes Charakteristikum fehlt, so läßt sich dies nur durch das Vorliegen eines systematischen Fehlers hinsichtlich dieses Merkmales erklären: was durchaus zur Aufgabe der fraglichen Theorie führen kann. Daß wir beispielsweise Farben als externe Eigenschaften sehen, heißt nicht, daß wir Farben als externe Entitäten repräsentieren: es werden immer nur Gegenstände (oder Orte) als farbig repräsentiert, nie aber Farben als so-undso beschaffen. Der Idealfall einer Theorie der als repräsentierte Eigenschaften verstandenen Farben ist sicherlich eine Position, die Farben alle fünf Merkmale begründet zuweisen kann.

Nun gibt zwar die Aussicht auf mögliche, systematische Fehler in unseren visuellen Wahrnehmungen keinen unmittelbaren Anlaß zum Optimismus; aber der relativ große Spielraum innerhalb der bisherigen Bestimmungen der Merkmale des introspektiven Charakters von Farbwahrnehmungen hat auch die positive Konsequenz, daß die meisten Positionen, die Farben als repräsentierte Eigenschaften ansehen, die Zugabe eines systematischen Fehlers hinsichtlich eines bestimmten Merkmales umgehen können, indem sie dieses auf eine etwas andere Art und Weise spezifizieren oder dessen Extension bis zu einem gewissen Grade erweitern. Dies wird uns vor allem bei den Theorien begegnen, die Farben als dispositionale Eigenschaften von Gegenständen annehmen. Doch dieser Charakter der Allgemeinheit oder relativen Unbestimmtheit findet sich nur bei drei der vier Merkmalen: die Intrinsität kann auch Dispositionen oder interne Relationen umfassen; die Objektivität zeigt eventuell einen graduellen Charakter; und die explanatorische Rolle kann generell sehr weit gefaßt werden, und ist im Prinzip durch die Repräsentiertheit bereits garantiert. Im Gegensatz dazu läßt sich die Externalität ganz genau definieren: eine Eigenschaft ist extern instantiiert, wenn sie weder im Geist, noch im visuellen System exemplifiziert ist, sondern „vor den Augen“. Externalität kann demnach als ein weiteres Fundament neben die Repräsentierbarkeit treten.

Zwischen den einzelnen Merkmalen bestehen dabei ganz bestimmte Implikationsbeziehungen. Die Externalität und die Objektivität sind beide 
eine Folge der Konjunktion der Repräsentierbarkeit mit der Objektivitätsthese des Direkten Realismus. ${ }^{34}$ Dabei könnte die Externalität auch als eine Art von „Objektivität“ aufgefaßt werden: und zwar in dem Sinne, daß sie behauptet, daß Farben Eigenschaften von externen Objekten sind. In den meisten Fällen fallen Externalität und Objektivität zudem ineins. Nur der relationalistische Subjektivismus wird (vergeblich) versuchen, Subjektivität und Externalität miteinander zu vereinen; und es ist eine (wenn auch recht unplausible) Theorie denkbar, die Farben als objektive Charakteristika von internen Gehirnzuständen ansieht (auf eine solche im Abschnitt über den Wörtlichen Projektivismus kurz eingegangen). Deswegen ist es sinnvoll, beide Merkmale zuerst einmal auseinanderzuhalten. In dem allgemeinen Abschnitt über den Farbsubjektivismus wird jedoch argumentiert, daß einerseits subjektive Farben nicht repräsentiert oder detektiert werden können; und die Behandlung der relationalistischen Subjektivismen wird zeigen, daß andererseits subjektive Farben auch nicht extern instantiiert sein können. Sowohl die Repräsentiertheit als auch die Externalität setzen somit die Objektivität voraus (und die Externalität ist, wenn überhaupt, eine stärkere Form der „Objektivität“" als die Objektivität selbst).

Jemand, der die These $\left(\mathrm{IND}_{\mathrm{R}}\right)$ akzeptiert, ist nun vor dem Hintergrund eines Direkten Realismus auch zur Annahme der These (REP) gezwungen (umgekehrt gilt dies natürlich auch, da (REP) die These $\left(I_{N D}\right)$ miteinschließt). Objektive Eigenschaften von externen Gegenständen müssen nach dem realistischen, durch die Physik geprägten Weltbild auf den intrinsischen und physikalischen Eigenschaften der betreffenden Objekte wenigstens supervenieren (wenn jene nicht sogar mit diesen identisch sind). Und die Erklärungskraft ergibt sich automatisch aus der nomologischen Korrelation, über die Repräsentationalität analysiert ist. In diesem Sinne können die vier letzteren Merkmale allesamt als eine notwendige Bedingung für die direkt-realistische Repräsentiertheit gelten. Daß sie nicht auch hinreichend sind, zeigt die Möglichkeit, daß die vier Charakteristika Objektivität, Externalität, Intrinsität und Erklärungskraft noch nicht unbedingt die Repräsentierbarkeit implizieren: wenn zum Beispiel die re-

34 Auch hier gilt, daß streng genommen die aktuale Repräsentierbarkeit nur eine aktuale Objektivität und Externalität impliziert. Doch die entsprechenden Bedingungen vorausgesetzt, können die beiden letzteren Merkmale den Farben (wenn überhaupt) wesentlich zugesprochen werden. 
präsentierten Farbeigenschaften Dispositionen sind, dann zeigen auch deren kategoriale Realisierungsbasen diese vier Merkmale.

Lehnt eine Theorie der Farben demnach Repräsentierbarkeit ab, dann ist es immer noch möglich, daß den Farben einige oder alle der anderen Merkmale zukommen können. Sie wird aber einräumen müssen, daß unsere intuitive Auffassung von den Farben nicht ganz der Wirklichkeit entspricht, da Farben keine von uns faktisch repräsentierbaren Eigenschaften sind. Folgt man dem Indirekten Realisten, dann ergeben sich ganz neue Möglichkeiten: wie zum Beispiel von internen und repräsentierten Farbeigenschaften eines Sinnesdatums ausgehen zu können. Objektivität und Externalität implizieren jedoch zusammen immer Intrinsität, solange der ontologische Realismus beibehalten wird (und wie gesagt: ohne eines der beiden Merkmale wird die Intrinsität selbst für eine Farbtheorie an Bedeutung verlieren). Zudem bringt die Objektivität vor dem Hintergrund eines für Außenwelt (mit Ausnahme mentaler Entitäten) geltenden globalen Physikalismus die Physikalität der Farben mit sich, da objektive Entitäten keine ontologische Geistabhängigkeit zeigen dürfen. Objektivistische Positionen hinsichtlich von Farben werden also auf die eine oder andere Weise physikalistische Theorien darstellen. Doch auf alle Fälle ist es wichtig, in Erinnerung zu behalten, daß die These $\left(\mathrm{IND}_{\mathrm{R}}\right)$ unter den in diesem Buch herrschenden Voraussetzungen die These (REP) impliziert. ${ }^{35}$

\subsubsection{Farben als phänomenale Farben}

Die den Farben durch die Intuitive Farbkonzeption zugeschriebene Phänomenalität ist bereits in ausreichender Ausführlichkeit beschrieben worden. Hervorzuheben sind dabei besonders der Erlebnischarakter der Farbqualia an sich sowie die Ähnlichkeiten und Verschiedenheiten derselben untereinander. Zudem weisen die einzelnen Farqualia bestimmte Eigenschaften zweiter Ordnung auf: wie Reinheit und Gemischtheit, bestimmte Inkompatibilitäten, oder auch Einfachheit und Einheitlichkeit. Farben sind phänomenale Farben. Doch damit dies überhaupt Gültigkeit haben kann, müssen

35 Hier wird implizit vorausgesetzt, daß insbesondere subjektive Eigenschaften nicht repräsentiert werden können. Die Argumentation hierzu findet sich im Kapitel über die subjektivistischen Farbtheorien. 
Farben von uns wenigstens faktisch phänomenal erlebt werden können, da wir ihnen sonst keinen qualitativen Charaker zusprechen würden. Es ergibt sich also diesmal die folgende Version der Individuationsthese (IND):

$\left(\mathrm{IND}_{\mathrm{P}}\right)$ Aktual gilt: die in den Farbwahrnehmungen menschlicher Subjekte $S$ phänomenal erlebten oder bewußt werdenden Eigenschaften sind immer $P$-Eigenschaften.

Das heißt nicht unbedingt, daß Farben mit den Farbqualia - als Eigenschaften der Wahrnehmungen - gleichgesetzt werden. Denn wenn die Transparenzintuition stimmt, sind uns die objektiv und extern instantiierten Eigenschaften in unseren Sinneserfahrungen phänomenal präsentiert (wie es etwa die Repräsentationalisten behaupten); und auch die meisten Subjektivismen werden die Identifikation mit Qualia zu umgehen versuchen. Nun ist phänomenale Veridizität genau dann gegeben, wenn die Farbeigenschaften tatsächlich alle im phänomenalen Aspekt des introspektiven Charakters von Farbwahrnehmungen zusammengefaßten Merkmale instantiieren. Es ist jedoch nicht so leicht einzusehen, wie sie nur einige Merkmale der Phänomenalität zeigen können, andere dagegen nicht, weil im Grunde jede Veränderung der Eigenschaften von Qualia auch einen Unterschied darin bedingt, wie wir sie erleben. Dies ist darauf zurückzuführen, daß letztlich alle phänomenalen Beziehungen und Eigenschaften zweiter Ordnung der Qualia auf deren intrinsischen Beschaffenheiten supervenieren, und daß somit die uns introspektiv zugänglichen Merkmale der Qualia diesen wesentlich zukommen. Die Natur der Qualia ist uns (zu einem Teil) transparent gegeben. Zwar können wir einer Wahrnehmung aufgrund von Introspektion fälschlicherweise ein bestimmtes Quale zuschreiben, da dieser epistemische Zugang nicht infallibel ist, aber der über ein ganz bestimmtes Quale $Q$ definierte Erlebnischarakter wird immer die dem $Q$-Quale wesentlichen Merkmale beinhalten (wie eine Rotwahrnehmung immer einen Rotgehalt und ein Rotquale zeigt, auch wenn sie nicht repräsentational veridisch ist).

Doch es ist trotzdem möglich, zwei Arten von Qualiamerkmalen zu unterscheiden: die einen - wie Einfachheit und Einheitlichkeit - kommen allen Farbqualia gleichermaßen oder allgemein zu; die anderen, die konkret 
mit den Farbtondifferenzen zusammenhängen, kommen den einzelnen Qualia dagegen nur individuell zu. Weiterhin kann die Forderung, daß Farben phänomenale Farben sein sollen, soweit abgeschwächt werden, daß sie die Phänomenalität der ihnen entsprechenden Farbqualia vollständig erklären können. Diese Option wird von einigen Repräsentationalisten der formal einfacheren, aber ontologisch vielleicht unplausibleren Identifikation von Farben und Farbqualia vorgezogen; doch sie erfordert nicht nur die Akzeptanz der These (NEC), sondern auch eine Strukturähnlichkeit zwischen den phänomenalen Beziehungen der Qualia und den entsprechenden Beziehungen der Farben, die nicht unbedingt so einfach gewährleistet werden kann. Und auch manche Subjektivisten postulieren neben den Qualia noch eine weitere Art von farb-phänomenalen Eigenschaften, die sie dann mit den Farben gleichsetzen. In jedem Fall ergibt sich nun für phänomenale Farben die folgende Analyse:

(PHE) Notwendig gilt: die Eigenschaften $P$ zeigen entweder dieselben allgemeinen und individuellen - phänomenalen Merkmale und Beziehungen wie die Farbqualia der Farbwahrnehmungen von aktualen, menschlichen Subjekten $S$, oder sie können diese vollständig und angemessen erklären.

\subsubsection{Die Herleitung des zentralen Bikonditionals}

Aus den beiden Thesen $\left(\mathrm{IND}_{\mathrm{R}}\right)$ und $\left(\mathrm{IND}_{\mathrm{P}}\right)$ läßt sich nun, jeweils unabhängig voneinander, ein Bikonditional ableiten, welches sich zur Klassifikation der möglichen oder auch vertretenen Farbtheorien sehr gut eignet. Betrachten wir zunächst die These $\left(\mathrm{IND}_{\mathrm{R}}\right)$, der zufolge Farben von uns faktisch repräsentiert werden. Aus den Überlegungen zu einer externalistischen Gehaltstheorie für Wahrnehmungen kann nun die These $\left(\mathrm{NK}_{\mathrm{NB}}\right)$, welche Repräsentation als nomologische Korrelation unter Normalbedingungen deutet, verwendet werden, um zu schließen, daß die normalerweise mit unseren aktualen Farbwahrnehmungen nomologisch korrelierten Eigenschaften Farben sind. 
$(*)$ Aktual gilt: die mit den Typen $W_{\mathrm{P}}$ der Farbwahrnehmungen
menschlicher Subjekte $S$ unter Normalbedingungen korrelierten
Eigenschaften sind immer $P$-Eigenschaften.

Nimmt man nun noch die Aktualitätsthese hinzu, die aussagt, daß ein $P$ Gehalt faktisch immer mit einem $P$-Quale zusammen vorkommt, ergibt sich, daß Farben aktual mit Farbwahrnehmungstypen verbunden sind, die sich über ihren phänomenalen Charakter individuieren lassen. Denn ein $P$ Gehalt liegt ja genau dann vor, wenn zu der Eigenschaft $P$ eine nomologische Korrelation besteht. Damit ergibt sich:

(**) Aktual gilt: die über ihre Farbqualia individuierbaren Farbwahrnehmungstypen $W_{\mathrm{P}}$ menschlicher Subjekte $S$ sind unter Normalbedingungen immer mit $P$-Eigenschaften nomologisch korreliert.

Bei dieser These handelt es sich bereits um die rechte Seite des angesprochenen Bikonditionals. Für die linke wird einfach die zu anfangs aufgestellte Analysethese (ANA) herangezogen. Eigentlich könnte schon (**) als Bikonditional fungieren, doch die Klassifikation wird sich einfacher durch die Einbeziehung der These (ANA) aufstellen lassen. Mit Hinsicht auf die folgende Formulierung des Bikonditionals ist es noch wichtig, darauf hinzuweisen, daß es sich um eine uninterpretierte Version handelt. Das heißt, es wird unbestimmt oder offengelassen, in welchen Welten und für welche Subjektgruppen die rechte Seite gültig ist. Doch die Minimalinterpretation wird - laut der Aktualitätsthese - aus der aktualen Gültigkeit für Menschen bestehen. Für eine mögiche Farbtheorie, die (ACT) ablehnt, aber trotzdem von der Repräsentiertheit von Farben ausgeht und damit also $\left(\mathrm{IND}_{\mathrm{R}}\right)$ annimmt, wird die rechte Seite des Bikonditionals ebenfalls mindestens aktual und für Menschen, wie sie faktisch beschaffen sind, gelten. Außerdem bezieht sich die folgende Formulierung nicht mehr auf Farben als Determinable allgemein, sondern auf die einzelne Farbeigenschaften als Determinanten; einen Unterschied in der Gültigkeit macht dies jedoch nicht aus. ${ }^{36}$

36 Das Zeichen „=“" zeigt an, daß es sich auf der rechten Seite nicht unbedingt um eine metaphysisch notwendige Identitätsaussage handeln muß, sondern auch ein- 
(BK) Farbe $F_{\mathrm{i}} \equiv$ Eigenschaft $P_{\mathrm{i}} \leftrightarrow$ in der Welt $\mathrm{w}$ gilt: $P_{\mathrm{i}}=$ unter Normalbedingungen mit dem $F_{\mathrm{i}}$-phänomenalen Wahrnehmungstypus $W_{\mathrm{i}}$ von Subjekten $S$ nomologisch korrelierte Eigenschaft.

Die Identifikation von Farben mit den $P$-Eigenschaften hat dementsprechend genau dann Gültigkeit, wenn in der fraglichen Welt (oder den fraglichen Welten) w gilt: die $P$-Eigenschaften weisen zumindest faktisch eine nomologische Korrelation unter Normalbedingungen mit den über ihre Phänomenalität individuierten Farbwahrnehmungstypen auf. Die einzelnen ontologischen Positionen hinsichtlich von Farben werden sich nun dahingehend unterscheiden, wie sie die (durch den Paramter w ausgedrückte) Modalität der rechten Seite von (BK) sowie den ebenfalls darin enthaltenen Subjektparameter ausfüllen. Stipulativ kann erst einmal davon ausgegangen werden, daß für $S$ alle in der betreffenden Welt existierenden und farbwahrnehmenden Subjekte in Frage kommen. Die einzelnen Theorien werden dann darüber eine Aussage treffen müssen, ob auch von den aktualen Menschen verschiedenene Lebewesen dazuzurechnen sind oder nicht. Die Modalität von der rechten Seite kann (immer vor dem Hintergrund des ontologischen Realismus und des Physikalismus) neben der Aktualität sinnvollerweise nur noch metaphysische oder epistemische Notwendigkeit annehmen. Jemand, der die Notwendigkeitsthese (NEC) vertritt, kann diese zum Beispiel statt der Aktualitätsthese bei der Herleitung von (BK) benutzen und erhält somit eine metaphysisch notwendige, rechte Seite des Bikonditional.

Damit das Bikonditional auch bei der Klassifikation solcher Farbtheorien, die $\left(\mathrm{IND}_{\mathrm{R}}\right)$ ablehnen, helfen kann, sollte es auch aus $\left(\mathrm{IND}_{\mathrm{P}}\right)$ ableitbar sein. Theorien, die keine der beiden Individuationstheorien akzeptieren, müssen sinnvollerweise auch die Grundannahme (IND) ablehnen, so daß diese Möglichkeit hier nicht weiter behandelt werden muß. Laut $\left(\operatorname{IND}_{\mathrm{P}}\right)$ werden Farben mit den phänomenal präsentierten Eigenschaften gleichgesetzt werden. Nun ergibt es sich aber aus der Aktualitätsthese (ACT), daß Farbwahr-

fach nur eine kontingent wahre Prädikation vorliegen kann. Und auf eine Klammerung ist aus Gründen der Übersichtlichtkeit verzichtet worden: auf jeden Fall genießt das Bikontionalszeichen „↔“ Priorität. 
nehmungen faktisch über ihren phänomenalen Charakter typen-individuiert werden können. Nimmt man die beiden letzten Aussagen zusammen, dann folgt daraus, daß phänomenale Farben aktual immer mit den entsprechenden Wahrnehmungstypen zusammen auftreten sind:

(***) Aktual gilt: die über ihre Farbqualia individuierbaren Farbwahrnehmungstypen $W_{\mathrm{P}}$ menschlicher Subjekte $S$ sind immer mit $P$ Eigenschaften nomologisch korreliert.

Es wird sich dabei, wie wir sehen werden, um eine ganz anders beschaffene und begründete Nomologizität handeln als um die in der These $\left(\mathrm{NK}_{\mathrm{NB}}\right)$ über den Begriff der Repräsentationalität erwähnte. Wenn (***) jedoch allgemein gilt, dann ist es kein Problem, diese Gültigkeit auch auf Normalbedingungen einzuschränken. Das Resultat ist wiederum die rechte Seite von (BK), welche zusammen mit der Analysethese (ANA) das Bikonditional ergibt. Interessanterweise kann zudem geschlossen werden, daß Farbtheorien, die allein auf $\left(\mathrm{IND}_{\mathrm{P}}\right)$ - und damit (PHE) - basieren, keine Normalbedingungen einführen müssen (und vielleicht auch nur stipulativ können). Der Grund hierfür läßt sich auf der einen Seite darin sehen, daß sie auf die Repräsentiertheit von Farben verzichten. Doch auf der anderen Seite verbirgt sich dahinter noch eine weitere Besonderheit solcher Positionen. Wenn Farben allein über die Phänomenalität von Farbwahrnehmungen analysiert werden - wie es zumindest Theorien, die (PHE) akzeptieren und (REP) ablehnen, tun -, dann wird (BK) epistemisch notwendig wahr. Denn es wird auf beiden Seiten des Bikonditionals die folgende begrifflich-logische Definition von Farbeigenschaften stehen: Farben sind per definitionem die Eigenschaften, die aktual mit den entsprechenden Farbqualia nomologisch korreliert sind. Bei der betreffenden Nomologizität handelt es sich also ebenfalls um eine logisch-begriffliche Nomologizität, die die epistemische Notwendgikeit von (BK) mitbegründen hilft. 


\subsubsection{Die Aktualitäts- und Notwendigkeitsthesen unter Nor- malbedingungen}

Aus dem Bikonditional lassen sich noch zwei weitere, wichtige Thesen ableiten. Da Farben uns als Eigenschaften von externen Gegenständen in der Welt erscheinen und wir dementsprechend auch im Alltag davon ausgehen, daß diesen Gegenständen Farben als Eigenschaften zukommen, ist die Frage von Interesse, wann unsere Farbzuweisungen korrekt sind und wann nicht. Setzt man stipulativ voraus, daß ein gegebener, externer Gegenstand faktisch die Farbe $F_{\mathrm{i}}$ besitzen soll, und denkt man sich zudem, daß das fragliche Objekt wahrgenommen wird und eine Farbwahrnehmung in dem Betrachter hervorruft, dann ergibt sich aus dem Bikonditional für die aktuale Welt und menschliche Subjekte die sogenannte Aktualitätsthese unter Normalbedingungen.

$\left(\mathrm{ACT}_{\mathrm{NB}}\right)$ Aktual gilt: ein Gegenstand instantiiert die Farbe $F_{\mathrm{i}} \leftrightarrow$ der Gegenstand führt in einem Subjekt $S$ unter Normalbedingungen immer zu Wahrnehmungen mit einem $F_{\mathrm{i}}$-Quale.

Für Objektivisten und für alle Subjektivisten, die Farben als (teilweise) extern instantiierte Eigenschaften ansehen wollen, gilt die These $\left(\mathrm{ACT}_{\mathrm{NB}}\right)$ auf alle Fälle. Für die Subjektivisten, die Farben dagegen als intern (oder gar nicht) instantiierte Eigenschaften ansehen, die unsere Wahrnehmungen bloß auf die externe Welt projezieren, darf die These $\left(\mathrm{ACT}_{\mathrm{NB}}\right)$ nicht allzu wörtlich genommen werden: daß der Gegenstand die Farbe $F_{\text {i }}$ „,instantiiert“, heißt dann vielmehr, daß wir ihn üblicherweise als Träger der betreffenden Farbe ansehen, obwohl diese in Wirklichkeit nur auf ihn projeziert wird. Zudem kann es sein, daß der Subjektivismus auf die Einschränkung auf Normalbedingungen verzichten wird oder muß. Der Objektivismus kann dagegen zusätzlich noch den Aktualitätsoperator auf die rechte Seite des Bikonditionals beschränken, da er von der Rigidzität von aktualen Farbzuschreibungen ausgeht. Die linke Seite von $\left(\mathrm{ACT}_{\mathrm{NB}}\right)$ gilt für ihn damit automatisch in allen möglichen Welten: ist ein Gegenstand beispielsweise in der aktualen Welt rot, ist er das in allen Welten. Doch diese Punkte sollen erst im Zusammenhang mit dem Euthyphron-Kontrast aus- 
führlicher diskutiert werden.

In jedem Fall spielt die These $\left(\mathrm{ACT}_{\mathrm{NB}}\right)$ eine wesentliche Rolle für die Colorimetrie, die es sich zum Ziel gesetzt hat, diejenigen Eigenschaften an den Gegenständen zu identifizieren, die für unsere Farbwahrnehmungen kausal oder explanatorisch verantwortlich sind - ganz gleich, ob es sich bei den extern instantiierten und von den Farbwahrnehmungen repräsentierten Eigenschaften um Farben handelt, oder nicht. Akzeptiert eine Theorie der Farben zusätzlich die Notwendigkeitsthese (NEC), dann läßt sich auch die entsprechende Notwendigkeitsthese unter Normalbedingungen formulieren (die Herleitung über das Bikonditional verläuft dabei genauso, nur daß (ACT) durch (NEC) ersetzt wird):

$\left(\mathrm{NEC}_{\mathrm{NB}}\right)$ Notwendig gilt: ein Gegenstand instantiiert die Farbe $F_{\mathrm{i}} \leftrightarrow$ der Gegenstand führt in einem Subjekt $S$ unter Normalbedingungen immer zu Wahrnehmungen mit einem $F_{\mathrm{i}}$-Quale.

Die Normalbedingungen können dabei in jeder Welt, und voraussichtlich auch für jede farbwahrnehmende Spezies in dieser Welt, verschiedene sein; und die $F_{\mathrm{i}}$-spezifischen Qualia werden rigide über die aktuale Welt bestimmt. Diese Notwendigkeitsthese $\left(\mathrm{NEC}_{\mathrm{NB}}\right)$ gilt selbstverständlich nur für bestimmte Theorien der Farben. Die Aktualitätsthese $\left(\mathrm{ACT}_{\mathrm{NB}}\right)$ hat indessen für (fast) alle Positionen gleichermaßen Gültigkeit (insofern diese auch die normale Aktualitätsthese (ACT) akzeptieren). 